\title{
Arrested development - a comparative analysis of multilayer corona textures in high-grade metamorphic rocks
}

\author{
Paula Ogilvie and Roger L. Gibson \\ School of Geosciences, University of the Witwatersrand, P O WITS, Johannesburg 2050, South Africa \\ Correspondence to: Roger L. Gibson (roger.gibson@wits.ac.za)
}

Received: 9 July 2016 - Published in Solid Earth Discuss.: 25 July 2016

Revised: 21 December 2016 - Accepted: 5 January 2017 - Published: 6 February 2017

\begin{abstract}
Coronas, including symplectites, provide vital clues to the presence of arrested reaction and preservation of partial equilibrium in metamorphic and igneous rocks. Compositional zonation across such coronas is common, indicating the persistence of chemical potential gradients and incomplete equilibration. Major controls on corona mineralogy include prevailing pressure $(P)$, temperature $(T)$ and water activity $\left(a \mathrm{H}_{2} \mathrm{O}\right)$ during formation, reaction duration $(t)$ single-stage or sequential corona layer growth; reactant bulk compositions $(X)$ and the extent of metasomatic exchange with the surrounding rock; relative diffusion rates for major components; and/or contemporaneous deformation and strain. High-variance local equilibria in a corona and disequilibrium across the corona as a whole preclude the application of conventional thermobarometry when determining $P-T$ conditions of corona formation, and zonation in phase composition across a corona should not be interpreted as a record of discrete $P-T$ conditions during successive layer growth along the $P-T$ path. Rather, the local equilibria between mineral pairs in corona layers more likely reflect compositional partitioning of the corona domain during steadystate growth at constant $P$ and $T$.

Corona formation in pelitic and mafic rocks requires relatively dry, residual bulk rock compositions. Since most melt is lost along the high- $T$ prograde to peak segment of the $P$ $T$ path, only a small fraction of melt is generally retained in the residual post-peak assemblage. Reduced melt volumes with cooling limit length scales of diffusion to the extent that diffusion-controlled corona growth occurs. On the prograde path, the low melt (or melt-absent) volumes required for diffusion-controlled corona growth are only commonly realized in mafic igneous rocks, owing to their intrinsic an-
\end{abstract}

hydrous bulk composition, and in dry, residual pelitic compositions that have lost melt in an earlier metamorphic event.

Experimental work characterizing rate-limiting reaction mechanisms and their petrogenetic signatures in increasingly complex, higher-variance systems has facilitated the refinement of chemical fractionation and partial equilibration diffusion models necessary to more fully understand corona development. Through the application of quantitative physical diffusion models of coronas coupled with phase equilibria modelling utilizing calculated chemical potential gradients, it is possible to model the evolution of a corona through $P-T-X-t$ space by continuous, steady-state and/or sequential, episodic reaction mechanisms. Most coronas in granulites form through a combination of these endmember reaction mechanisms, each characterized by distinct textural and chemical potential signatures with very different petrogenetic implications. An understanding of the inherent petrogenetic limitations of a reaction mechanism model is critical if an appropriate interpretation of $P-T$ evolution is to be inferred from a corona. Since corona modelling employing calculated chemical potential gradients assumes nothing about the sequence in which the layers form and is directly constrained by phase compositional variation within a layer, it allows far more nuanced and robust understanding of corona evolution and its implications for the path of a rock in $P-T-$ $X$ space.

\section{Introduction}

Fundamental to the study of metamorphic rocks is the application of equilibrium thermodynamics in the understanding of the development of a mineral assemblage within evolv- 
ing pressure $(P)$, temperature $(T)$ and chemical potential regimes. In an equilibrated assemblage, the chemical potentials of all components are equal throughout the equilibrium volume. However, different rates of intergranular diffusion for major and trace components limit the capacity of a rock to fully eliminate gradients in chemical potentials and attain equilibrium on both micro- and macro-scales (Fisher, 1977; Joesten, 1977; Fisher and Lasaga, 1981; Foster, 1981; Ashworth and Birdi, 1990; Carlson, 2002; White et al., 2008; White and Powell, 2011). A more realistic model of partial equilibrium, i.e. equilibrium for some components and not for others, is likely to be attained in a rock. In a sense partial equilibrium is fortuitous, since evidence of disequilibrium preserved in reaction textures reveals basic physico-chemical reaction dynamics operating during metamorphism that are obscured if a rock equilibrates completely. However, partial disequilibrium also compromises petrographic and geothermobarometric evidence as records of the metamorphic evolution of a rock and can lead to erroneous interpretations (Mueller et al., 2010, 2015; White and Powell, 2011). Thus, an understanding of how partial equilibrium manifests itself petrographically and chemically is critical if we are to appreciate both the limitations and opportunities it affords in petrogenetic studies.

The most obvious manifestation of partial equilibrium is reaction textures comprising coronas and symplectites. The spatially segregated phases preserved within these reaction textures are the best petrographic evidence available to study the evolution of chemical potential gradients governing the reorganization of components within a rock with changing $P-T-X$ (composition) conditions (e.g. White et al., 2008; Štípská, et al., 2010; White and Powell, 2011; Baldwin et al., 2015). The disequilibrium commonly preserved in coronas and symplectites does not, however, preclude the application of equilibrium thermodynamics in modelling and interpreting those textures; it only invokes a reconsideration of the appropriate equilibration volume in which chemical potential gradients are absent (White and Powell, 2011). Within any reaction texture, on an appropriate scale, chemical equilibrium exists, and attendant chemical potentials may be determined for a given $P$ and $T$ within the local bulk composition dictated by the equilibration volume. This concept of local equilibrium was first introduced by Korzhinski (1959) and has been the premise upon which all studies of reaction textures are predicated.

In this paper, we present an analysis of more than 50 metamorphic corona textures developed in high-temperature granulite facies rocks (Tables A1 and A2 in the Appendix) and discuss two contrasting modelling methodologies used in interpreting the evolution of these textures. There are innumerable examples of reaction fronts and replacement textures encountered in lower-temperature metamorphic rocks where the role of a discrete fluid phase is critical in the development of the texture. An exhaustive review of low-temperature replacement textures is not attempted here. Rather, we fo- cus on the kinetics of reaction mechanisms and processes with particular reference to those applicable in the granulite $P-T$ regime. The review concludes with an appraisal of efforts employing equilibrium thermodynamics and calculated phase diagrams to model corona textures and assesses their significance and limitations when used to infer the $P-T-X$ evolution of a metamorphic rock (White et al., 2008; Štípská et al., 2010; Baldwin et al., 2015).

\section{Reaction kinetics}

Metamorphic reactions are initiated when a pre-existing mineral assemblage becomes unstable owing to changing $P$ $T-X$ conditions. Chemical equilibrium is re-established by adjustment of chemical constituents into a new mineral assemblage coupled with a requisite change in phase compositions in higher-variance equilibria. New minerals typically grow as a layer or sequence of layers between reactant phases. This layer succession forms a reaction rim most commonly observed as a corona in granulite facies rocks. Processes involved during metamorphic reaction include (a) nucleation of product minerals; (b) transport of components to the reaction interface through the reactant by volume or intragranular diffusion; (c) dissolution of the reactant phases; (d) transport of components across the reaction interface along grain boundaries or through melt; (e) incorporation of the diffusing components into the product surface through precipitation; and (f) the rate of supply or removal of heat (Fisher, 1977; Joesten, 1977; Brady, 1983; Foster, 1986; Tracey and McLellan, 1985; Carlson, 2002; Dohmen and Chakraborty, 2003; Mueller et al., 2010; Abart and Petrishcheva, 2011; Abart et al., 2012). Where reaction rate is primarily governed by nucleation and precipitation, the reaction is referred to as interface-controlled. Where reaction rate is constrained by rates of component diffusion, it is termed transport-controlled. Mueller et al. (2010) stress that the serial nature of these processes means that the slowest of them is the limiting constraint on overall reaction rate and extent as a function of both temperature and time.

A model predicting the relative importance of either interface or diffusion controls on a particular reaction rate with respect to $P$ and $T$ was derived by Dohmen and Chakraborty (2003). Although only defined for mineral exchange reactions in the presence of a fluid phase, they derive a reaction mechanism map for the determination of the rate-limiting step in any reaction based on relative dominance of either interface-controlled or transport-controlled mechanisms. Employing a thermodynamic model predicated on Fick's laws governing chemical mass transfer, Abart and Petrischeva (2011) demonstrate that, during initial rim growth, reaction is interface-controlled and gradually becomes diffusion- or transport-controlled as the reaction proceeds. Abart et al. (2012) augmented this thermodynamic model to include chemical segregation within a reaction front 
as a rate-limiting reaction mechanism during the growth of reaction rims with lamellar internal structure or symplectites. These models have been substantiated by a vast body of rigorous experimental work constraining the kinetics of reaction rim growth (e.g. Farver and Yund, 1996; Yund, 1997; Fisler et al., 1997; Milke et al., 2001; Watson and Price, 2002; Milke and Heinrich, 2002; Milke and Wirth, 2003; Abart and Schmidt, 2004; Schmid et al., 2009; Götze et al., 2010; Keller et al., 2008; Niedermeier et al., 2009; Dohmen and Milke, 2010; Keller et al., 2010; Gardés et al., 2011; Gardés and Heinrich, 2011; Joachim et al., 2011a, b; Mueller et al., 2012; Helpa et al., 2014, 2015; Jonas et al., 2015; Abart et al., 2016). Phenomenological models of disequilibrium elemental and isotopic compositions produced experimentally with incomplete diffusive element exchange (e.g. Mueller et al., 2008, 2012; Watson and Mueller, 2009) may be utilized to constrain the textural, isotopic and compositional evolution of mineral assemblages and infer timescales of reaction duration (Lasaga, 1983; Ague and Baxter, 2007; Niedermeier et al., 2009; Mueller et al., 2015). Ongoing experimental work aimed at characterizing rate-limiting reaction mechanisms and their petrogenetic signatures in more complex, highervariance systems is imperative to allow further refinement of partial equilibration models necessary to fully understand coronas. Reviews of the experimental basis for kinetic theory, reaction mechanisms and the petrogenetic implications of this work are provided by Putnis (2009), Dohmen and Milke (2010), Mueller et al. (2010, 2015), and Zhang (2010).

\section{Diffusion and corona growth}

Diffusion is a consequence of the random motion of atoms, ions or molecules within a host reference frame (Mueller et al., 2010; Zhang, 2010). This random motion may result in a net diffusive flux when the concentration (or, rather, chemical potential) of a component is not uniform in that reference frame (e.g. a reaction rim). The resultant diffusive mass transport in one dimension is governed by Fick's laws. Fick's first law relates diffusive component flux to component diffusivity in the presence of a concentration or chemical potential gradient:

$\boldsymbol{J}=-D \frac{\partial C}{\partial x}$.

In Eq. (1), $\boldsymbol{J}$ is the diffusive mass flux (a vector), $D$ is the diffusion coefficient (or diffusivity), $C$ is the concentration of a component (in mass per unit volume), $x$ is distance, and $\partial C / \partial x$ is the concentration gradient. Diffusivities are measures of the rate of component transport or diffusion. Values of diffusion coefficients (typically in square metres per second) are dependent on temperature, pressure, composition, and the physical state and structure of the phase (Zhang, 2010). The time dependence of diffusive mass transport (again in one dimension) and evolving concentration gradients are determined by Fick's second law:

$\frac{\partial C}{\partial t}=D \frac{\partial^{2} C}{\partial x^{2}}$.

Additional influences on evolving concentration gradients and diffusive flux in natural systems, which include the effect of bulk flow of the reaction framework, are quantified through extensions to Fick's laws (Mueller et al., 2010; Zhang, 2010).

Phenomenological models of corona formation through diffusion-controlled reaction employ a combination of Fick's first law in conjunction with equilibrium thermodynamics (Fisher, 1970; Joesten, 1977; Foster, 1981). Fick's first law forms the basis for the first of these equations, which relates component fluxes $J_{i}$ to chemical potential gradients $\mathrm{d} \mu_{i} / \mathrm{d} x$ such that for each component $i=1$ to $S$,

$J_{i}=-\sum_{j=1}^{S} L_{i j} \frac{\mathrm{d} \mu_{j}}{\mathrm{~d} x}$.

$L_{i j}$ are phenomenological coefficients for diffusion in a multi-component system (Joesten, 1977). Straight coefficients $(i=j)$ relate diffusion of component $i$ to the chemical potential gradient of $i$, and the cross coefficients $(i \neq j)$ relate diffusion of component $i$ to the chemical potential gradient of $j$. Joesten (1977) and Fisher (1970) assume that the contribution of terms involving cross coefficients is negligible.

The Gibbs-Duhem equation relates component chemical potential gradients in the coronas to each other in the presence of a mineral $k$, in which the molar content of component $i$ is $n_{i k}$, such that in a layer containing $k$,

$\sum_{i=1}^{S} n_{i k} \frac{\mathrm{d} \mu_{i}}{\mathrm{~d} x}=0$.

A final equation relates the flux change between layers $r-1$ and $r$ to the stoichiometric coefficients $v_{k}^{r}$ of phases $k$ in the reaction at boundary $r$, such that for mass conservation and local mass balance at boundary $r$,

$J_{i}^{r}=J_{i}^{r-1}+\frac{\mathrm{d} \varepsilon^{\prime}}{\mathrm{d} t} \sum_{k=1}^{\phi} n_{i k} v_{k}^{r}$.

In Eq. (5), $\phi$ is the number of phases in layer $r$ and $\varepsilon^{\prime}$ is the modified form of the reaction progress variable $\varepsilon$ appropriate to layer growth (Ashworth and Sheplev, 1997). The factor $\frac{\mathrm{d} \varepsilon^{\prime}}{\mathrm{d} t}$ in Eq, (5) converts $n_{i k} v_{k}^{r}$ (moles of component per mole of reaction progress) to $J_{i}^{r}$ in its true units (mol component $\mathrm{m}^{-2} \mathrm{~s}^{-1}$ ).

Intrinsic to any corona formation model is mass balance. An overall reaction may be reconstructed using the measured proportion of phases to derive an open-system reaction, with boundary fluxes representing metasomatic interaction with 
the surrounding rock. The overall reaction may be summarized by a mass balance for each component $i$.

$$
\sum_{k=1}^{\phi} v_{k} n_{i k}=0
$$

In a closed system, the summation is over all minerals $k$. In an open system, the metasomatic fluxes at the end boundaries are treated as "dummy" phases with unit stoichiometric coefficients. An expression for overall corona model reaction affinity was derived by Ashworth and Sheplev (1997). The reaction affinity (i.e. Gibbs energy of reaction, $-\Delta G$ ) is expressed as a function of phase compositions, phase proportions $\left(v_{k}\right)$, layer thicknesses and chemical potential gradients across all layers in Eq. (6):

$(-\Delta G)=\sum_{k=1}^{\phi} v_{k} \sum_{i=1}^{S} n_{i k} \sum_{r=1}^{q^{k}-1} h^{r *}\left(\frac{\mathrm{d} \mu_{i}}{\mathrm{~d} x}\right)^{r *}$.

Flatter chemical potential gradients reduce the $(-\Delta G)$ accordingly, such that $(-\Delta G)$ approaches 0 , indicative of greater extent of equilibration. In contrast, large chemical potential gradients over thicker layers will cause the product $(-\Delta G)$ to deviate further from 0 , suggesting suppressed equilibration.

These equations predicate the steady-state diffusioncontrolled models developed for spatially segregated reaction products in multilayer coronas arranged in order of increasing or decreasing chemical potential (Fisher, 1977; Joesten, 1977; Mongkoltip and Ashworth, 1983; Foster, 1986; Grant, 1988; Johnson and Carlson, 1990; Carlson and Johnson, 1991; Ashworth and Birdi, 1990; Ashworth et al., 1992, 1998; Ashworth and Sheplev, 1997; Markl et al., 1998; Dohmen and Chakraborty, 2003; Gardés et al., 2011). As changing $P$ and $T$ induces incipient reaction between contiguous metastable reactants, components will start to migrate between the reactants. If the major components display variable intergranular diffusivities, they will be partitioned into a continuum of compositional subdomains, or incipient "effective bulk compositions", in each of which local equilibrium is attained with its own unique chemical potentials. The width of the corona and each of its layers will be dictated by the different length scales of diffusion for each component. A layered corona assemblage develops, across which transient chemical potential gradients exist, which drive diffusion through the layers. With prolonged reaction or enhanced intergranular diffusion, component flux through the corona layers equalizes chemical potentials at all points in the corona. Local incipient bulk compositions of subdomains should gradually expand with mass transfer across layers and approach the final steady-state effective bulk composition for the corona as a whole. Equilibrium is attained when no chemical potential gradients exist for any components, despite the spatial segregation of corona phases in layers.
The interpretation of corona textures has traditionally been a primary diagnostic tool for inferring metamorphic $P-T-t$ paths and, hence, tectonics (Whitney and McLelland, 1973; Grew, 1980; Joesten, 1986; Droop, 1989; Clarke et al., 1989; Ashworth et al., 1992; White and Clarke, 1997; Norlander et al., 2002; White et al., 2002; Kelsey et al., 2003; Johnson et al., 2004; Tsunogae and Van Reenen, 2006; Zulbati and Harley, 2007; Hollis et al., 2006). Diffusion-constrained conditions may arise on both the prograde and retrograde paths, but, most commonly, coronas are thought to have formed during retrogression from peak $P-T$ conditions as low-variance equilibria are crossed. The topology of the inferred low-variance equilibria with respect to the peak assemblage has commonly been used to constrain a retrograde $P$ $T$ path (Harley, 1989). The inherent assumption of disequilibrium between reactants and corona products was elegantly questioned in a study by White et al. (2002) on metapelites from the Musgrave Block in Australia. Phase equilibria modelling employing pseudosections in KFMASHTO demonstrated that corona textures could realistically be developed in a peak, high-variance assemblage that remains in equilibrium but undergoes large changes in mineral modes as the $P-T$ path tracks through the phase field. Thus, it may not be necessary to invoke crossing of low-variance equilibria and disequilibrium to explain corona textures. Indeed, the amount of decompression required to generate the equilibrium reaction texture described by White et al. (2002) was comparatively minor and may well have been overestimated by earlier researchers (Harley, 1989). Similarly, incomplete reaction may not be assumed in coronas where the cessation of textural development reflects the consumption of melt, in which case the reaction responsible has gone to completion (White and Powell, 2011).

Whilst there is a general understanding of the processes that induce corona formation (e.g. Harley, 1989; White et al., 2002, 2008; Johnson et al., 2004), the mechanism for corona development is obscured since the final steady-state configuration of corona layers observed in a rock reflects the complex evolution of chemical potential relationships with $P, T$ and bulk composition. These same complexities must also govern metamorphic processes on the prograde path, albeit on larger length scales. However, greater melt or fluid volumes and increasing temperatures on the prograde path facilitate equalization of chemical potentials through accelerated diffusion in the assemblage, such that only the spatial sequestration of phases (for example, between melt-rich leucosomes and melt-poor mesosomes) attests to the compositional partitioning of the rock and attendant chemical potential gradients that must have prevailed during diffusioncontrolled reaction (White et al., 2004). In coronas, transient disequilibrium is frozen in the rock as reaction textures. Coupled with experimental work, they present the best petrographic evidence available to us to allow the study of the evolution of chemical potential gradients governing the re- 
organization of components within a rock with changing $P-$ $T-X$ conditions (e.g. White et al., 2008).

\section{Corona growth models}

Two endmember corona formation models have evolved in the last 4 decades to explain the development of multilayered coronas, namely, single-stage, steady-state (e.g. Ashworth and Sheplev, 1997) and discontinuous, sequential (Joesten, 1986; White and Clarke, 1997) diffusion-controlled growth. The formation mechanism for an individual corona is typically predominantly governed by either of these two endmember models. Since each endmember model is governed by reaction processes which limit their petrogenetic significance, determining the extent to which a particular formation mechanism applies when studying granulite corona evolution is thus critical when using them to infer information regarding the $P-T-X$ path for a rock (White and Powell, 2011).

\subsection{Single-stage, steady-state diffusion-controlled corona growth}

This growth model attributes corona development to diffusion-controlled reaction mechanisms at constant pressure and temperature, utilizing local equilibrium and chemical potential gradients across each layer and the corona as a whole (Fig. 1). The spatial segregation of phases into layers reflects the relative mobility of components owing to variable intergranular diffusivities rather than distinct $P-T$ conditions. All layers in the reaction bands coexist contemporaneously with infinitesimal thickness at the incipient stages of reaction. Layer thickness increases with reaction duration and no change to a corona layer sequence occurs. Chemical potential gradients evolve toward a steady-state and final configuration balancing the rate of production and consumption of each component within each layer (Korzhinskii, 1959; Joesten, 1977; Mongkoltip and Ashworth, 1983; Foster, 1986; Grant, 1988; Johnson and Carlson, 1990; Carlson and Johnson, 1991; Ashworth and Birdi, 1990; Ashworth et al., 1992, 1998; Ashworth and Sheplev, 1997; Markl et al., 1998).

Figure 1 illustrates incipient stages of single-stage, steadystate corona formation chemographically and in chemical potential space by considering two phases (A and D) initially at equilibrium under $P_{1}$ and $T_{1}$, with bulk composition indicated by the circle (Fig. 1a). If under new $P$ and $T$ conditions $\left(P_{2}, T_{2}\right)$, reaction rate is diffusion-controlled, relative differences in intergranular diffusivities partition the original bulk composition (circle) into two endmember, non-overlapping, local bulk compositions (square, triangle, Fig. 1b). The resulting product mineral assemblage forms layers that are spatially segregated but in local equilibrium and comprise the mineral assemblage stabilized in each local effective bulk composition (Fig. 1b). A ternary $G-X$ surface (Fig. 1c) in- dicates that the tangent planes to the minimum free-energy assemblages have different orientations, and, accordingly, components have different chemical potentials in each assemblage. The coexistence of two local juxtaposed equilibria buffers the chemical potentials of diffusing components across the coronas (Joesten, 1977). Figure 1d represents the associated isothermal-isobaric chemical potential saturation surface for each of the local phase assemblages (modified after Joesten, 1977). Each local bulk composition, represented by a three-phase assemblage, is invariant in chemical potential space at constant $P$ and $T$. The invariant assemblage $\mathrm{ABC}$ (triangle) lies at a higher chemical potential for component 3 and lower chemical potentials for components 1 and 2 than does the invariant assemblage BCD represented by the square. A projection of the saturation surface on the $\mu_{\text {comp } 1}-\mu_{\text {comp2 }}$ plane more clearly indicates the difference between chemical potentials for each local equilibrium (Fig. 1e). Maintenance of these local equilibria requires that chemical potential gradients must exist across each layer and, thus, that the system as a whole is in disequilibrium, which drives diffusion of components from one compositional domain to another. Chemical potential differences across each layer adjust to steady-state values that balance the rates of production and consumption of each component within the layer (Joesten, 1977). Chemical potential gradients for rapidly diffusing components may be eliminated across the corona, whilst those for the slowest-moving components (typically Al and Si, e.g. Ashworth and Sheplev, 1997) are maintained, establishing partial equilibrium.

Continued corona evolution entails the growth of a layer assemblage at the expense of its neighbour (Joesten, 1977). The relative diffusive fluxes of components in adjacent layers determine which mineral phases are consumed and produced at each layer boundary, as well as the reaction stoichiometry (Joesten, 1977; Fisher, 1977). All mineral layers grow simultaneously, by a set of partial reactions at the layer interfaces liberating and consuming components in appropriate proportions to account for mass balance in the overall system (Joesten, 1977, 1986; Fisher, 1977). The only layer that grows at both contacts is the layer that initially contained the original reactant interface (Joesten, 1977, 1986). Fisher (1973) demonstrated that diffusion will automatically tend to shift potentials toward values such that the flux differences at every point in a corona balance local reactions, thereby establishing a steady-state configuration. Growth of coronas will decelerate and eventually cease when either diffusive transport becomes inefficient or chemical potential gradients are erased and/or intergranular diffusivities are reduced with cooling during retrogression (Joesten, 1977; Fisher, 1977; Ashworth and Sheplev, 1997).

The corona in Fig. 2 is a schematic reconstruction of those described by Johnson and Carlson (1990) from metagabbros in the Adirondack Mountains that they interpreted as a natural example of this corona formation mechanism. A primary igneous assemblage involving contiguous olivine and 
(a)
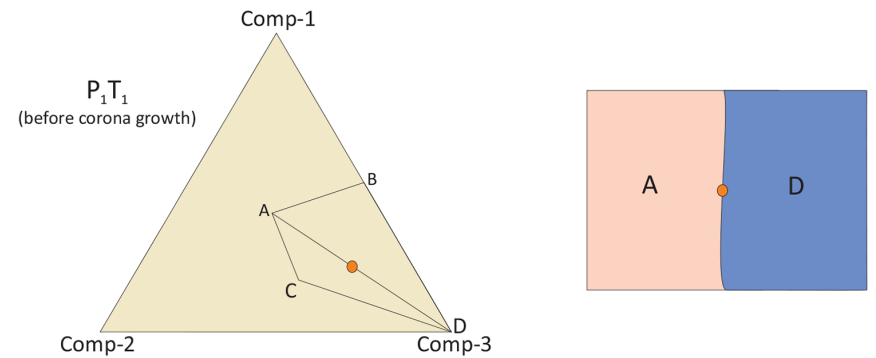

(b)
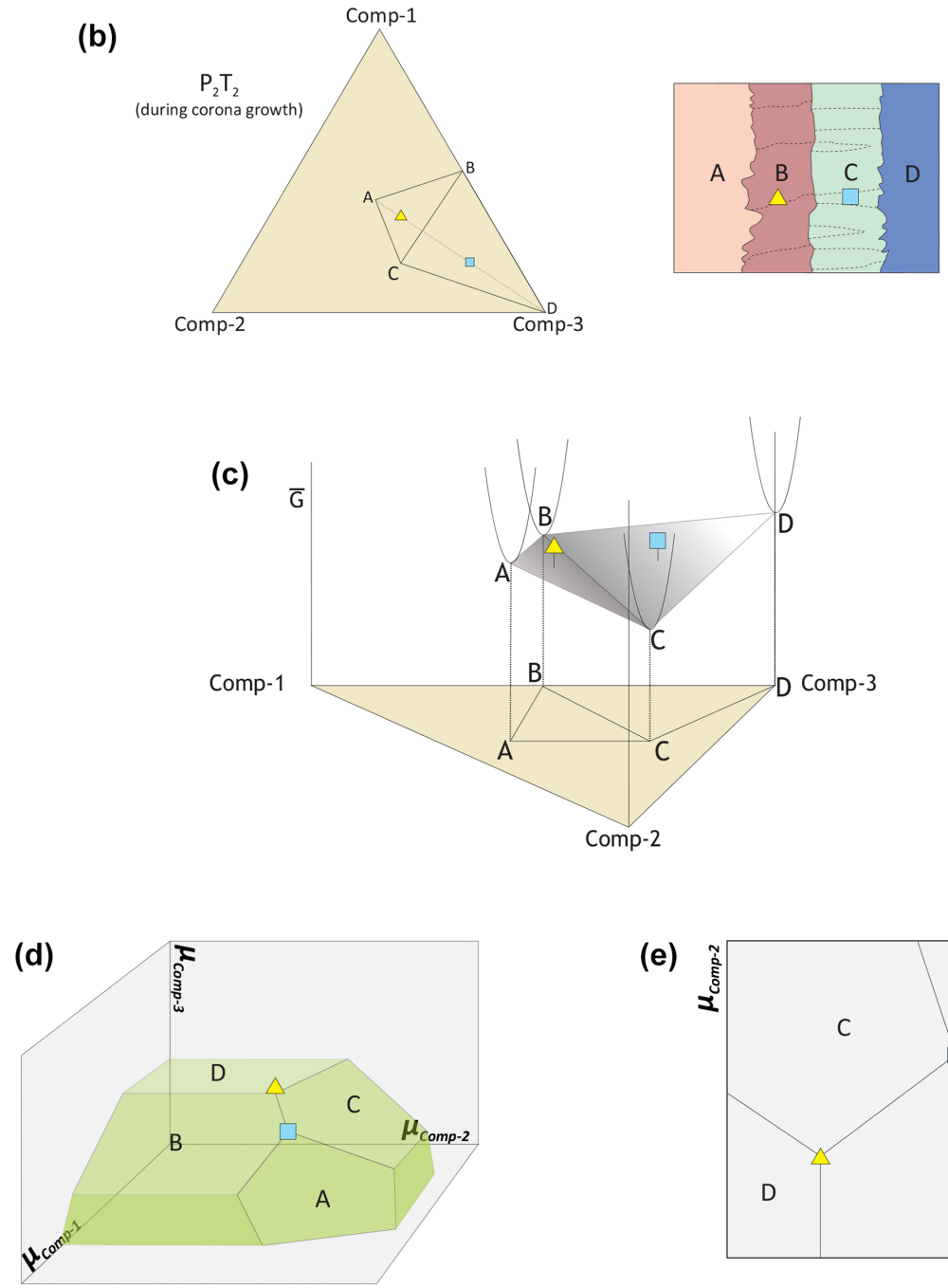

(e)

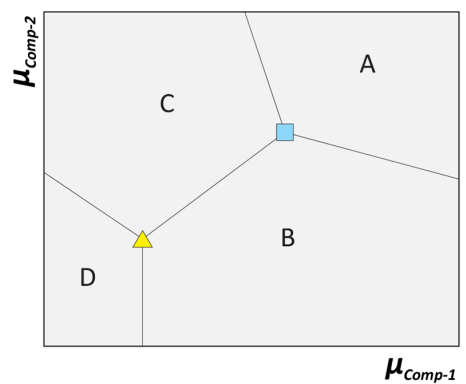

Figure 1. Chemographic relationships and chemical potential saturation surfaces for local transient equilibria at corona boundaries during incipient stages of single-stage, steady-state diffusion-controlled corona growth (after Joesten, 1977). (a) Original phases (A and D) initially at equilibrium under $P_{1}$ and $T_{1}$, with bulk composition indicated by the circle. (b) Under new $P$ and T conditions $\left(P_{2}, T_{2}\right)$, reaction progress becomes diffusion-controlled. The corona domain is partitioned into a continuum of compositional subdomains, or incipient effective bulk compositions (triangle, square), each with unique chemical potentials, in which local equilibrium is attained. (c) Ternary $G-X$ surface, in which local equilibria are separated by chemical potential differences. (d) The chemical potential saturation surface for each of the local phase assemblages. (e) Projection of the saturation surface on the $\mu_{\text {comp } 1}-\mu_{\text {comp2 } 2}$ plane. Chemical potential gradients between local equilibria drive the diffusion of components from one compositional domain to another until chemical potentials are equalized and equilibrium is attained. 
(a)
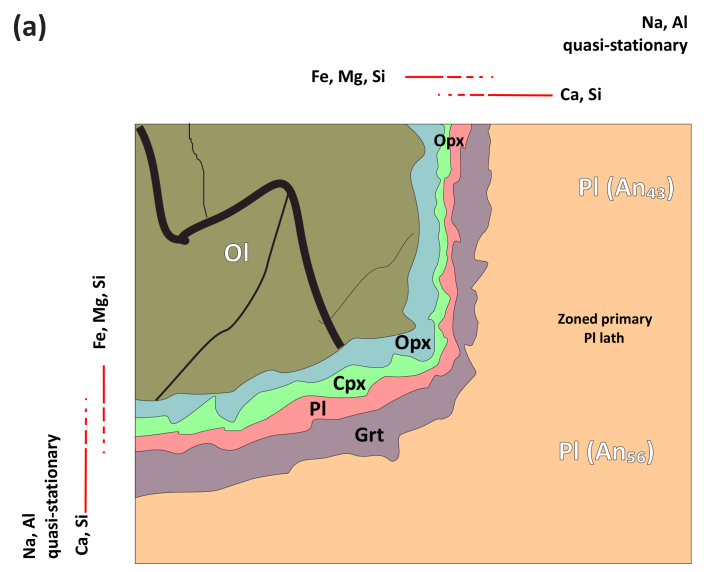

(b)

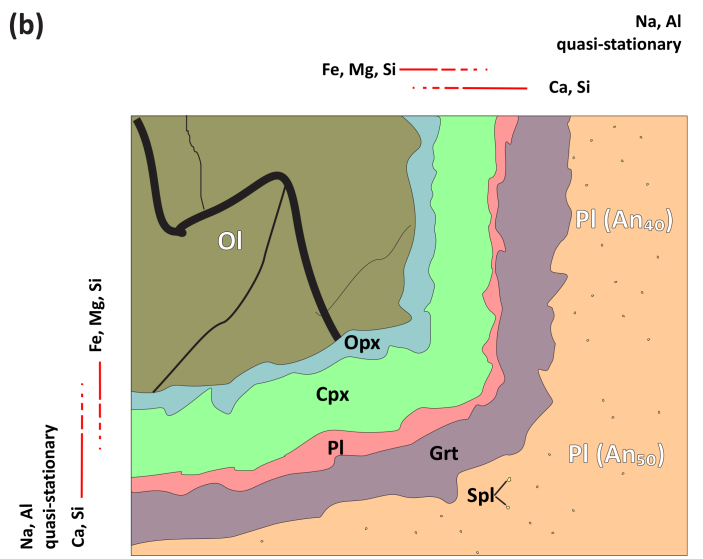

Figure 2. Open-system, single-stage, steady-state diffusioncontrolled growth of prograde corona layers between olivine and plagioclase (modified after Johnson and Carlson, 1990). (a) With incipient reaction, different rates of intergranular diffusion for major components manifest themselves as spatially segregated layers. The corona domain is partitioned into a continuum of compositional subdomains or incipient effective bulk compositions in which local equilibrium is attained, each with unique chemical potentials. $\mathrm{Fe}, \mathrm{Mg}$ and $\mathrm{Si}$ released from olivine diffuse down chemical potential gradients toward plagioclase, whereas $\mathrm{Na}, \mathrm{Ca}, \mathrm{Al}$ and $\mathrm{Si}$ released from plagioclase diffuse toward olivine. Layers comprising the slowest diffusing species (Al) adjoin the most aluminous reactant. (b) Reactions occur at layer boundaries, and layers expand as diffusion progresses. The width and composition of each corona layer depend on the relative fluxes of the diffusing elements. Minor spinel clouding occurs in reactant plagioclase as $\mathrm{Ca}$ and $\mathrm{Si}$ diffuse preferentially into the reaction band, creating an Si deficiency in reactant plagioclase. Phases in the diagrams are labelled using Kretz (1983) mineral abbreviations.

plagioclase (Fig. 2a) becomes unstable during granulite facies metamorphism and is replaced by a new stable assemblage (Fig. 2b) involving orthopyroxene, clinopyroxene, plagioclase and garnet, i.e. $O l|\mathrm{Opx}+\mathrm{Cpx}| \mathrm{Pl}|\mathrm{Grt}| P l$ (reactants in italics). Variable relative rates of intergranular diffusion manifest themselves as spatially segregated product layers, depending on the diffusional length scale of each component, and the corona domain is partitioned into a continuum of compositional subdomains or incipient effective bulk compositions in which local equilibrium is attained, each with unique chemical potentials (Fig. 1). Asymmetric composition profiles for species are established across product bands reflecting variable intergranular diffusivities, e.g. Al content in product bands increases toward the Al-rich reactant. Fe, $\mathrm{Mg}$ and Si released from olivine diffuse down chemical potential gradients toward plagioclase, whereas $\mathrm{Na}, \mathrm{Ca}, \mathrm{Al}$ and Si released from plagioclase diffuse toward olivine. Reactions occur at layer interfaces and layers expand as element flux progresses (Fig. 2b). Inherent in the model is that the product mineral assemblage does not change as reaction proceeds. With time, chemical potentials and fluxes approach steady-state values. $\mathrm{Mg}, \mathrm{Ca}, \mathrm{Na}$ and $\mathrm{Al}$ migrate into the corona and $\mathrm{Fe}$ and $\mathrm{Si}$ move out from the corona. Minor spinel occurs in reactant plagioclase as $\mathrm{Ca}$ and $\mathrm{Si}$ diffuse preferentially into the reaction band, creating an Si deficiency that stabilizes spinel in relict reactant plagioclase (Johnson and Carlson, 1990).

\subsection{Sequential diffusion-controlled corona growth}

This corona growth model involves successive, stepwise, growth of layers, leading to overprinting and partial reequilibration of younger layers as new equilibria are encountered on either the prograde or retrograde path. These changes are typically triggered by changing $P$ and/or $T$ but can also be triggered through changing component fluxes through the corona as a function of evolving local effective bulk compositions (e.g. Griffin, 1972; Griffin and Heier, 1973; Joesten, 1986; Droop, 1989; Indares, 1993; White et al., 2002; Johnson et al., 2004; Štípská et al., 2010; Baldwin et al., 2015). In contrast to the single-stage, steady-state model, the internal layer configuration of the corona reaction band evolves with time as new layers develop and old layers are resorbed. Relative diffusion fluxes and attendant chemical potential differences shift and evolve from one steadystate configuration to another under new $P-T-X$ conditions.

Sequential corona development with changing $P$ and $T$ has been demonstrated in prograde coronas found in mafic rocks between olivine and plagioclase by Griffin (1972) and Mork (1986). Griffin (1972) derived a sequential model for corona formation that involved cooling from temperatures in excess of the dry basalt solidus $\left(>1200^{\circ} \mathrm{C}\right)$, between 0.8 and $1.1 \mathrm{GPa}$, and the crossing of univariant equilibria (Figs. 3 and 4). Initially, olivine and plagioclase crystallized at point A, but, as the rock cooled, it was buried and followed the path delineated by the arrow in Fig. 4. At point B, the olivine and plagioclase reacted to produce Tschermakitic clinopyroxene (Cpx I) and aluminous orthopyroxene (Opx I; Fig. 3a). As the rock tracked through $P-T$ space from B to C (Fig. 4), the clinopyroxene (Cpx I) exsolved spinel and anorthite to form a less Tschermakitic clinopyroxene (Cpx II; Fig. 3b). This clinopyroxene was partly consumed at point $\mathrm{C}$ (Fig. 4) 
(a)

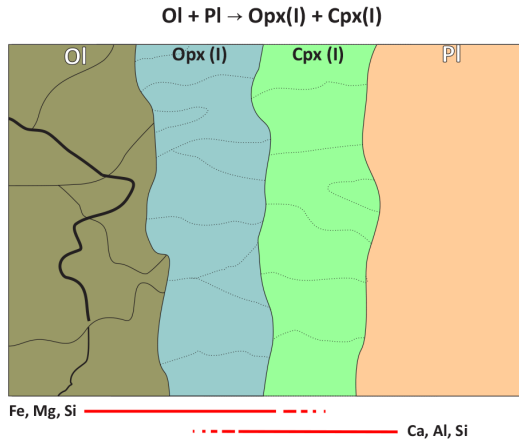

(c)

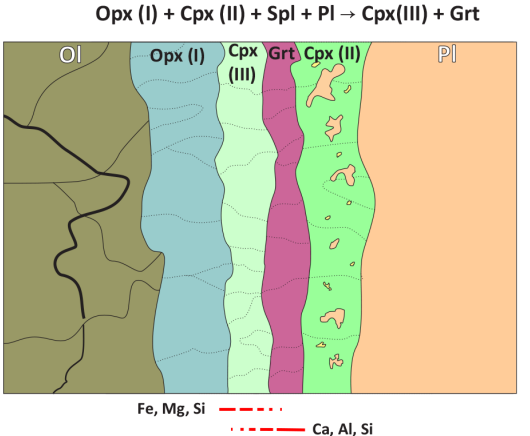

(b)

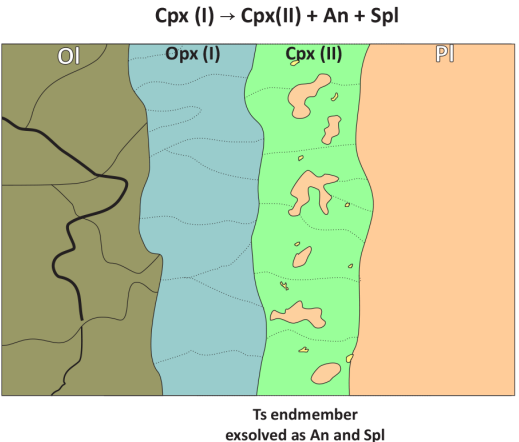

(d)

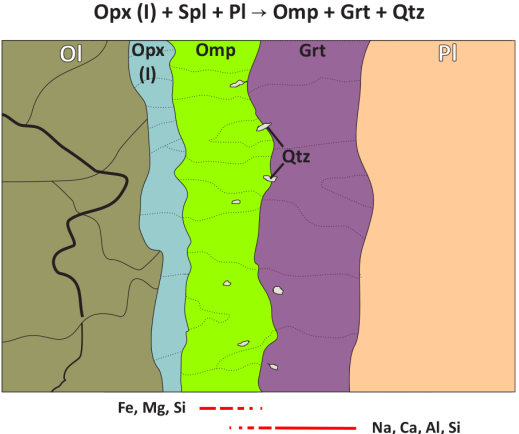

(e)

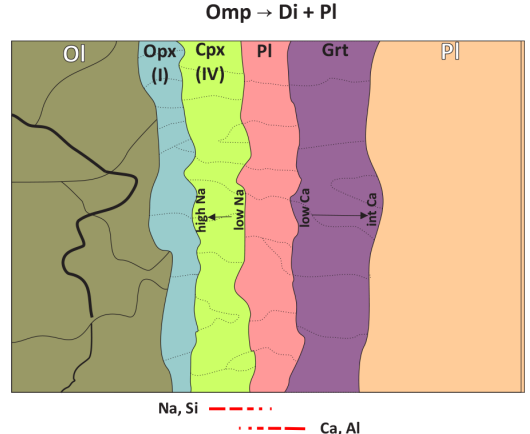

Figure 3. Multi-stage sequential layer development in a corona between olivine and plagioclase formed in response to changing $P$ and $T$ along the $P-T$ path shown in Fig. 2 (after Griffin, 1972). (a) Original olivine and plagioclase react to form orthopyroxene and clinopyroxene. (b) Clinopyroxene breaks down to form a less Tschermakitic composition with plagioclase and spinel. (c) Clinopyroxene reacts with orthopyroxene, spinel and plagioclase to produce garnet. (d) Orthopyroxene reacts with spinel and plagioclase to produce omphacite, garnet and quartz. (e) Omphacite decomposes to clinopyroxene and plagioclase.

to produce garnet and a jadeitic clinopyroxene (Cpx III; Fig. 3c). Further cooling into the eclogite facies produced omphacitic clinopyroxene and garnet with lesser quartz at point D (Fig. 3d). Finally, decompression on exhumation induced the exsolution of the jadeite component from omphacite to yield diopside (Cpx IV) and plagioclase towards point E (Figs. 3e and 4).

Sequential corona development may also occur at constant $P$ and $T$ through changes in the effective element fluxes across the corona band. A multilayer corona may evolve in a steady or quasi-stationary state controlled by diffusion (single-stage, steady-state growth) and then subsequently modify through retrograde reaction between two adjacent layers at constant $P$ and $T$ through changing composition of the effective equilibration volume as the composition of a reactant evolves with protracted reaction. Brady (1977) and Vidale (1969) introduced a modification to the steady-state model that was used to explain variability in coronal layer development between the same reactants by Johnson and Carlson (1990). Vidale (1969) modelled the development of calc-silicate bands in a system with a waning availability of certain components. According to his model, rapidly diffus- 


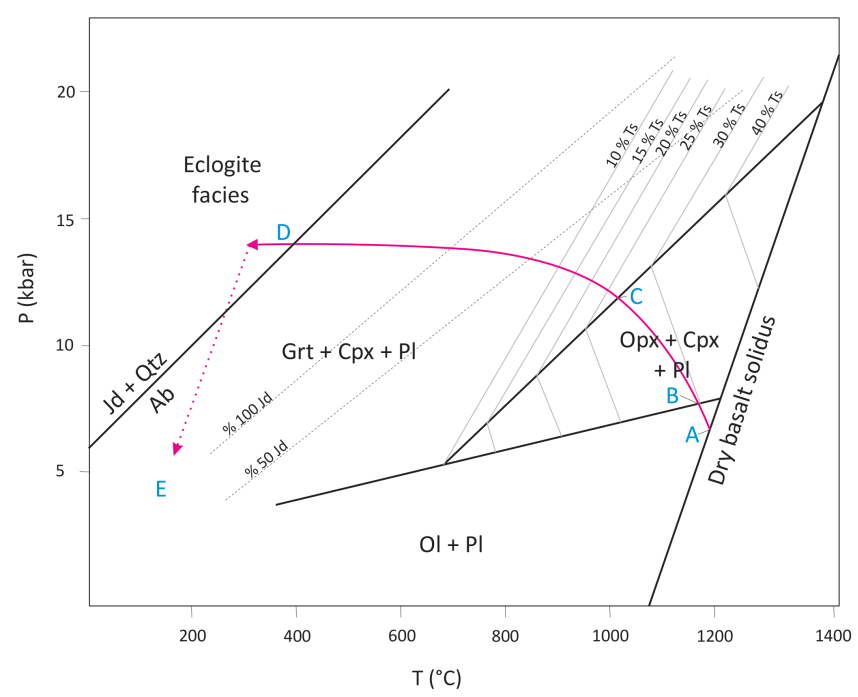

Figure 4. $P-T$ grid indicating univariant equilibria crossed during cooling to produce the sequence of reactions in Fig. 1 (after Griffin, 1972).

ing components in a reaction band will eventually eliminate their chemical potential gradients. The chemical potentials of these rapidly diffusing components in the phases comprising the corona assemblage are then equivalent to those in matrix phases outside the corona band. As the number of components exerting a diffusive control on the reaction is reduced, so mineral phases are lost from the band (Vidale, 1969; Brady, 1977). This manifests itself as "cannibalization" of corona layers comprising the rapidly diffusing components. The original steady state is modified as the system enters a transient state that will evolve through time toward a new steady state with constant chemical potential gradients.

Johnson and Carlson (1990) employed the sequential development model to explain the variability in corona product assemblages developed between plagioclase and olivine in a mafic granulite from the Adirondack Mountains (plagioclase $(O l|\mathrm{Opx}| \mathrm{Cpx}|\mathrm{Pl}| \mathrm{Grt} \mid \mathrm{Pl}-\mathrm{Fig}$. 5). As the reactant plagioclase was gradually depleted in $\mathrm{Ca}$ and $\mathrm{Si}$, it was converted from labradorite to andesine + spinel (Fig. 5a). This modification of the chemical potentials of $\mathrm{Ca}$ and $\mathrm{Si}$ by equilibria outside of the corona band manifests itself as the destabilization and subsequent cannibalization of first the plagioclase corona layer and then the clinopyroxene layer (Fig. 5a, b), as the system evolved toward a new steady-state scenario with constant chemical potential gradients. According to Johnson and Carlson (1990), all corona bands were initially plagioclaseand clinopyroxene-bearing but then evolved to different final configurations with greater or lesser cannibalization of these phases, depending on the availability of $\mathrm{Ca}$ and $\mathrm{Si}$ in the surrounding phases. Where the olivine grain adjoins the spinelpoor plagioclase (originally less calcic, $\mathrm{An}_{43}$ ), both product plagioclase and clinopyroxene have been consumed and the orthopyroxene is in contact with garnet (Fig. 5b, c). In con- trast, where olivine is adjacent to spinel-rich reactant plagioclase (originally more calcic, $\mathrm{An}_{56}$ ), corona plagioclase and clinopyroxene are retained (Fig. 5c).

Sequential layer development in a corona through variation in $P, T$ and changing bulk composition of the corona reaction volume was invoked by Indares (1993) to explain coronas between olivine and plagioclase in an olivine gabbro from the Shabogamo Intrusive Suite, eastern Grenville Province $(O l|\mathrm{Opx}| \mathrm{Cpx}|\mathrm{Pl}| \mathrm{Grt} \mid \mathrm{Pl}$ - Fig. 6). Initially, calcic plagioclase reacted with olivine to form orthopyroxene and garnet coronas at high $P$ and $T$, under eclogite facies conditions (Fig. 6a). The relative difference in intergranular diffusivities of components results in two distinct corona layers, grading from $\mathrm{Al}$-rich garnet adjacent to plagioclase to (Alpoor) orthopyroxene adjacent to olivine. Excess $\mathrm{Al}$ in the plagioclase was accommodated by the formation of corundum (Fig. 6a). At the same pressure and temperature, the garnet layer grew by reaction between calcic plagioclase and corona orthopyroxene in a local effective bulk composition different from that which produced the initial corona orthopyroxene and garnet, which included olivine (Fig. 6b). Continued reaction generated excess $\mathrm{Si}$ and $\mathrm{Al}$ in the reactant plagioclase, which reacted with corundum to form kyanite (Fig. 6b). In Fig. 6c, the reactant plagioclase is relatively enriched in $\mathrm{Na}$ through the two former reactions. Na then diffused out of plagioclase and reacted with corona orthopyroxene and garnet to form omphacite. In response, more kyanite formed in the plagioclase to accommodate excess residual Si and Al. With subsequent exhumation and decompression, corona garnet reacted with kyanite and corundum in plagioclase to form spinel and more calcic plagioclase (Fig. 6d). In addition, garnet reacted with omphacite and some excess Si to produce intervening plagioclase.

The sequential development of symplectites in pelitic rocks has been elegantly modelled using calculated phase diagrams involving chemical potentials for coupled spinel + plagioclase symplectites and monomineralic plagioclase coronas after kyanite $(K y|\mathrm{Spl}+\mathrm{Pl}| \mathrm{Pl} \mid Q t z+F s p)$ by Štípská et al. (2010) and Baldwin et al. (2015). With isothermal decompression from peak conditions, kyanite was no longer stable, and a zoned monomineralic plagioclase layer formed between the kyanite and matrix with quartz in excess and only $\mathrm{Al}$ considered immobile. As the plagioclase layer evolved, the diffusion of Si through the plagioclase layer from the matrix was retarded and the local equilibrium volume encompassing the kyanite and plagioclase layer contact became a silica-deficient one. The chemical potential of $\mathrm{SiO}_{2}$ at the kyanite contact was accordingly lowered sufficiently to stabilize spinel in a symplectite intergrowth with plagioclase.

\section{Controls on corona development in granulites}

Of all the substantive literature references to corona textures, only a few relate to compositions that are neither pelitic 
(a)
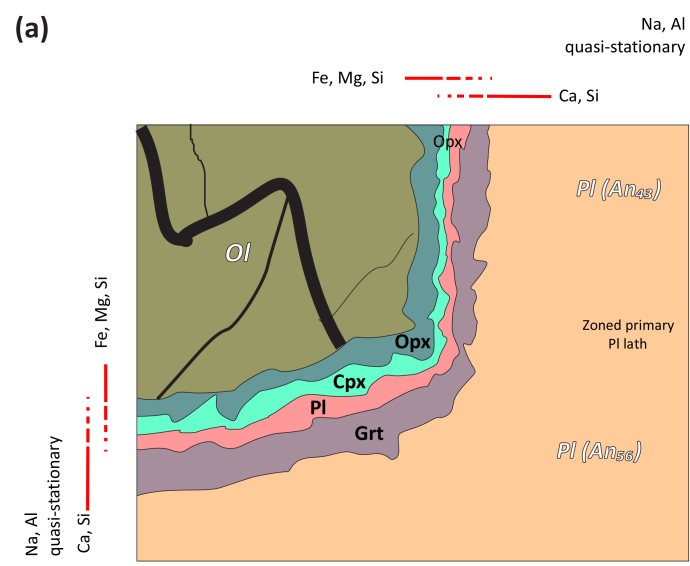

(b)
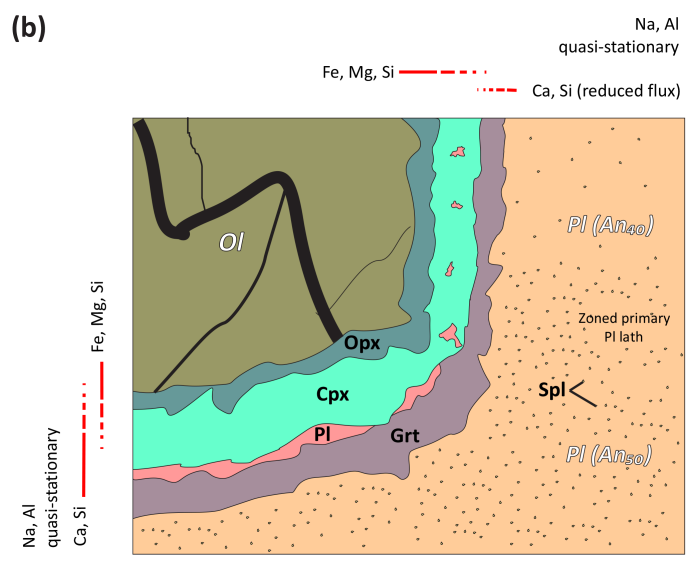

(c)
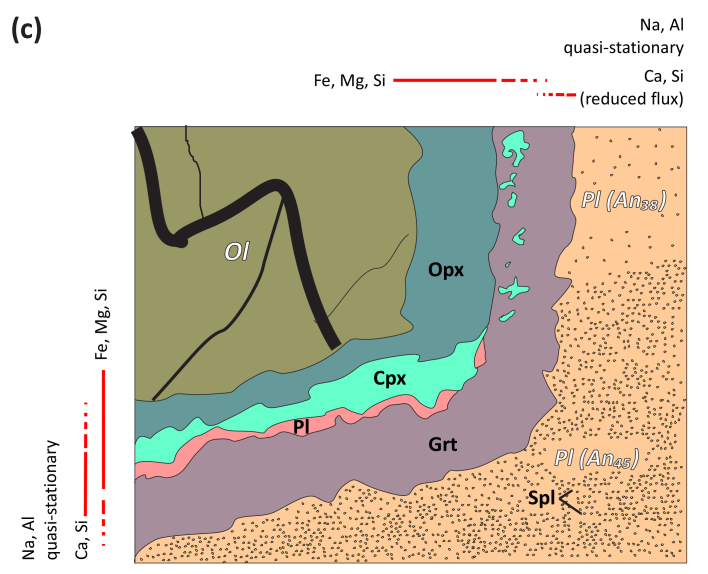

Figure 5. Multi-stage sequential layer corona layer development at constant $P$ and $T$ in response to waning boundary fluxes of rapidly diffusing components from the reactants into the corona in an open system (after Johnson and Carlson, 1990). (a) Initial steady-state layer configuration for an olivine-plagioclase corona. (b) Depletion of $\mathrm{Ca}$ and $\mathrm{Si}$ in the reactants leads to the consumption of plagioclase and then (c) clinopyroxene in transient states. The system gradually evolves toward a new steady state. Cannibalization of corona plagioclase and clinopyroxene is more enhanced where the original reactant is Ca-poor (top right, $\mathrm{An}_{38}$ ). or mafic. Table A1 presents details of prograde coronas in the literature, whereas Table A2 comprises a selection of the more numerous references to coronas formed during retrograde re-equilibration. Selected coronas from mafic and pelitic rocks are schematically illustrated in Figs. 7 and 8, respectively. The assemblages and microstructure in coronas in both pelitic and mafic rocks vary considerably depending on (a) metamorphic conditions $(P, T$ and water activity $-a \mathrm{H}_{2} \mathrm{O}$ ), (b) inferred formation mechanism through either steady-state and/or sequential layer development, (c) reactant compositions, (d) reaction kinetics, and (e) the amount of deformation or strain intensity on either the prograde or retrograde path.

\subsection{Pressure, temperature and $a \mathrm{H}_{2} \mathrm{O}$}

Pressure, temperature and $a \mathrm{H}_{2} \mathrm{O}$ conditions determine which mineral phases form within the corona. In olivine gabbros or troctolites from the Adirondack Highlands, coronal assemblages vary from $O l|\mathrm{Opx}+\mathrm{Cpx}| \mathrm{Grt} \mid P l$ in the northeast (Johnson and Carlson, 1990 - Fig. 5a) to $O l|\mathrm{Opx}| \mathrm{Cpx}+\mathrm{Spl} \mid P l$ in the southwest (Whitney and McLelland, 1973 - Fig. 7a), with the presence of garnet in the former being attributed to higher pressures towards the northeast. In the Newer Basic Intrusion of NE Scotland, the coronal assemblage $O l|\mathrm{Opx}| \mathrm{Hbl}+\mathrm{Spl} \mid P l$ is observed (Mongkoltip and Ashworth, 1983 - Fig. 7b). In this case, hornblende is favoured over clinopyroxene under higher $a \mathrm{H}_{2} \mathrm{O}$ conditions. Similarly, the dominance of hornblende in the corona assemblage between garnet and clinopyroxene described in Carlson and Johnson (1991) (Fig. 7c) versus the restriction of pargasite to the layer closest to garnet in the coronas described by Baldwin et al. (2004) (Fig. 7d) is attributed to higher $a \mathrm{H}_{2} \mathrm{O}$ in the former corona compositional domain.

In metapelites, coronas after sapphirine and quartz comprise the sequence $S p r|\operatorname{Sil}| \mathrm{Opx} \mid Q t z$ at higher pressures but $\operatorname{Spr}|\mathrm{Sil}| \mathrm{Opx}+\mathrm{Crd} \mid Q t z$ at lower pressures and temperatures and/or higher $a \mathrm{H}_{2} \mathrm{O}$ conditions (e.g. Lal et al., 1987). Coronas after gedrite and kyanite from the ThorOdin Dome in British Columbia comprise the sequence Ged $|\mathrm{Crd}| \mathrm{Crd}+\mathrm{Spl}$ symplectite $\mid \mathrm{Crd}+\mathrm{Crn}$ symplectite $\mid K y$ (Norlander et al., 2002 - Fig. 8a). The lower-temperature equivalent corona (assuming minimal bulk compositional differences) is Ged $|\mathrm{Crd}| \mathrm{St} \mid K y$, which is seen in the Errabiddy metapelitic granulites in Western Australia (Baker et al., 1987).

\subsection{Sequential versus single-stage corona formation mechanism}

Corona assemblages are also governed by the mechanism by which they formed, i.e. either in a single-stage, steadystate event, as sequential layers in response to varying pressure, temperature or component fluxes into the reaction vol- 
(a)

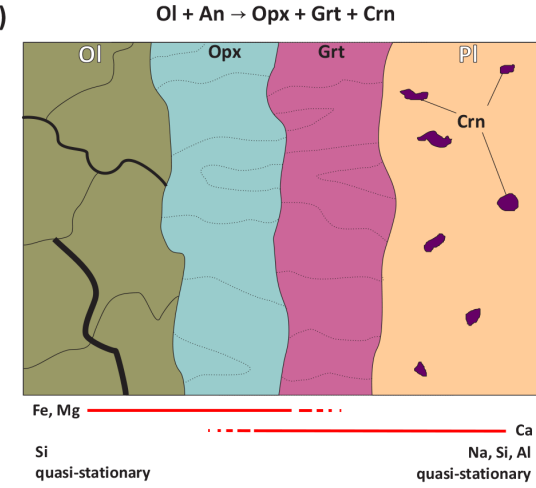

(c)

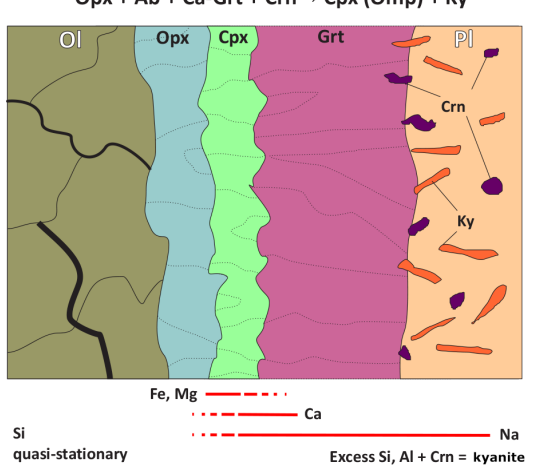

(b)

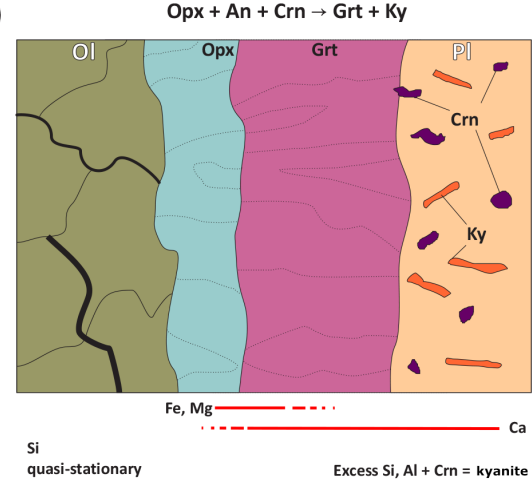

(d)

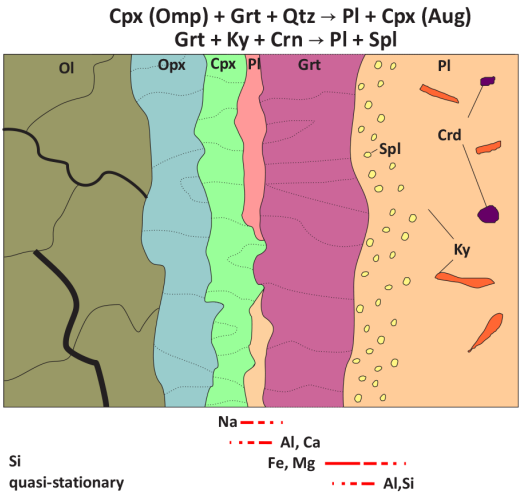

Figure 6. Multi-stage sequential corona layer development between plagioclase and olivine owing to varying component fluxes across the corona bands and, later, owing to decompression (modified after Indares, 1993). Corona layer growth in panels (a-c) occurs under constant high $P$ and $T$, initially from discrete reactions between reactants and then subsequently between individual corona layers as component fluxes vary across the corona. The formation of the plagioclase layer in panel (d) is ascribed to decompression. Detailed reaction mechanisms are discussed in the text.

ume, or by a mechanism intermediate between these two endmember formation models. Most coronas listed in Tables A1 and A2 appear to be interpreted via the single-stage, steadystate model, but models in which sequential growth dominates are invoked commonly. Determining which model of corona formation is applicable in a specific context is commonly difficult but vital if information on the $P-T$ path is to be gleaned correctly from the corona (White and Clarke, 1997). This is critically evident in contrasting interpretations of the coronas formed between olivine and plagioclase in metagabbros from Risør, Norway (Joesten, 1986; Ashworth, 1986). Joesten (1986) cited textural evidence and the diffusional instability of any closed-system, steady-state diffusion model for the coronas in support of a model involving a primary magmatic origin for the coronas, followed by secondary annealing. He suggested that cuspate olivineorthopyroxene contacts, thickening of orthopyroxene layers at narrow terminations of olivine grains, irregular contacts between orthopyroxene-spinel and amphibole-spinel layers, and heterogeneity in the corona assemblage developed depending on the adjacent magmatic phase (i.e. either plagioclase, amphibole or clinopyroxene) are all inconsistent with a diffusion-controlled origin. These features were thought to be more likely a result of olivine dissolution in a melt, followed by the sequential growth of corona layers with cooling at magmatic temperatures above the olivine-plagioclase stability field. Joesten (1986) proposed that these primary magmatic coronas were diffusionally unstable and that they were spontaneously partially to completely annealed on cooling.

In contrast, Ashworth (1986) suggested the Risør coronas formed by single-stage, steady-state diffusion-controlled replacement of plagioclase and olivine with an open-system modification to mass balance model constraints. Textural evidence apparently inconsistent with a diffusion model was attributed to locally variable kinetic controls on reaction mechanism, for example, epitaxial growth of tabular amphibole on magmatic grains versus heterogeneous nucleation at reactant contacts. Ashworth (1986) did not address the sectoral heterogeneity of the coronas nor the irregular contacts between amphibole-spinel and orthopyroxene-spinel layers. However, it is conceivable that variation in the bulk composition of the equilibration volume - both spatially and temporally as reaction proceeded - may account for such heterogeneity (e.g. Johnson and Carlson, 1990).

Alternative sequential models of corona formation, invoking varying $P, T$ and/or boundary fluxes, may similarly have 
(a)

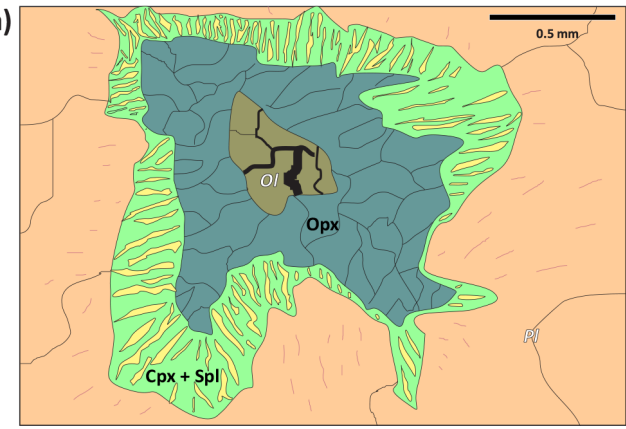

(c)

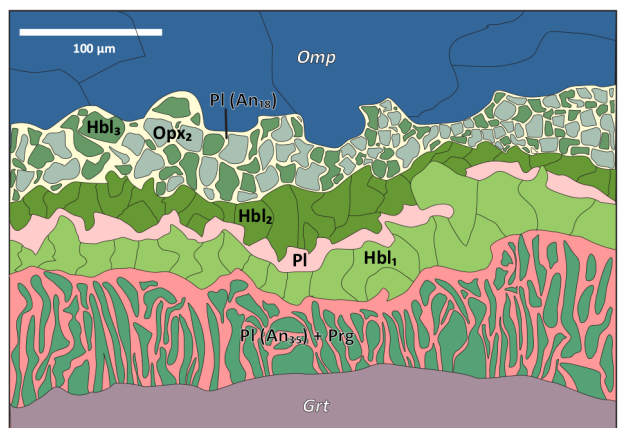

(e)

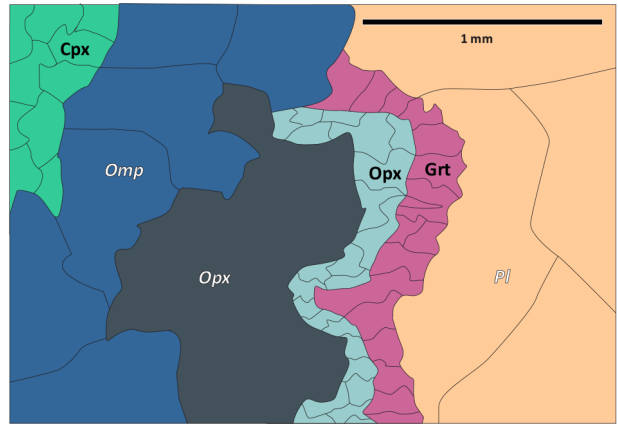

(b)

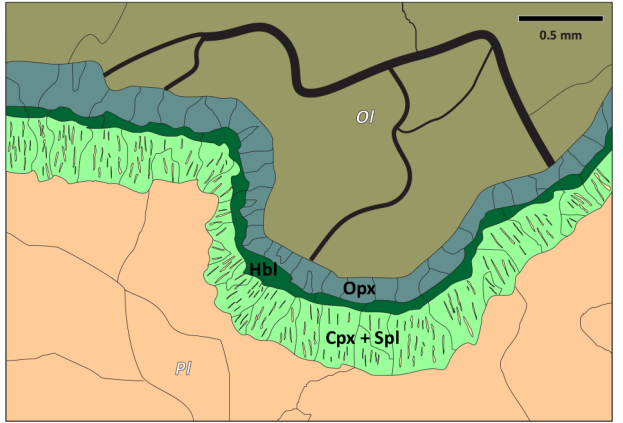

(d)

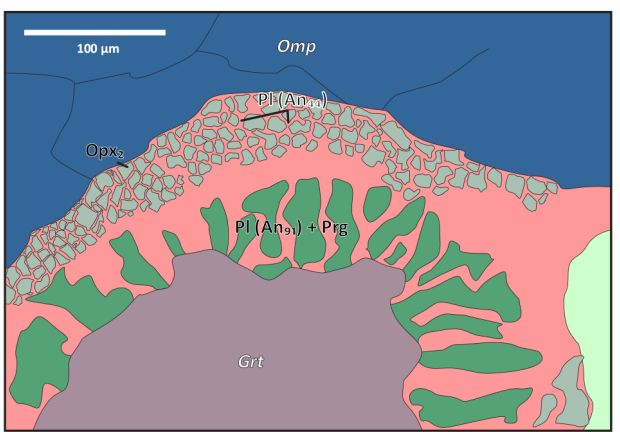

(f)

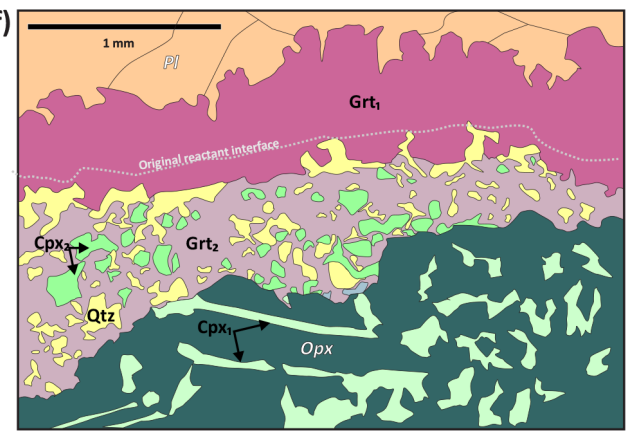

Figure 7. Common corona textures developed in mafic granulites. (a) Prograde corona developed between olivine and plagioclase during burial following shallow intrusion in the southwestern Adirondacks, New York (after Whitney and McLelland, 1973). Garnet is not present in this corona owing to low inferred pressures during corona reaction. There is no variation in $X_{\mathrm{Mg}}$ of pyroxenes. (b) A retrograde corona developed between olivine and plagioclase in an olivine metagabbro from northeast Scotland (after Mongkoltip and Ashworth, 1983). The presence of amphibole suggests higher $a \mathrm{H}_{2} \mathrm{O}$ than in more anhydrous domainal compositions where only clinopyroxene is stable. Al content and $X_{\mathrm{Fe}}$ of $\mathrm{Opx}$ and $\mathrm{Hbl}$ increase toward Pl reactant. (c) Retrograde corona developed between garnet and clinopyroxene during a static thermal event with the intrusion of numerous granite plutons in the Llano Uplift, Texas (after Carlson and Johnson, 1991). The presence of hornblende implies relatively high $a \mathrm{H}_{2} \mathrm{O}$ during reaction. Both hornblende and plagioclase are asymmetrically zoned across the corona band. Plagioclase becomes less calcic $\left(\mathrm{An}_{35}\right.$ to $\left.\mathrm{An}_{18}\right)$ and amphibole $\mathrm{Fe} / \mathrm{Mg}$ and $\mathrm{Al} / \mathrm{Si}$ ratios decrease toward omphacite. (d) Retrograde corona developed between garnet and clinopyroxene from the Snowbird tectonic zone, western Canadian Shield (after Baldwin et al., 2004). The restricted distribution of hornblende in this corona compared to that in panel (c) suggests a less hydrous bulk corona composition. Marked zonation in plagioclase occurs from $\mathrm{An}_{91}$ adjacent garnet to $\mathrm{An}_{44}$ at clinopyroxene margin. (e) Prograde corona developed between plagioclase and orthopyroxene during deformation-enhanced reaction in a dolerite towards a shear zone (after White and Clarke, 1997). Garnet exhibits asymmetric zonation as $X_{\mathrm{Alm}}, X_{\mathrm{Prp}}$ and $X_{\mathrm{Grs}}$ increase toward Pl. Garnet zoning diminishes toward shear zone. (f) Prograde corona developed between plagioclase and orthopyroxene in a mafic granulite from Yenisey Ridge, Siberia (after Ashworth et al., 1998). Layer 1 garnet $\left(\mathrm{Grt}_{1}\right)$ is zoned: Fe increases and Ca decreases $\left(X_{\mathrm{Grs}}: 0.24-0.21 ; X_{\mathrm{Alm}}: 0.54-0.60\right)$ toward layer 2 . A slight compositional perturbation across layer 1 is thought to mark the initial Pl-Opx boundary. In layers 3 and 4, Ca in garnet is almost constant, with higher $\mathrm{Fe}$ and lower $\mathrm{Mg}$ than in layer 1. No systematic zonation is observed in pyroxene. Non-equilibrium thermobarometric estimates for corona formation are $740 \pm 20^{\circ} \mathrm{C}$ and $9.5 \pm 0.7 \mathrm{kbar}$ (Ashworth et al., 2001). 
(a)

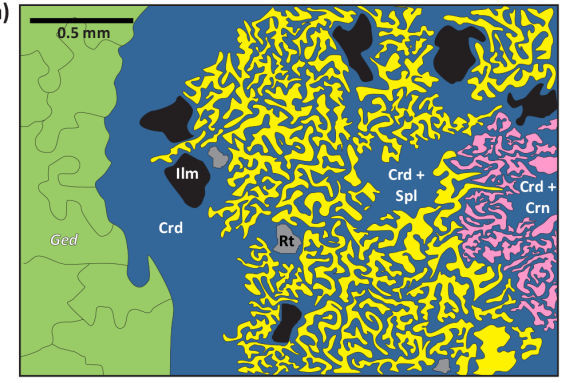

(b)

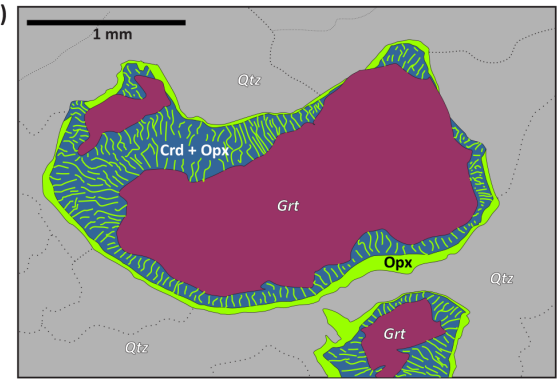

(c)

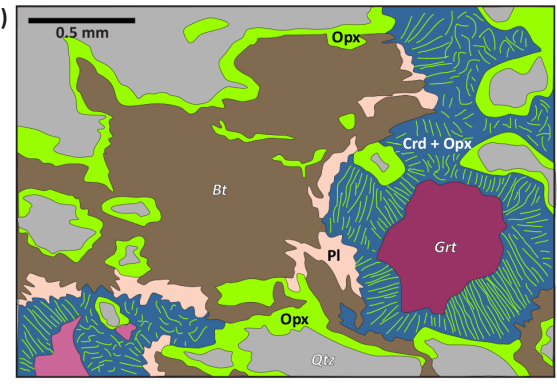

(d)

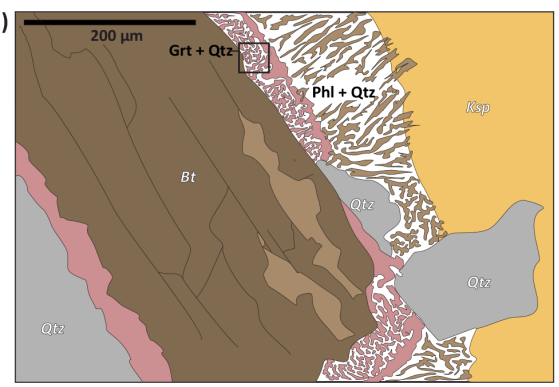

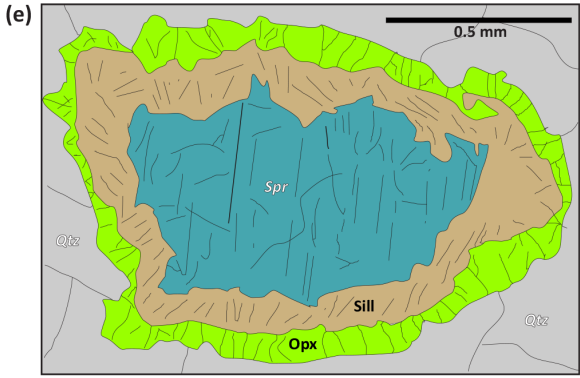

(f)

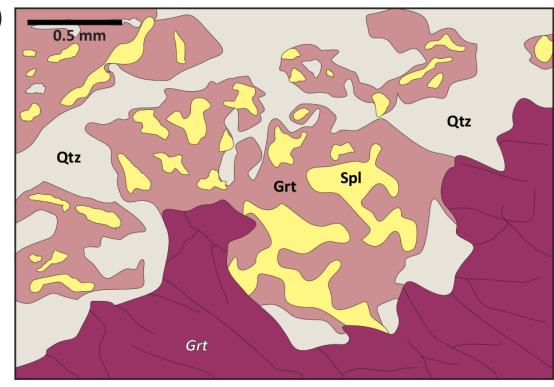

(g)

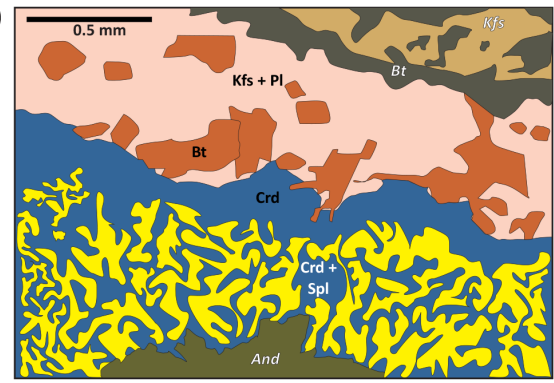

(h)

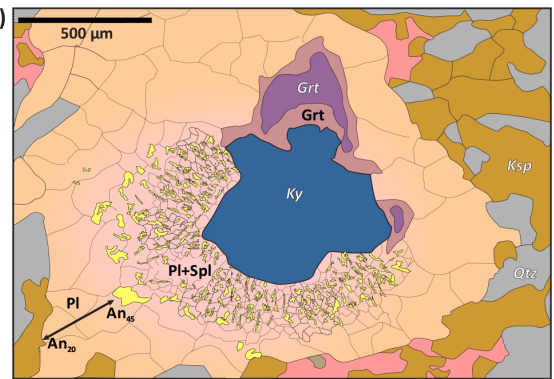

Figure 8. Sectoral complexity in corona textures developed in pelitic granulites. (a) Complex corona between kyanite and gedrite (after Norlander et al., 2002). No compositional variation in any corona phases was observed. Conditions of formation constrained at $<5 \mathrm{kbar}$ and $\sim 750^{\circ} \mathrm{C}$ with TWQ and conventional thermobarometers. (b) Common complex corona developed after garnet and quartz (after Hollis et al., 2006). No systematic variation is described in corona products. (c) Complex sectoral corona between garnet, biotite and quartz. Monomineralic plagioclase is constrained to the corona immediately adjacent to biotite. Similarly, blocky orthopyroxene occurs only in the corona sectors where garnet reacts with quartz (after Kelsey et al., 2003). Cordierite $X_{\mathrm{Mg}}$ varies across symplectite increasing toward orthopyroxene in general. No variation in orthopyroxene composition is observed. (d) Symplectite-dominated corona developed between biotite and K-feldspar (after Bruno et al., 2001). Where biotite reacts with quartz, monomineralic garnet comprises the corona. Elsewhere, a complex, symplectite-dominated corona comprising garnet, quartz and phlogopite occurs where biotite and feldspar react. Corona garnet is weakly zoned. (e) Monomineralic sillimanite and orthopyroxene developed after sapphirine and quartz (after Ellis, 1980, and Grew, 1980). (f) Retrograde spinel-garnet symplectite replacing peak garnet during post-peak decompression (after White et al., 2002). This corona develops in response to changing modes in a high-variance equilibrium assemblage. No univariant reaction is crossed. (g) Prograde complex corona comprising spinel-cordierite symplectite and leucocratic biotite, K-feldspar and plagioclase after andalusite (after Johnson et al., 2004). $X_{\mathrm{Mg}}$ of cordierite decreases toward biotite (0.55-0.51) with no variation in spinel composition. Cordierite moat formation occurs during an andalusite melting reaction consuming quartz and biotite, followed by continued breakdown of andalusite to cordierite-spinel symplectite in $\mathrm{SiO}_{2}$ deficient domains. (h) Sectoral replacement of kyanite by plagioclase + spinel symplectite and zoned monomineralic plagioclase. Where primary garnet abuts kyanite, the symplectite is not developed, and kyanite is replaced by low-Ca garnet enclosed by unzoned plagioclase (After Stípská et al., 2010). 
important implications for the reconstruction of $P-T$ paths. For the same corona textures between olivine and plagioclase in the New York Adirondacks (Figs. 2, 5 and 6), three different $P-T$ paths were constructed by Griffin (1972), Johnson and Carlson (1990), and Indares (1993) based on their inferences about the drivers behind the corona reactions, namely, changing pressure and temperature (Griffin, 1972; Joesten, 1986), changing component fluxes (Johnson and Carlson, 1990), or a combination of all three parameters (Indares, 1993). Mass balance constraints and compositional zonation within each corona assemblage were cited in each case in support of the adopted model.

Criteria for the identification of single-stage, steady-state layer growth include mineral zonation and a marked spatial organization of product reaction bands such that each layer represents a non-overlapping volume in compositional space (Joesten, 1977; Fisher, 1977), all arranged in an orderly sequence of increasing or decreasing chemical potential (Fisher, 1977). If the corona has not attained equilibrium, asymmetric composition profiles in minerals within a corona layer and in the corona as a whole are consistent with chemical potential gradients induced by relative differences in intergranular diffusion rates of components at approximately constant $P-T$ conditions (Indares, 1993; White and Clarke, 1997). In contrast, a sequential corona model predicts symmetric, radial zoning of phases with respect to grain boundaries. Mass balance constraints commonly preclude the formation of an intervening layer by reaction between two initially contiguous layers in a sequential model. This necessitates the diffusion of requisite components from outside the limits of the immediate equilibration volume within a single-stage, steady-state diffusional regime. Even so, evidence may be equivocal, and it may not be possible to exclusively establish single-stage, diffusion-controlled multilayer corona growth from stepwise, sequential growth in response to changing $P-T$ conditions or component fluxes. In these cases, the corona formation mechanism likely reflects a combination of both endmember corona models. Tectonic context and structural data might provide independent constraints on the relative contributions of either endmember model to the overall corona formation mechanism. Ultimately, clarification is best attained by modelling the spatial arrangement of textures in a series of chemical potential phase diagrams, which allow the full range of possible textural configurations, given different formation mechanisms, to be evaluated (White and Powell, 2011; Štípská et al., 2010; Baldwin et al., 2015).

\subsection{Reactant compositions}

The compositions of local reactants principally determine the effective bulk composition of the corona, with a minor degree of open-system communication with matrix. The most obvious manifestation of local compositional control on corona configuration is demonstrated by the three main types of coronas observed in mafic rocks, where metasomatic exchange with the enclosing rock is minimal and the corona bulk composition is principally determined by the reactants. Local corona bulk compositions comprising orthopyroxene, clinopyroxene, plagioclase and garnet form after olivine and plagioclase $(O l|\mathrm{Opx}| \mathrm{Cpx}|\mathrm{Pl}| \mathrm{Grt} \mid P l$ - Figs. 2, 3 and 5). More aluminous, hydrous corona bulk compositions after garnet and clinopyroxene stabilize amphibole, plagioclase and orthopyroxene $(G r t|\operatorname{Prg}| \mathrm{Pl}|\mathrm{Cpx} / \mathrm{Opx}| C p x-$ Fig. $7 \mathrm{c}$, d). Commonly, clinopyroxene reacts with plagioclase to yield clinopyroxene (with or without orthopyroxene), quartz and garnet coronas $(C p x|\mathrm{Cpx} / \mathrm{Opx}| \mathrm{Qtz}|\mathrm{Grt}| P l-\mathrm{Fig} .7 \mathrm{e}, \mathrm{f})$.

Markl et al. (1998) described coronas after fayalite and Kfeldspar or plagioclase $(F a|\mathrm{Opx}| \mathrm{Grt}+\mathrm{Opx} \mid P l / K f s)$, in which the layer thicknesses, product proportions and their compositions vary systematically depending on whether plagioclase or K-feldspar is the reactant. Carlson and Johnson (1991) described a corona after garnet and quartz in a metagabbro from the Llano Uplift in Texas comprising the layer sequence $G r t|\mathrm{Pl}+\mathrm{Mgt}| \mathrm{Opx}+\operatorname{Aug} \mid Q t z$. In metapelites, coronas after garnet and quartz typically yield a coronal assemblage of Grt $|\mathrm{Crd}+\mathrm{Opx}| \pm \mathrm{Pl}|\mathrm{Opx}| Q t z$ (Hollis et al., 2006 Fig. 8b). The presence of augite, plagioclase and magnetite in a metagabbro corona may be attributed to significantly more calcic garnet $(\sim 8 \mathrm{wt} \% \mathrm{CaO})$ with a higher $X_{\mathrm{Fe}}$ than typical pelitic garnets. Van Lamoen (1979) and Nishiyama (1983) reported coronas after olivine and plagioclase in metamafic rocks and conclusively demonstrated a correlation between the compositions of reactant olivine and product orthopyroxene.

Sectoral development in complex coronas is perhaps the most obvious manifestation of reactant compositional control on corona mineralogy and morphology. Kelsey et al. (2003) described sectoral development of coronas around garnet in pelitic granulites from the Mather Paragneiss in the Rauer Group, Antarctica (Fig. 8c). In these granulites, garnet is enclosed by a complex corona that comprises Grt $\mid \mathrm{Crd}+\mathrm{Opx}$ symplectite $|\mathrm{Opx}| Q t z$ where garnet was initially adjacent to quartz and $G r t \mid \mathrm{Crd}+\mathrm{Opx}$ symplectite $|\mathrm{P}| \mid B t$ where it was initially adjacent to biotite. These corona sectors appear to define unique, highly localized effective bulk compositions. The sharp changes in mineral proportions between sectors attests to the limited degree of chemical communication between the $G r t+B t$ and $G r t+Q t z$ compositional domains. Bruno et al. (2001) described coronas after biotite and quartz or feldspar, in which corona mineralogy varies around a single biotite grain from $B t|\mathrm{Grt}| Q t z$ where biotite abuts quartz to $B t|\mathrm{Grt}| \mathrm{Grt}+\mathrm{Qtz}|\mathrm{Phg}+\mathrm{Qtz}| K f s$ where biotite is adjacent to $\mathrm{K}$-feldspar and $B t|\mathrm{Grt}| \mathrm{Grt}+\mathrm{Jd} \mid P l$ where plagioclase encloses biotite (Fig. 8d). Štípská et al. (2010) noted complex radial and sectoral heterogeneity in coronas after kyanite (Fig. 8h). Where kyanite is enclosed by plagioclase-K-feldspar-quartz matrix, it is replaced by a reasonably uniform corona comprising $K y \mid \mathrm{Pl}+\mathrm{Sp} \pm \mathrm{Crn}$ symplectite|Pl|Matrix. The monomineralic plagioclase layer 
is strongly zoned with respect to anorthite content, grading from $X_{\text {An }}=0.45$ to 0.20 adjacent to the matrix. Locally, where kyanite abuts garnet from the peak assemblage, the plagioclase-spinel symplectite is absent and a thin Ca-poor garnet monomineralic layer is rather developed, which is in turn enclosed by unzoned monomineralic plagioclase. Štípská et al. (2010) ascribed the antipathetic occurrence of the garnet corona layer and the spinel + plagioclase symplectite to higher $\mathrm{FeO}$ and $\mathrm{MgO}$ chemical potentials in the equilibration volume encompassing both garnet and kyanite as a reactant, which stabilized garnet in the calculated product phase equilibria.

\subsection{Reaction kinetics - diffusion}

The spatial array of corona product bands and the presence or absence of associated symplectite is a function of relative intergranular diffusivities of major system components. Typically, Al and $\mathrm{Si}$ are relatively immobile compared to more rapidly diffusing components such as $\mathrm{Fe}, \mathrm{Mg}$ and, to a lesser extent, Ca (e.g. Johnson and Carlson, 1990; Carlson and Johnson, 1991; Ashworth and Birdi, 1990; Ashworth et al., 1992; Ashworth and Sheplev, 1997). In natural coronas that are inferred to have formed in a single-stage, steady-state diffusion-controlled scenario, typically limited Al diffusion manifests itself as both modal and phase compositional zonation in the corona; i.e. Al-rich minerals occur in layers closest to the aluminous reactant, and, within these layers, the corona minerals exhibit asymmetric zonation in compositional profiles, e.g. $y(\mathrm{Opx})$ increases toward the Al-rich reactant. Since $\mathrm{Fe}$ and $\mathrm{Mg}$ typically diffuse more rapidly than $\mathrm{Al}$, ferromagnesian minerals tend to segregate into layers farthest from the aluminous reactant. $X_{\mathrm{Fe}}$ varies across the corona depending on relative diffusion length scales of Fe and $\mathrm{Mg}$. Coronas after sapphirine and quartz in metapelites (Ellis, 1980 - Fig. 8e) and between sillimanite and orthopyroxene (Kriegsman and Schumacher, 1999; Table A2) demonstrate spatial segregation of aluminous corona layers (sillimanite and sapphirine, respectively) from more $\mathrm{Fe}$ - and $\mathrm{Mg}$-rich corona products (orthopyroxene and cordierite, respectively). Coronas after garnet and clinopyroxene in more mafic bulk compositions segregate into pargasite adjacent to garnet and orthopyroxene + plagioclase adjacent to clinopyroxene (Baldwin et al., 2004 - Fig. 7d).

Diffusion-controlled reaction rates arise most commonly on the retrograde $P-T$ path (Table A2) in melt-depleted, residual bulk rock compositions. In metapelites, coronal reaction textures are commonly attributed to near-isothermal decompression following peak conditions on a clockwise $P-T$ path (e.g. coronas after garnet and quartz; Kelsey et al., 2003 - Fig. 8c) or to near-isobaric cooling (e.g. coronas after sapphirine and quartz; Grew, 1980 - Fig. 8e). White et al. (2002), however, urge caution in inferring large amounts of decompression and cooling along the retrograde path to produce corona textures; phase equilibria modelling of spinel-bearing symplectites after garnet from an Fe-rich pelitic granulite in the Musgrave Block, Australia (Fig. 8f), suggested to them that coronas might develop on any number of retrograde $P-T$ path trajectories through a high-variance field in which the mode of garnet is decreasing while that of the corona products is increasing. Thus, large amounts of decompression are not required to produce coronas and symplectites after garnet, and, hence, estimates of decompression from other terranes (e.g. Harley, 1989) may well have been overestimated.

Coronas developed on the prograde path (Table A1) are far less common than coronas that form during retrogression (Table A2), owing largely to more prolonged reaction duration, the presence of a melt or fluid that promotes greater length scales of diffusion, and/or deformation on the prograde path. Thus, the diffusion-constrained conditions on the prograde path suitable for corona growth likely occur where deformation is largely absent (e.g. White and Clarke, 1997 Fig. 7e), in low $a \mathrm{H}_{2} \mathrm{O}$ mafic rocks (Ashworth et al., 1998 Fig. 7f; Johnson and Carlson, 1990 - Fig. 2) or melt-depleted pelitic rocks, or where the rate of change in pressure and temperature occurs sufficiently fast such that diffusion rates are exceeded. Typically, the latter scenario arises in contact aureoles characterized by rapid heating and cooling (Johnson et al., 2004 - Fig. 8g; Mcfarlane et al., 2003; Ings and Owen, 2002; Barboza and Bergantz, 2000; Wheeler et al., 2004; Daczko et al., 2002; Dasgupta et al., 1997; Joesten and Fisher, 1988), but it can also occur in shock-heated rocks within large impact structures (Gibson, 2002; Ogilvie, 2010).

\subsection{Deformation and strain}

High-strain intensities have been shown experimentally to enhance equilibration (Delle Piane et al., 2007; Heidelbach et al., 2009; Götze et al., 2010; Keller et al., 2010; Helpa et al., 2015). Deformation is thought to enhance diffusioncontrolled reaction rates through inducing defects which act as additional diffusion pathways, e.g. dislocations and or new subgrain boundaries (Helpa et al., 2015). Experimental work is supported by field observations. White and Clarke (1997) described coronas developed after orthopyroxene and plagioclase in a dolerite adjacent to a shear zone in the western Musgrave Block, Australia (Fig. 7e). Towards the shear zone, coronas diminish in complexity until complete equilibration and recrystallization is attained in the highest-strain domains within the shear zone. Koons et al. (1987) documented similar findings in a quartz diorite from the Sesia Zone, Western Alps, whilst Smit et al. (2001) described enhanced replacement of garnet by, and deformation of, orthopyroxene + cordierite symplectite approaching bounding shears zones in the Limpopo Belt, South Africa. With increasing deformation, equilibrium domains progressively approach that of the bulk rock composition without any discernable change in pressure and temperature. White and Clarke (1997) attributed this enhanced equilibration in high- 
strain domains to a combination of a reduction in grain size with an attendant increase in intergranular area, accelerated intracrystalline diffusion and nucleation, and increased permeability and $a \mathrm{H}_{2} \mathrm{O}$.

\section{Conditions of corona formation}

Thermobarometric estimates for the average $P-T$ conditions of corona formation in mafic and pelitic granulites are depicted in Fig. 9. In most cases, average $P-T$ conditions exceed the wet solidus for their respective bulk rock compositions. The few exceptions plotting below the solidus may be attributed to retrograde compositional resetting with cooling. Figure 9 is consistent with corona formation in granulite facies rocks that have an intrinsically low $a \mathrm{H}_{2} \mathrm{O}$ bulk rock composition (e.g. mafic granulites) and/or have undergone a degree of melt loss. Under these conditions, intergranular diffusion limits reaction rate and the extent of equilibration, especially when melt is absent in coarse-grained assemblages. Retrograde corona development is likely constrained to the high- $T$, suprasolidus, heating portion of the $P-T$ path immediately following peak $T$. Since most melt is lost at or near peak conditions (White and Powell, 2002), only a fraction of melt is retained in the restitic post-peak assemblage, and since diffusion in melts is much more efficient than on dry grain boundaries (Zhang, 2010), element mobility diminishes markedly in the absence of a melt phase. Reduced melt volumes thus limit length scales of diffusion during cooling to the extent that diffusion-controlled corona growth occurs. On the prograde path, the low/absent melt volumes required for corona growth are only commonly realized in mafic igneous precursors, owing to their intrinsic anhydrous bulk composition, and in dry, restitic pelitic compositions that have lost melt in an earlier metamorphic event. White and Powell (2011) distinguish two types of coronas formed either on the prograde or retrograde paths, namely, progressive or non-progressive coronas. Progressive coronas develop on the same $P-T$ path as the assemblage that they replace, in response to a smooth change in $P-T$ conditions from those that produced the peak assemblage (e.g. Johnson et al., 2004; Hollis et al., 2006; Kelsey et al., 2003). Nonprogressive coronas develop in a separate $P-T$ event to those that generate the peak assemblage (e.g. Johnson and Carlson, 1990; Gibson, 2002; McFarlane et al., 2003).

\section{Corona microstructure}

Corona microstructure in prograde and retrograde coronas for which data are available is summarized in Figs. 10 and 11. The average maximum corona layer thickness in mafic prograde coronas is $475 \mu \mathrm{m}$ (range: $70-1000 \mu \mathrm{m} ; n=19$ ), and the average maximum vermicule length is $118 \mu \mathrm{m}$ (range: $50-300 \mu \mathrm{m} ; n=19)$. Pelitic prograde coronas are characterized by an average maximum corona thickness of $496 \mu \mathrm{m}$ (a)

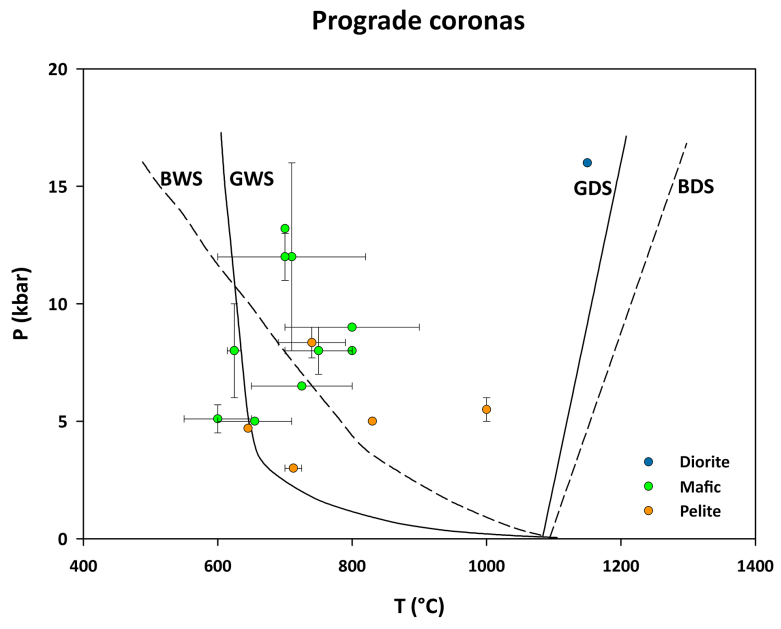

(b)

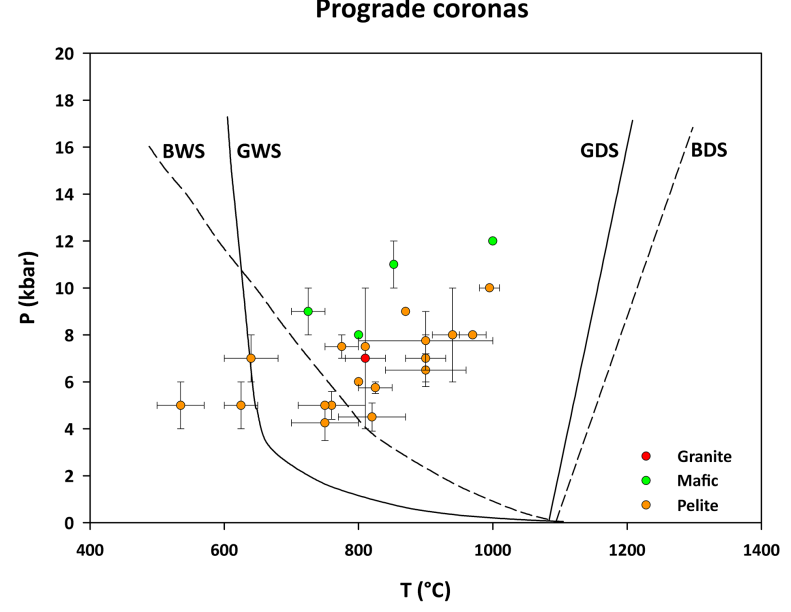

Figure 9. Summary of $P-T$ conditions of formation for coronas reviewed in this study. (a) $P-T$ conditions for prograde coronas. (b) $P-T$ conditions for retrograde coronas. In general, conditions of corona formation occur above the wet solidus for each respective bulk composition. The few coronas that plot at lower temperatures than the wet solidi may be subject to retrograde diffusional resetting of the thermometers and, in reality, may have formed at higher suprasolidus temperatures. Error bars are for the range of each estimate. BWS: wet basalt solidus; GWS: wet granite solidus; GDS: dry granite solidus and BDS: dry basalt solidus. Solidi were digitized in $P-T$ space from the geosciences resource database available at http://www.geosci.usyd.edu.au/users/prey/Granite/Granite.html.

(range: $75-1500 \mu \mathrm{m} ; n=13$ ) and an average maximum vermicule length of $115 \mu \mathrm{m}$ (range: $10-300 \mu \mathrm{m} ; n=13$ ). Thus, mafic and pelitic prograde coronas do not differ significantly with respect to maximum corona layer thickness and vermicule length. However, pelitic prograde coronas developed in contact metamorphic aureoles appear to exhibit greater maximum corona layer thicknesses $(>500 \mu \mathrm{m})$ compared to regional pelitic prograde coronas (Fig. 10a).

Most retrograde coronas described in the literature occur in pelitic bulk compositions (Table A2; Fig. 11). Pelitic ret- 
(a)

Prograde coronas

Maximum corona thickness $(\mu \mathrm{m})$

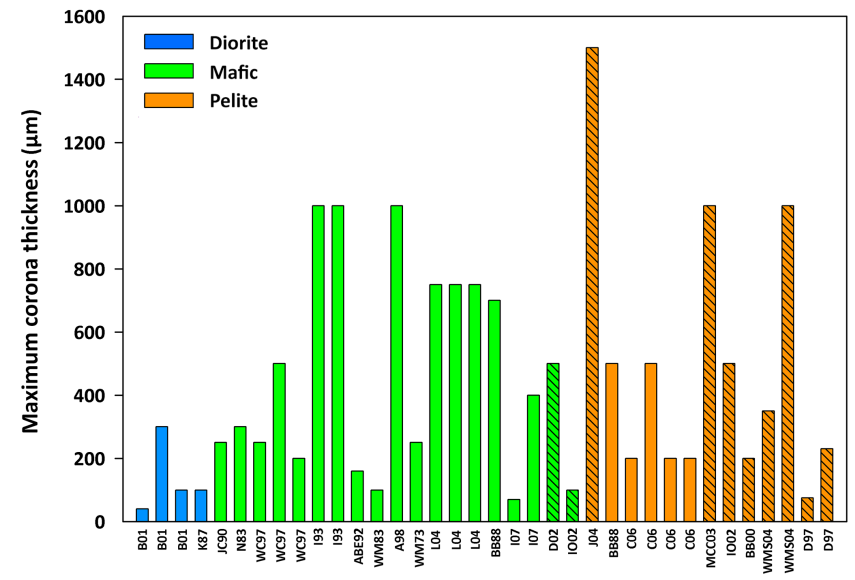

(b)

Prograde coronas

Maximum vermicule length $(\mu \mathrm{m})$

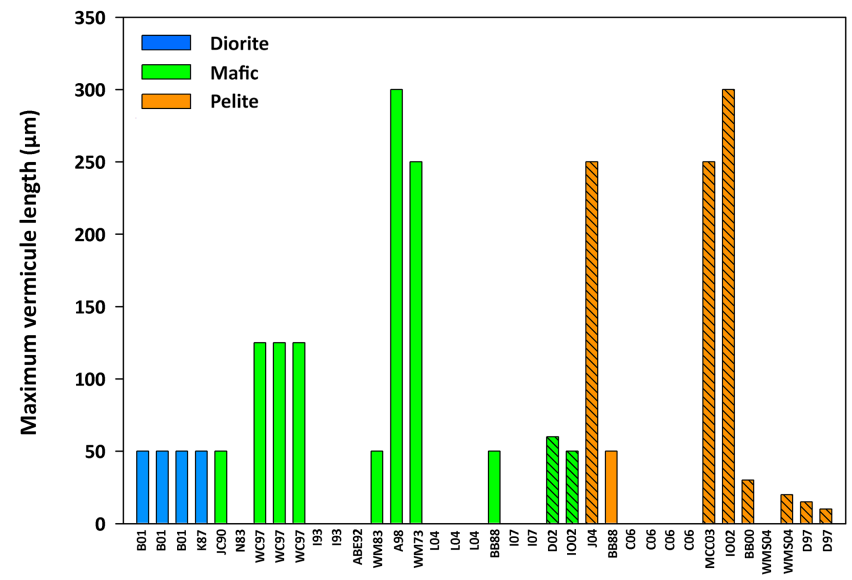

Figure 10. Variation in prograde corona microstructure in mafic and pelitic bulk rock compositions. (a) Variation in maximum corona thickness in prograde coronas. (b) Variation in maximum vermicule length in prograde coronas. Hatched bars are prograde coronas from contact aureoles. Each corona reference is tagged by a code (e.g. WM73) which correlates with the detailed characteristics of each corona in the Tables included in Appendix A.

rograde coronas are characterized by an average maximum corona thickness of $571 \mu \mathrm{m}$ (range: $100-3000 \mu \mathrm{m} ; n=28$ ) and an average maximum vermicule length of $147 \mu \mathrm{m}$ (range: $20-500 \mu \mathrm{m} ; n=28$ ). The average maximum corona layer thickness in mafic retrograde coronas is $262 \mu \mathrm{m}$ (range: 80 $500 \mu \mathrm{m} ; n=5$ ), and the average maximum vermicule length is $27 \mu \mathrm{m}$ (range: $10-40 \mu \mathrm{m} ; n=5$ ). Whilst retrograde pelitic coronas do not differ significantly from prograde pelitic coronas in terms of width and vermicule length, retrograde mafic coronas are distinctly narrower and show significantly reduced vermicule length relative to prograde mafic coronas (Fig. 11). The latter most likely reflects greater length scales (a)

Retrograde coronas Maximum corona thickness ( $\mu \mathrm{m})$

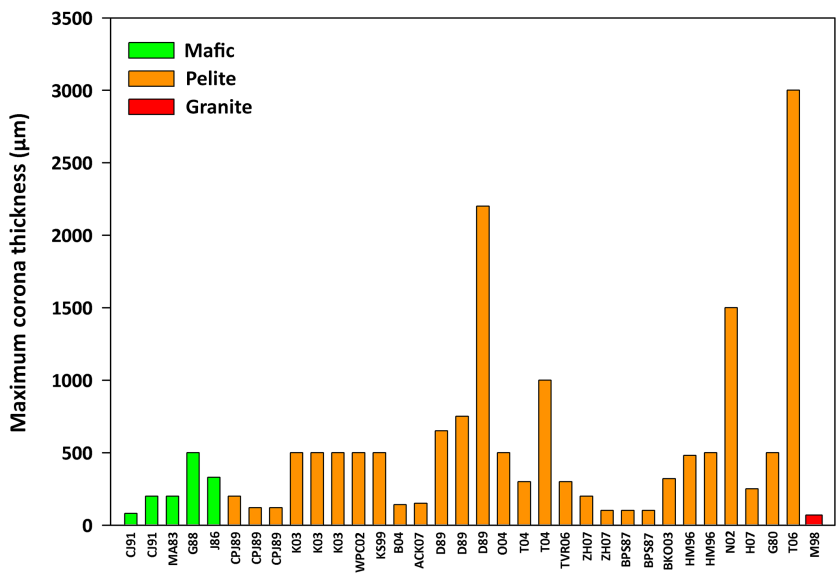

(b)

Retrograde coronas Maximum vermicule length $(\mu \mathrm{m})$

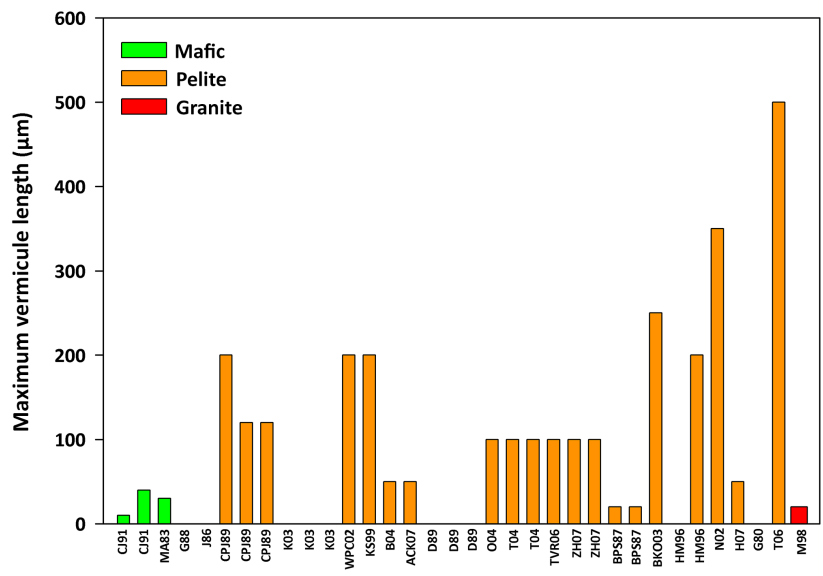

Figure 11. Variation in retrograde corona microstructure in mafic and pelitic bulk rock compositions. (a) Variation in maximum corona thickness in retrograde coronas. (b) Variation in maximum vermicule length in retrograde coronas.

of melt-enhanced diffusion along the prograde path. A similar relative paucity of melt may explain the difference in corona thickness and vermicule length in retrograde mafic coronas compared to retrograde pelitic coronas.

\section{Internal compositional zonation in coronas}

Complex compositional zonation is commonly observed in coronas (Fig. 12). Fully equilibrated coronas, where no compositional zonation or chemical potential gradients exist, are rare. In the population of coronas studied, only $30 \%$ were fully equilibrated, of which $60 \%$ were in pelitic bulk compositions. Commonly, coronas exhibit asymmetric zonation across the band as a whole, reflecting variable length scales of diffusion for major components during single-stage, 
(a)

$x_{\mathrm{Mg}}$ variation

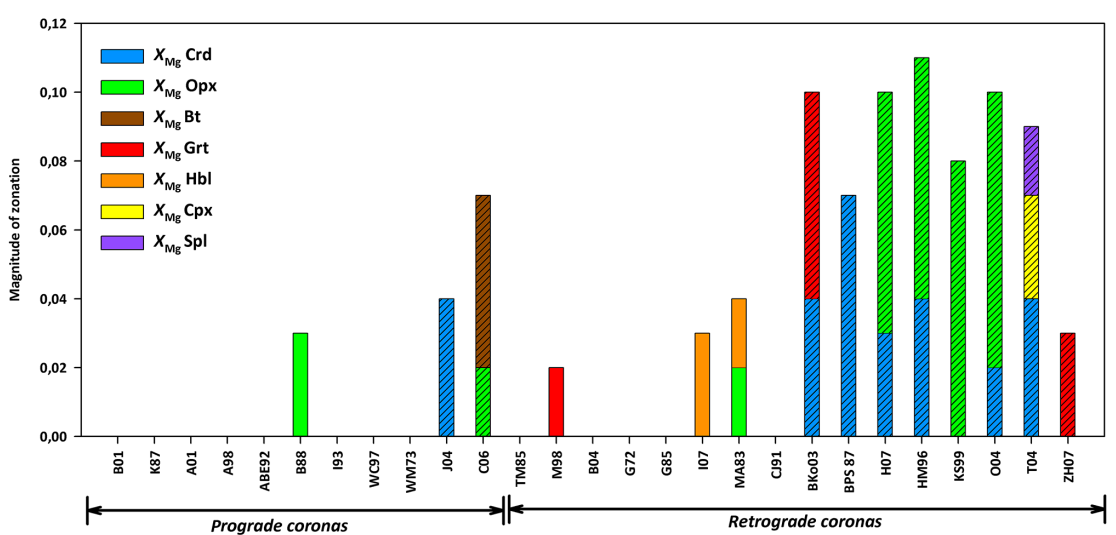

(b)

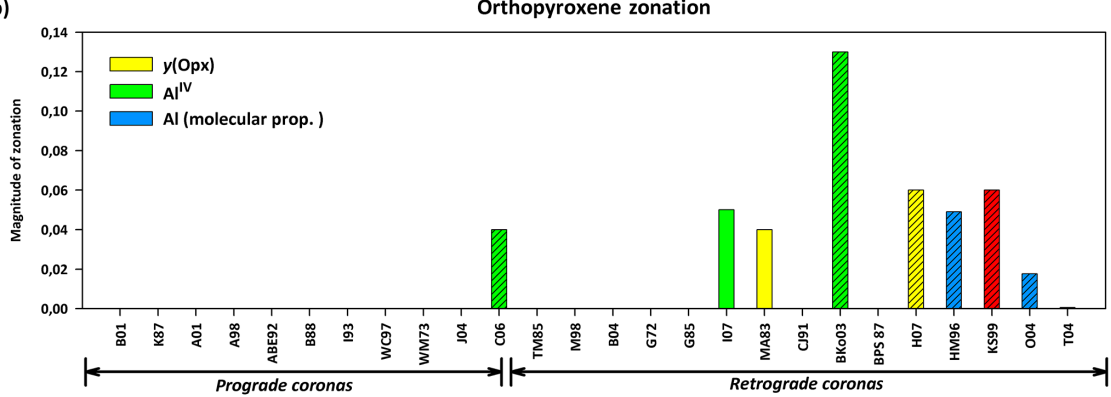

(c)

Garnet zonation

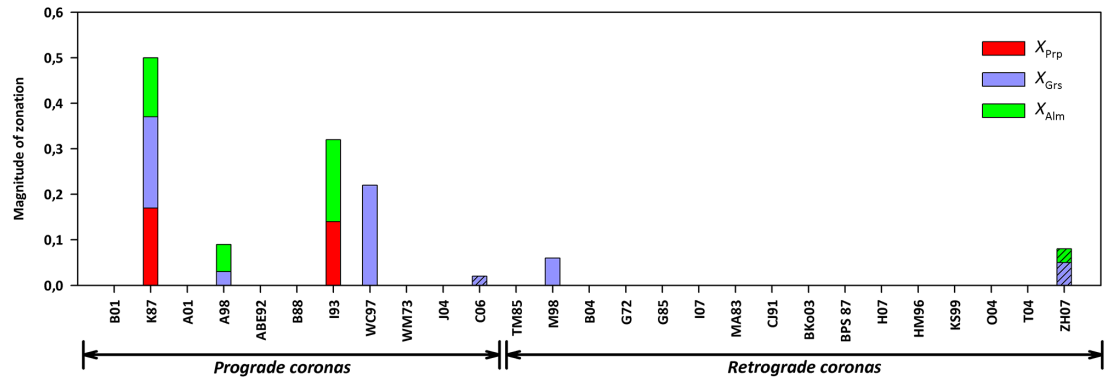

(d)

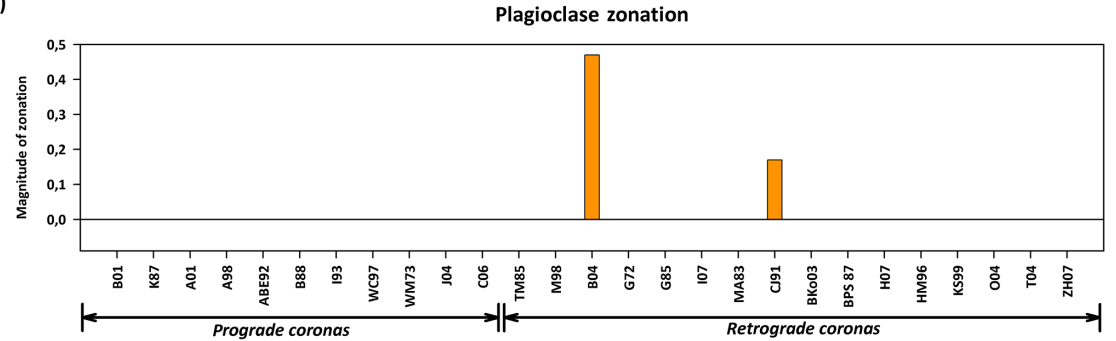

Figure 12. Magnitude of compositional zonation in product corona bands. Hatched fields indicate pelitic bulk rock compositions; unhatched fields are mafic. (a) $X_{\mathrm{Mg}}$ variation in product phases. (b) Variation in Al content in orthopyroxene across each corona. (c) Garnet zonation across each corona. (d) Plagioclase zonation across coronas where it is documented.

steady-state growth (e.g. Ashworth et al., 1998 - A98; Johnson et al., 2004 - J04; Fig. 12). Less commonly, radial zonation occurs within a product layer or vermicule from the band centre/vermicule core to the rim, indicative of sequen- tial corona growth (e.g. Zulbati and Harley, 2007 - ZH07; Fig. 12). The maximum magnitude of zonation in $X_{\mathrm{Mg}}$ of orthopyroxene across a corona band in the coronas reviewed is 0.08 (Kriegsman and Schumacher, 1999 - K99; Osanai et 
al., 2004 - O04; Fig. 12) and 0.07 in cordierite (Baker et al., 1987 - BKS87; Fig. 12). Unfortunately, Al content in orthopyroxene is expressed as $y(\mathrm{Opx}), \mathrm{Al}^{\mathrm{IV}}$ and $\mathrm{Al} \mathrm{wt} \%$ in the literature commonly without accompanying raw analyses, so that these values cannot be recomputed to a single formulation of $\mathrm{Al}$ in orthopyroxene to aid comparison. Maximum asymmetric zonation magnitude with respect to $y(\mathrm{Opx})$ is 0.08 in Hollis et al. (2006 - H06; Fig. 12); 0.13 with respect to $\mathrm{Al}^{\mathrm{IV}}$ (a.p.f.u. - atoms per formula unit) (Brandt et al., 2003 - BKO03; Fig. 12); and 0.05 with respect to recalculated molecular proportion (Hisada and Miyano, 1996 - H96; Fig. 12). Maximum magnitude of zonation in garnet is 0.22 for $X_{\text {Grs }}$ (White and Clarke, 1997 - WC97; Fig. 12), 0.18 for $X_{\text {Alm }}$ (Indares, 1993 - I93; Fig. 12) and 0.17 for $X_{\operatorname{Prp}}$ (Koons et al., 1987 - K87; Fig. 12). Maximum magnitude in plagioclase zonation $\left(\Delta X_{\mathrm{An}}\right)$ is 0.42 (Baldwin et al., $2004-$ B04; Fig. 12).

Product phase zonation makes the application of quantitative thermobarometry exceptionally difficult. In some instances, corona product phases in local equilibrium adjacent to a reactant possess low enough variance to apply a conventional thermobarometer. For example, Baldwin et al. (2004) obtained $P-T$ conditions of corona formation from GrtOpx-Pl-Qtz equilibria using garnet rim and orthopyroxeneplagioclase symplectite compositions in direct contact. Some authors have applied conventional thermobarometers to spatially segregated phases in a corona that are not in direct contact (e.g. Perchuk et al., 2002; Brandt et al., 2003). This approach is only valid if there is no variation in phase composition across the corona band and chemical potential gradients do not exist.

Ashworth et al. (1998) derived a non-equilibrium extension to conventional thermobarometry based on opensystem, steady-state diffusion modelling of coronas that has been successfully employed to estimate $P-T$ conditions of formation of asymmetrically zoned coronas (Ashworth et al., 2001). Unfortunately, non-equilibrium thermobarometry, like conventional thermobarometry, is very sensitive to uncertainties in compositional data and prone to underestimating peak temperatures of formation because of retrograde resetting upon cooling. The preferred thermobarometric technique for coronas entails phase equilibria modelling in THERMOCALC (e.g. Baldwin et al., 2015), where modes and phase compositions are used to jointly constrain a field of equilibration in $P-T-X$ space. THERMOCALC allows the modelling of corona textures in chemical potential space (White et al., 2008; White and Powell, 2011; Štípská et al., 2010 and Baldwin et al., 2015) facilitating direct comparison of the observed phase zonation and spatial array of layers across a corona in which chemical potential gradients prevail with predicted compositions at a range of temperatures and pressures.

\section{Modelling of coronas}

Diffusion modelling of metamorphic reactions began in earnest with the foundational work of Thompson (1959) and Korzhinskii (1959), who demonstrated that infinitesimally small regions of rock can attain local equilibrium in the presence of chemical potential gradients for all or some components. This meant that even if the system is in disequilibrium as a whole, with gradients in chemical potentials of components in the intergranular medium, it is nevertheless possible to relate the mineral assemblage at any point to the chemical potentials at that point. Korzhinskii (1959) devised a graphical method for plotting a saturation surface in chemical potential space that allowed the determination of relative chemical potential differences across a series of layers (Fig. 1). This method facilitated an understanding of how layer sequences would evolve as components diffuse down chemical potential gradients. The limitation of Korzhinskii's technique is that many diffusion paths from one reactant to another are possible in the chemical potential diagram, such that more than one possible layer sequence could evolve for a particular $P-T$ condition (Nishiyama, 1983). The advances in thermodynamic formulations of phases required to model these relationships would only be developed by researchers in later decades (Powell and Holland, 1988, 1990; Holland and Powell, 1998, 2003, 2011; Powell et al., 1998, 2005) and even then only readily applied to coronas using the appropriate activity-composition relationships through pioneering studies by White et al. (2008), Štípská et al. (2010) and Baldwin et al. (2015). In the interim, researchers modelled coronas through a quantitative physico-chemical modelling approach, in which component fluxes and chemical potential gradients required to reproduce observed corona layers configurations were derived assuming reaction was driven and governed by minimization of Gibbs free energy.

\subsection{Quantitative physical modelling of coronas}

The quantitative physical modelling of coronas is premised on the fact that, in layered reaction products, mineral layers grow by reaction at their contacts and the stoichiometries of the layer contact reactions are determined by the relative diffusion fluxes of components within the layer. Component fluxes and chemical potential differences across each layer attain steady-state values as a function of the rate of production and consumption of phases in the layer (Fisher, 1975; Dohmen and Chakraborty, 2003). Joesten (1977) combined the approaches of Fisher (1975) and Korzhinskii (1959) into a hybrid methodology that allowed the prediction of a unique sequence of mineral layers produced by steady-state diffusion for a given choice of phenomenological coefficients in an isochemical system. Joesten's model is based on three fundamental assumptions: first, diffusing components are in local equilibrium with contiguous minerals at every point in a corona, despite the fact that the corona as a whole is in 
disequilibrium; second, component fluxes and chemical potential gradients remain constant at each point in the corona in a steady state throughout its evolution; and third, all components are considered to be conserved within the reaction band; i.e. there is no communication with a system beyond the boundaries of the reaction bands (the system is closed).

Joesten's model required the simultaneous solution of the three sets of equations defined previously (Eqs. 3, 4 and 5), independently relating component fluxes to chemical potential gradients in a layer, chemical potential gradients to each other in the presence of a mineral with a particular composition, and the flux change between layers to reaction coefficients at layer boundaries (e.g. Ashworth and Sheplev, 1997). It is possible to evaluate the stability of a multilayer reaction band for a postulated set of intergranular diffusion coefficients if the compositions of the phases in each band are known. The model predicts the relative widths of layers in the reaction band, modal proportions of phases within each layer, component fluxes across layers and reaction stoichiometry at layer boundaries.

Early attempts to model corona textures using Joesten's formalism focussed on corona reaction bands formed between olivine and plagioclase in metagabbros (e.g. Nishiyama, 1983; Joesten, 1986; Grant, 1988). This early work was hindered by the closed-system constraint in Joesten's model. For example, Grant (1988) was unable to produce enough $\mathrm{Ca}$ from the observed reactant plagioclase to accommodate all the $\mathrm{Ca}$ in the corona reaction band. Furthermore, the failure of Joesten's model to account for hydrous corona products, such as hornblende, from anhydrous plagioclase and olivine reactants led researchers to embrace an open-system, metasomatic modification to Joesten's model. An open-system modification was introduced by Johnson and Carlson (1990) and Ashworth and Birdi (1990). Material balance calculations allowed them to determine the external component fluxes across the outer boundaries of the corona, thereby accommodating open-system communication with the enclosing matrix. Johnson and Carlson (1990) and Carlson and Johnson (1991) introduced external boundary flux equations to model open-system behaviour. Ashworth and Birdi (1990) treated metasomatic fluxes at corona boundaries as theoretical "phases" with "negative" compositions where components were lost from the system and "positive" compositions where they entered into the corona system. The open-system studies of Johnson and Carlson (1990) and Carlson and Johnson (1991) accommodated gradual changes in the composition of the reactants and external fluxes throughout corona evolution, thus manifesting themselves as variable product assemblages.

Open-system diffusion models for coronas had much more success in explaining corona development in a variety of different bulk compositions, from mafic rocks to metapelites, than the earlier isochemical models (Johnson and Carlson, 1990; Carlson and Johnson, 1991; Ashworth and Birdi, 1990; Ashworth et al., 1992, 1998; Ashworth, 1993; Ashworth and
Sheplev, 1997). Ashworth (1993) noted that, although the overall extent of reaction was constrained by highly mobile components with large diffusive fluxes, the actual spatial arrangement of minerals in coronas appears to be strongly controlled by those components with lower diffusivities, particularly $\mathrm{Al}$ and Si. He noted that, in all cases, an Al-rich layer (commonly symplectitic) was located adjacent to the most aluminous reactant, grading into an Al-poor layer adjacent to the less aluminous reactant, and both separated by a "transitional" layer of intermediate contents of $\mathrm{Al}$ (Fig. 13).

Ashworth and Birdi (1990) compared the Al / Si ratio in aluminous reactants and the adjacent symplectite for a number of coronas using an isocon diagram (Fig. 14). The isocon plot suggested that total $\mathrm{Al}$ and $\mathrm{Si}$ (strictly $\mathrm{A} \mathrm{O}_{3 / 2}$ and $\mathrm{SiO}_{2}$, since the components used are oxides) included within the phases in the symplectite appear to be "inherited stoichiometrically" from the adjacent reactant. Any mismatch between the $\mathrm{Al} / \mathrm{Si}$ ratio of the reactant and individual phases comprising the symplectite is accommodated by proportional growth of symplectite phases in the appropriate ratio such that cumulatively the $\mathrm{Al} / \mathrm{Si}$ ratio is retained. Ashworth and Birdi (1990) proposed that this was a consequence of low diffusivities of $\mathrm{Al}$ and $\mathrm{Si}$ relative to $\mathrm{Mg}$ and $\mathrm{Ca}$. According to them, any mismatch between the $\mathrm{Al} / \mathrm{Si}$ ratio of the symplectite and reactant implies open-system behaviour for these components. Thus, the endmember scenario involving near-complete open-system behaviour for $\mathrm{Al}$ and $\mathrm{Si}$ would be a monomineralic reaction band in which mismatch in the $\mathrm{Al} / \mathrm{Si}$ ratio is greatest. Mongkoltip and Ashworth (1983) ventured still further that the occurrence of two immobile components is a necessary condition for symplectite formation. This assertion agreed with the metasomatic equilibrium theory of Korzhinskii (1965), which states that any divariant equilibrium assemblage of $n$ phases contains at least $n$ inert or immobile components. Assessing open- or closed-system behaviour for $\mathrm{Al}$ and $\mathrm{Si}$ is critical in deciding which assumptions are realistic when determining the overall reaction. If $\mathrm{Al}$ and $\mathrm{Si}$ are preserved in the symplectite, then closure to $\mathrm{Al}$ and $\mathrm{Si}$ can be used to constrain the system of simultaneous equations defining the overall reaction, such that it is not underdetermined. If this assumption is not valid, a constant volume may have to be assumed (Carlson and Johnson, 1991).

The first thermodynamic treatment of conservation of volume during diffusion metasomatism was undertaken by Carmichael (1987). Carmichael challenged the assumption that pressure remains constant during irreversible diffusion metasomatism. During reaction, there is a tendency for the boundary between two juxtaposed reactants to be displaced perpendicular to the interface between the reactants at a magnitude corresponding to the change in volume of solid phases of the reaction. If there is any mechanical resistance to this displacement, constant volume replacement is approached. Carmichael (1987) was able to model a field of nonhydrostatic stress induced by the migration of the boundary be- 


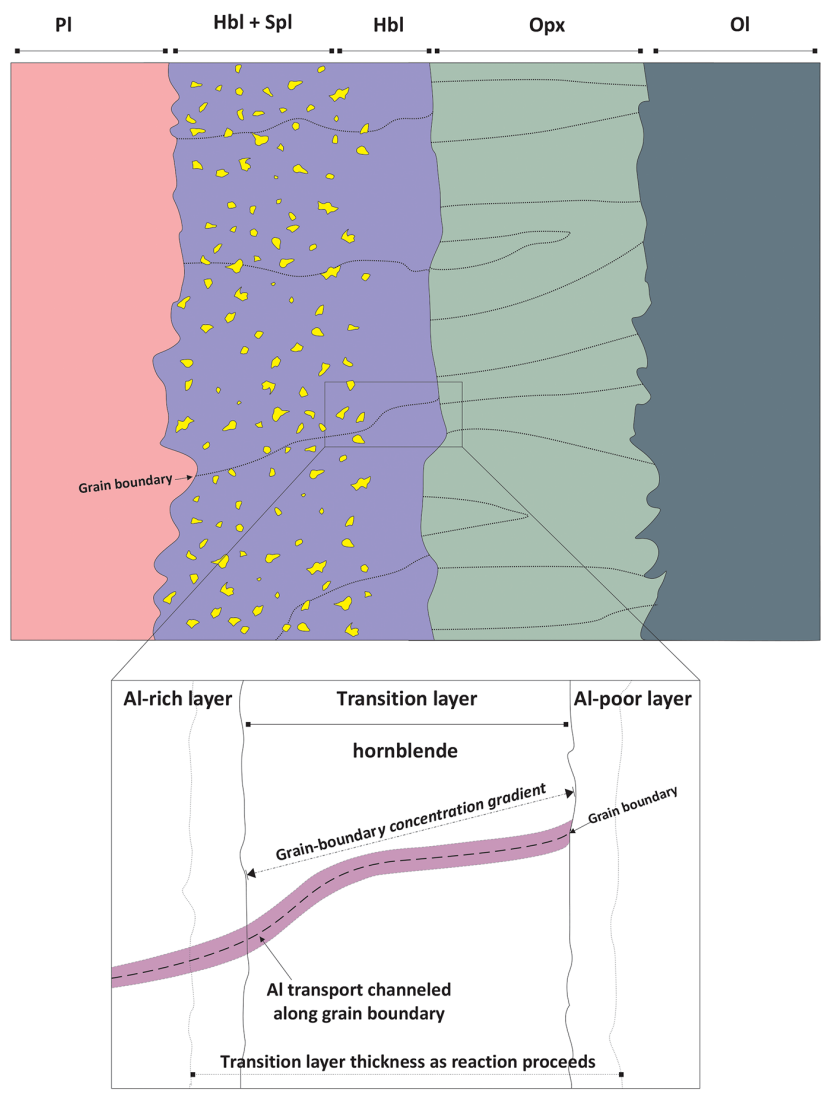

Figure 13. Sketch of a typical corona developed between plagioclase and olivine in metagabbros (after Ashworth, 1993). As reaction proceeds, layers grow by diffusion along grain boundaries of requisite components down concentration gradients to layer boundaries where they are consumed in the production of product phases. $\mathrm{Al}$ is considered to be the most immobile diffusing species, since $\mathrm{Al}$ concentration gradients are most marked. Al exerts the greatest control on segregation of corona products in bands, from the most Al-rich symplectite adjacent to plagioclase to Al-poor orthopyroxene adjacent to olivine.

tween reactants. The stress field is oriented in a manner which opposes the displacement and strain accompanying the migration of the boundary. The stress field may be dissipated by either rock deformation or secondary mass transfer out of the reacting volume. According to Carmichael's model, the secondary mass transfer may be so efficient as to eliminate the induced stress caused by boundary migration, such that the original interface between reactants remains undisplaced. This realization allows reasonable approximations to be made for the original boundary between reactants (and the relative proportions of reactants involved in reaction) such that an overall reaction may be derived.

In this context, the spacing of lamellae or vermicules in symplectites reflects a balance between diffusive energy dissipation and grain-boundary energy. Ashworth and Chambers (2000) derived a theory quantifying this relationship em-

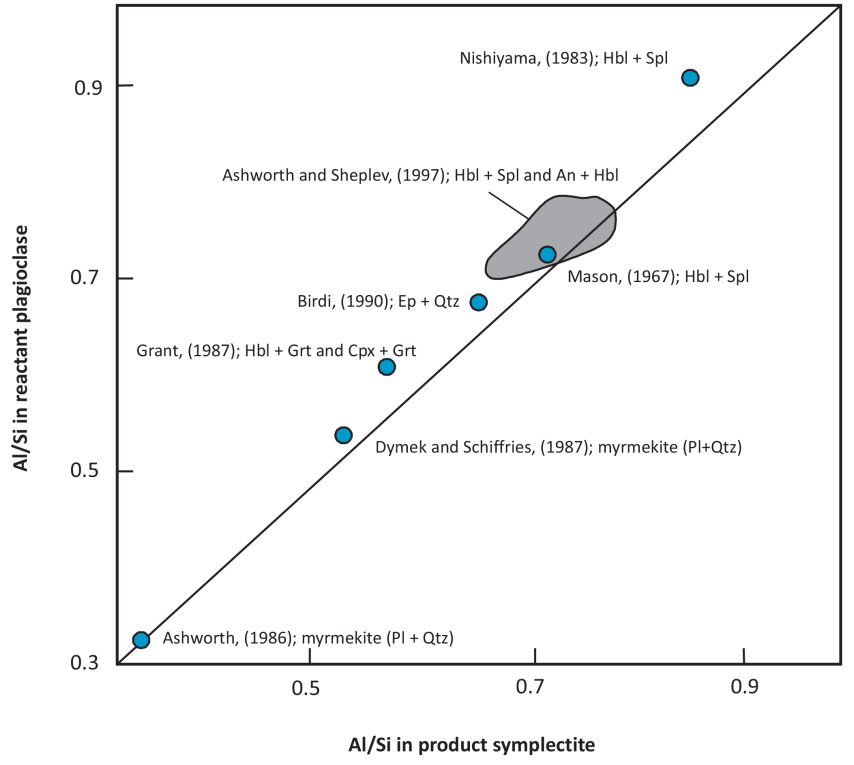

Figure 14. Isocon plot of $\mathrm{Al} / \mathrm{Si}$ ratios in symplectites and the adjacent reactant plagioclase. The isocon line represents $\mathrm{Al} / \mathrm{Si}$ ratios that are preserved exactly between reactant and products. Any deviation from this line indicates a degree of open-system behaviour. In general, analysed symplectites from the literature plot above the isocon line, suggesting that the $\mathrm{Al} / \mathrm{Si}$ ratio is lower in the product symplectite than it is in the reactant plagioclase; i.e. the corona system is losing $\mathrm{Al}$ to the external system relative to $\mathrm{Si}$ with prolonged reaction.

ploying both non-equilibrium thermodynamics and the principle of the maximum rate of energy dissipation. Accordingly, the spacing of lamellae in a symplectite for a particular reaction is a function of the reaction rate (i.e. reaction front velocity), diffusion coefficient of the slowest-diffusing components and the width of the reaction front:

$\lambda=\sqrt[3]{\frac{L \delta}{v}}$,

where $\lambda$ is lamellae spacing, $\mathrm{L}$ is the Onsager coefficient, $\delta$ is the reaction front width and $\mathrm{v}$ is the reaction rate.

The finest symplectitic intergrowths (closest lamellae spacing) are predicted to occur when reaction rates greatly exceed diffusion coefficients for the slowest-diffusing species for a particular reaction front width.

Despite advances in diffusion metasomatic modelling of coronas in the early 1990s, success was still limited in that commonly more than one stable layer sequence was computable for the same inputs. Sheplev et al. (1991, 1992a, b) presented a criterion to determine which non-unique solution is more thermodynamically stable compared to others. The criterion was formalized by Ashworth and Sheplev (1997) and extended so as to obtain a measure of the affinity of reaction, or, rather, departure from equilibrium, preserved in the corona. A final refinement to the open-system diffusion 
model for coronas was derived by Ashworth et al. (2001), in which ratios of the affinity of independent endmember reactions modelled for a corona are compared to ratios calculated from an internally consistent thermodynamic database (Holland and Powell, 1998). The pressure and temperature at which the ratio of model endmember reaction affinities and real endmember reaction affinities approach the same value is considered to represent the closure pressure and temperature below which the corona remained inert to reaction. This allowed quantitative estimates of pressure and temperature of the formation of minerals in disequilibrium to be made.

\subsection{Calculated phase equilibria modelling}

A limitation of the quantitative physical modelling of coronas outlined above is that solid solutions and the gradational shifts in phase composition within a band cannot practically be accounted for in the modelling (White and Powell, 2011; Baldwin et al., 2015). In the last decade, advances in phase equilibria modelling have allowed geologically realistic corona compositional systems to be modelled in $P-T-X$ (Johnson et al., 2004) and chemical potential space (White et al., 2008; Štípská et al., 2010; White and Powell, 2011; Baldwin et al., 2015). It is possible to predictively model corona evolution with changing effective bulk composition through progressive metasomatic exchange of components with the external matrix in a rock and/or partitioning of the corona effective bulk composition with reduced length scales of component diffusion on cooling (e.g. Johnson et al., 2004; White et al., 2008; Štípská et al., 2010; Baldwin et al., 2015). For completeness and clarity, all component chemical potentials referred to in this section apply to those within the phases in the local equilibria under consideration.

One of the most robust and elegant applications of chemical potentials in constraining corona textural and compositional evolution in $P-T-X$ space is that undertaken by Štípská et al. (2010). These researchers modelled coronas developed after kyanite in a quartzofeldspathic gneiss from the Bohemian Massif (Fig. 8h). Phase equilibria modelling entailed an initial estimate of overall $P$ and $T$ conditions prevailing using a conventional $P-T$ pseudosection in NCKFMASHTO $\left(\mathrm{Na}_{2} \mathrm{O}-\mathrm{CaO}-\mathrm{K}_{2} \mathrm{O}-\mathrm{FeO}-\mathrm{MgO}-\mathrm{Al}_{2} \mathrm{O}_{3}-\mathrm{SiO}_{2}-\right.$ $\mathrm{H}_{2} \mathrm{O}-\mathrm{TiO}_{2}-\mathrm{Fe}_{2} \mathrm{O}_{3}$ ) (Štípská et al., 2010). For the purpose of phase equilibria modelling in chemical potential space, it is necessary to reduce the number of components treated, based on assumptions considering their inferred relative mobility. Štípská et al. (2010) ranked components in the corona according to a hierarchy of mobility or relative diffusivities in which slowest diffusing components are considered effectively immobile (i.e. chemical potential gradients are static and cannot change during reaction); other components are considered mobile (their chemical potential gradients vary on the scale of the corona); and some components are treated as completely mobile (their chemical potentials do not vary across the corona and are superimposed by the matrix). Ac- cordingly, Štípská et al. (2010) were able to reduce the model compositional system to NCKFMAS.

Prior to their consideration of the ferromagnesian minerals in the corona, Štípská et al. (2010) modelled the monomineralic plagioclase moat in NCKAS, with the further assumption that $\mathrm{K}_{2} \mathrm{O}$ is completely mobile and $\mathrm{Al}_{2} \mathrm{O}_{3}$ is immobile with static potentials; i.e. it is treated as an extensive variable in terms of phase composition. The chemical potentials for the matrix edge of the corona correspond to those for the equilibrated peak assemblage and the corona plagioclase composition in local equilibrium with matrix (i.e. $\mathrm{An}_{20}$ ) (Fig. 15a). The chemical potentials for the metastable kyanite corona contact were derived by modifying $\mu\left(\mathrm{Na}_{2} \mathrm{O}\right)$ at the matrix contact until the kyanite-plagioclase boundary with $\mathrm{An}_{45}$ appears on the phase diagram (Fig. 15a). In Fig. 15a, the chemical potential relations at the kyanitematrix boundary are overlain in $\mu(\mathrm{CaO})-\mu\left(\mathrm{SiO}_{2}\right)$ space, and local equilibrium potentials are indicated. Since the values of $\mu\left(\mathrm{Na}_{2} \mathrm{O}\right), \mu(\mathrm{CaO})$ and $\mu\left(\mathrm{SiO}_{2}\right)$ differ between the two equilibria, a chemical potential gradient is established and is represented by the vector in Fig. 15a. For equilibrium to be attained throughout the corona, chemical potentials must be equalized everywhere by diffusion. If element transport is constrained, these chemical potential gradients persist as stranded gradients (Baldwin et al., 2015).

Štípská et al. (2010) modelled the presence or absence of a garnet layer in the corona by superimposing $\mu(\mathrm{FeO})$ and $\mu(\mathrm{MgO})$ variations on the vector in $\mu\left(\mathrm{Na}_{2} \mathrm{O}\right)-\mu(\mathrm{CaO})-$ $\mu\left(\mathrm{SiO}_{2}\right)$ space obtained in Fig. 15b. The authors calculated $\mu(\mathrm{FeO})-\mu(\mathrm{MgO})$ diagrams for the matrix boundary, kyanite boundary and midway between them with respective $\mu\left(\mathrm{Na}_{2} \mathrm{O}\right)-\mu(\mathrm{CaO})-\mu\left(\mathrm{SiO}_{2}\right)$ dictated by the vector constrained in NCKAS space (Fig. 15a). The observed composition of garnet $\left(X_{\mathrm{Fe}}=0.70\right)$ defines a corresponding vector in $\mu(\mathrm{FeO})$ and $\mu(\mathrm{MgO})$ space (Fig. 15b). Štípská et al. (2010) manually constructed a phase diagram by combining the phase relations along the $X_{\mathrm{Fe}}=0.70$ vector in $\mu(\mathrm{FeO})-\mu(\mathrm{MgO})$ space with those corresponding in $\mu\left(\mathrm{Na}_{2} \mathrm{O}\right)-\mu(\mathrm{CaO})-\mu\left(\mathrm{SiO}_{2}\right)$ space (Fig. 15c). Two observed chemical potential paths were proposed to account for garnet-present and garnet-absent coronas that reproduced the known spatial array and composition of phases. They suggest that the chemical potential path required to produce garnet requires the $\mu(\mathrm{FeO})$ and $\mu(\mathrm{MgO})$ potentials to be boosted relative to those in local equilibrium with the matrix. This is consistent with the spatial association of original matrix garnet in the corona, such that the $\mu(\mathrm{FeO})$ and $\mu(\mathrm{MgO})$ potentials are locally augmented, thereby stabilizing a garnet layer in the coronas in local equilibrium with kyanite (Štípská et al., 2010).

Modelling of the development of the plagioclase-spinel symplectite required that $\mathrm{SiO}_{2}$ also be treated as immobile (Štípská et al., 2010). Constrained $\mathrm{SiO}_{2}$ diffusion from the matrix toward kyanite across the plagioclase moat induced a silica-deficient effective local bulk composition at 
(a)

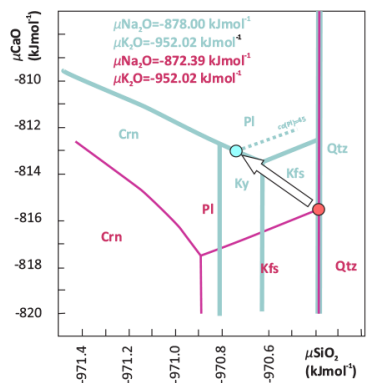

(b)

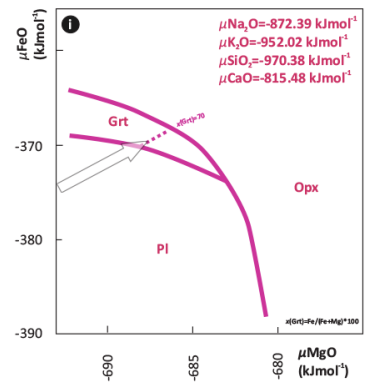

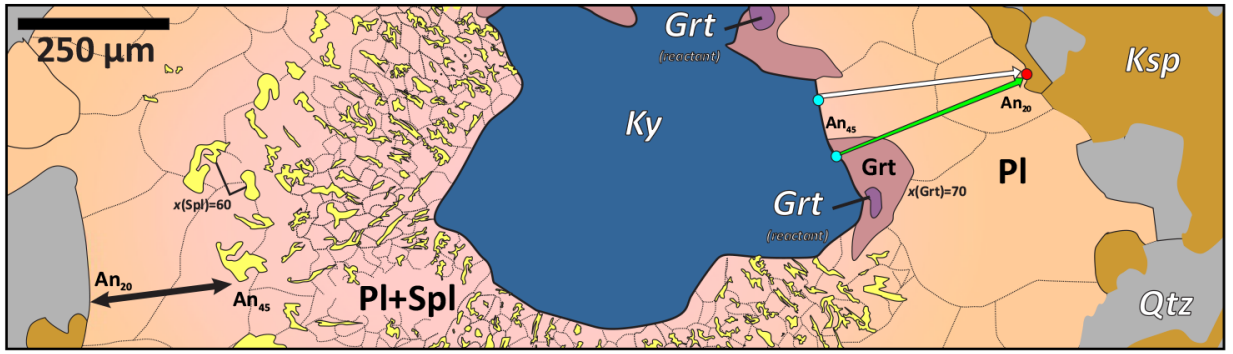
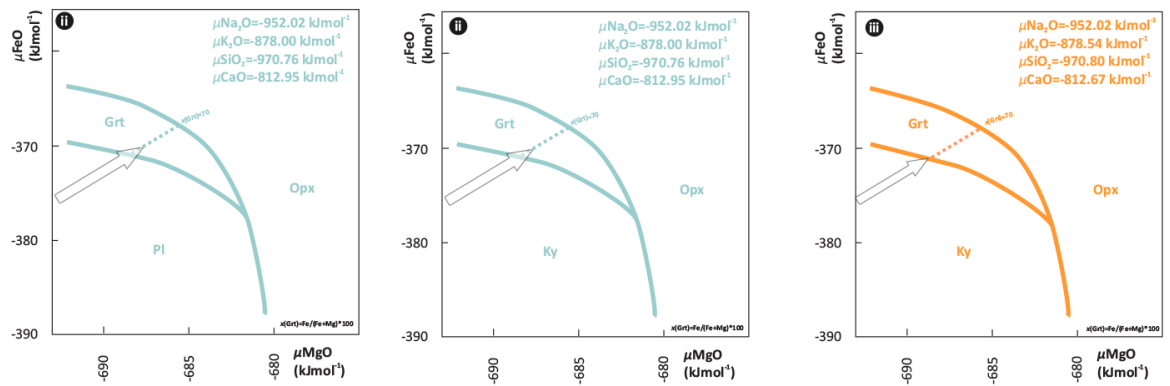

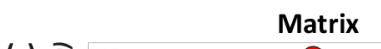

(c)

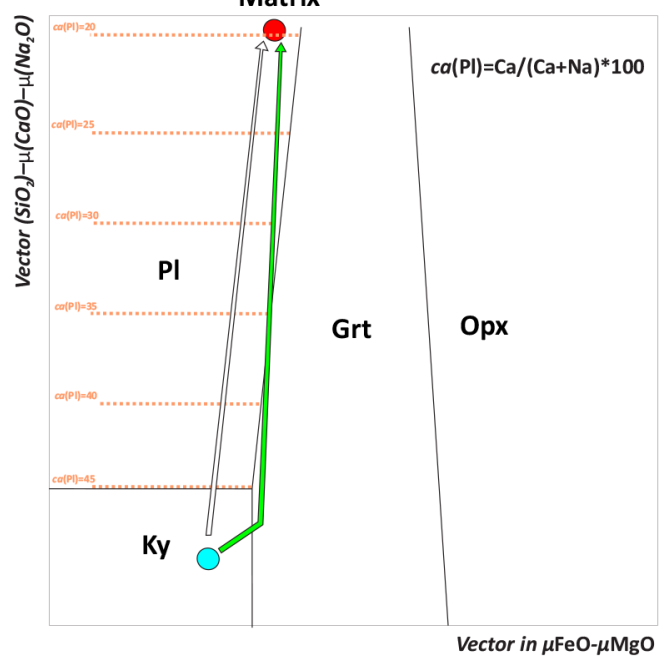

(d)

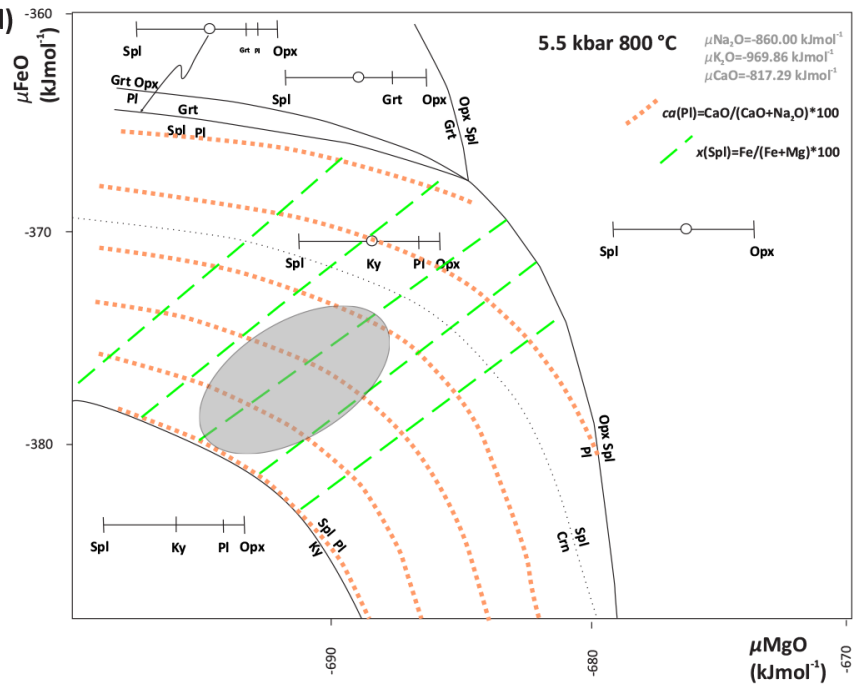

Figure 15. Chemical potential relationships governing the development of a corona after kyanite (after Štípská et al., 2010). All component chemical potentials referred to apply to those within the phases in the local equilibria under consideration. (a) $\mathrm{Calculated} \mu(\mathrm{SiO} 2)-\mu(\mathrm{CaO})$ diagrams in the NCKAS system for the matrix (red lines) and the kyanite boundary (light blue lines). Gradients in the chemical potentials from the matrix to the kyanite-plagioclase boundary are represented by a vector in $\mu\left(\mathrm{SiO}_{2}\right)-\mu(\mathrm{CaO})-\mu(\mathrm{Na} 2 \mathrm{O})$ space. (b) Superimposed $\mu(\mathrm{MgO})$ and $\mu(\mathrm{FeO})$ variations on the $\mu\left(\mathrm{SiO}_{2}\right)-\mu(\mathrm{CaO})-\mu\left(\mathrm{Na}_{2} \mathrm{O}\right)$ vector from panel (a): (i) for the matrix, (ii) for the plagioclasekyanite boundary and (ii) inside kyanite. The topology shows garnet and orthopyroxene fields, while spinel is metastable. Garnet compositional isopleths $x(\mathrm{Grt})$ are plotted within the garnet stability field. The arrow is a vector coincident with the $x(\mathrm{Grt})=70$ isopleth, where $x(\mathrm{Grt})=\mathrm{Fe} /(\mathrm{Fe}+\mathrm{Mg}) \times 100$. (c) Phase topology obtained by manual combination of the calculated phase relations along a slice at approximately fixed $\mu(\mathrm{MgO}) / \mu(\mathrm{FeO})$ (along $x(g)=70)$ from panel (b), with the calculated phase relations along the vector $\mu(\mathrm{SiO} 2)-\mu(\mathrm{CaO})-$ $\mu(\mathrm{Na} 2 \mathrm{O})$ from panel (a), contoured with compositional isopleths $\mathrm{ca}(\mathrm{pl})$. The dashed arrow shows a path from kyanite across garnet and plagioclase towards the matrix. (d) $\mu(\mathrm{FeO})-\mu(\mathrm{MgO})$ diagrams along the $c a(\mathrm{Pl})=45$ line calculated at $800{ }^{\circ} \mathrm{C}_{\text {and }} 5.5 \mathrm{kbar} \mathrm{SiO}_{2}$ and $\mathrm{Al}_{2} \mathrm{O}_{3}$ are immobile. Fields are labelled with $\mathrm{Al}_{2} \mathrm{O}_{3}-\mathrm{SiO}_{2}$ bar diagrams and contoured for $x(\mathrm{Grt}), x(\mathrm{Spl})$ and $c a(\mathrm{Pl})$. The grey ellipse shows regions of plagioclase-spinel symplectite where mineral compositions correspond to observed values $(\mathrm{ca}(\mathrm{Pl})=35-45 \mathrm{~mol} \%$ and $x(\mathrm{Spl})=60-63)$. 
the plagioclase-kyanite boundary, thus lowering the local $\mathrm{SiO}_{2}$ chemical potential sufficiently to stabilize spinel (assuming corundum was unable to nucleate). As a consequence, both $\mathrm{SiO}_{2}$ and $\mathrm{Al}_{2} \mathrm{O}_{3}$ chemical potentials are treated as quasi-stationary; i.e. they are modelled as the coupled extensive composition variables. As a consequence, phase fields in $\mu-\mu$ space are labelled with $\mathrm{Al}_{2} \mathrm{O}_{3}-\mathrm{SiO}_{2}$ bar compatibility diagrams. Štípská et al. (2010) proceeded to model the requisite chemical potentials for the symplectite stability initially in $\mu\left(\mathrm{Na}_{2} \mathrm{O}\right)-\mu(\mathrm{CaO})-\mu\left(\mathrm{SiO}_{2}\right)$ space. They derived a vector in chemical potential space between the symplectite contact with the plagioclase moat and the kyanite boundary (Fig. 15d) that accounted for the plagioclase composition within the symplectite. However, the restricted stability limits of spinel in $\mu-\mu$ space at the modelled conditions of post-peak conditions led Śtípská et al. (2010) to infer that the spinel-bearing symplectites must have formed during subsequent decompression after plagioclase moat formation, as the spinel stability field is far broader at lower pressures for the same potentials.

Similarly, Baldwin et al. (2015) modelled spinelplagioclase, sapphirine-plagioclase and corundumplagioclase symplectites after kyanite in a quartzofeldspathic granulite gneiss from the Athabasca granulite terrane, Snowbird tectonic zone, Canada. These researchers, like Štípská et al. (2010), deduced that the spinel-plagioclase symplectites must be metastable with respect to the corundum-bearing alternative. Assuming corundum was unable to nucleate, they were able to account for spatial relationships and compositions observed in the symplectites over a wide range of $P-T$ conditions and plagioclase compositions. Crucially they were able to deduce that, without the application of chemical potential phase diagrams suggesting otherwise, such reaction textures may occur over a wide range of $P-T$ conditions and extreme caution must be exercised in inferring $P-T$ conditions of retrograde metamorphism from them.

Štípská et al. (2010) and Baldwin et al. (2015) conclusively demonstrate that the use of chemical potentials is imperative and unavoidable when investigating coronas. Previous researchers (Johnson et al., 2004; Tajčmanová et al., 2007; Ogilvie, 2010) have attempted to model corona textures without the chemical potential phase diagrams. These authors invoked an equilibrium volume comprising the corona, with or without a matrix contribution, which they assumed to be effectively closed-system during textural development. Accordingly, corona growth involved a redistribution of chemical components within the limits of the equilibrium volume. This approach might account for some of the phases within the corona but fails to account for the non-linear exchange of components both within local equilibria across the corona but also external metasomatic exchange with the enclosing matrix during corona evolution. Tajčmanová et al. (2007) tried to circumvent this problem by constructing a $T-X$ section to model the compositional par- titioning, owing to variable diffusion of components across the corona and predicted phases. Similarly, Ogilvie (2010) attempted to model shifts in corona phase compositions and modes through the inferred exchange of components between the corona effective bulk compositions and the external matrix through a $T-X$ section involving pure reactants on one axis and pure matrix as the other axis. The fundamental problem with both these approaches, as noted by White and Powell (2011), is that at best, it is only possible to account for observed assemblages in a qualitative generalized sense. This is because the high variance of the phase fields from the $T-X$ section or $P-T$ pseudosection predicts that stable phases should be present in the coronas that are not actually observed. This can only be treated by considering some components as mobile and removing them from the bulk composition utilized to model the corona. Crucially, the manner in which the chemical potentials evolve through $P-T$ space involves non-linear changes in chemical potentials and local effective bulk compositions. Since $P-T$ pseudosections are constrained at a static bulk composition and a $T-X$ section can only model linear changes in bulk composition, by their nature they are not flexible enough to allow modelling of the intricacies of corona development either owing to variable external component flux into the corona (for example, by melt ingress or loss) or variable multi-component length scales of diffusion.

\section{Concluding remarks}

Evidence of partial equilibrium, preserved in coronas, allows us to examine fundamental processes governing reaction mechanism, rates and extents of equilibration in metamorphic (and, more rarely, igneous) rocks. Mechanisms of corona formation have been reviewed, i.e. single-stage, steady-state diffusion-controlled vs. sequential development. Determining which model of corona formation is most applicable in the corona study (and/or relative contribution of each endmember model to the overall reaction mechanism) is critical, since both models have limitations in the information that may be gleaned from them in petrogenetic studies. A comprehensive review of prograde and retrograde coronas for mafic and pelitic bulk rock compositions from both regional and contact aureole terranes reveals that major controls on corona mineralogy include $P, T$ and $a \mathrm{H}_{2} \mathrm{O}$ during formation, mechanism of formation, reactant bulk compositions and extent of metasomatic exchange with the surrounding rock, relative diffusion rates for major components, and associated deformation and strain. In general, corona formation occurs under granulite facies conditions, in low $a \mathrm{H}_{2} \mathrm{O}$ and/or melt-depleted, bulk rock compositions (Fig. 9). With respect to corona microstructure, prograde coronas in pelitic rocks developed in contact metamorphic aureoles exhibit greater maximum corona thickness than those in regional coronas (Fig. 11a). Mafic and pelitic prograde coronas do 
not differ significantly with respect to maximum corona layer thickness and vermicule length; however, corona thickness and maximum vermicule length in retrograde mafic coronas are significantly smaller than both retrograde pelitic coronas and prograde mafic coronas, which likely attests to the role of melt in enhancing length scales of diffusion during corona formation (retrograde mafic rocks are more likely to be meltpoor and anhydrous). Increased maximum layer thickness and vermicule length in prograde mafic coronas compared to retrograde mafic coronas (Fig. 11) may reflect greater length scales of diffusion in potentially more melt-rich bulk compositions with protracted reaction along the prograde path. Prograde pelitic coronas do not differ significantly from retrograde pelitic coronas with respect to microstructure (Fig. 11), owing to the intrinsically more hydrous pelitic bulk compositions and capacity to generate diffusion-enhancing melt during decompression.

High-variance local equilibria in a corona and disequilibrium across the corona as a whole preclude the application of conventional thermobarometry when determining $P-T$ conditions of corona formation. Although tempting, the asymmetric zonation in phase composition across a corona, indicative of single-stage, steady-state diffusion-controlled formation should not be interpreted as a record of discrete $P_{-}$ $T$ conditions during successive layer growth along the $P$ $T$ path. Rather, the local equilibria between mineral pairs in corona layers reflect compositional partitioning of the corona domain during steady-state growth at constant $P$ and $T$. A non-equilibrium extension of conventional thermobarometry derived by Ashworth et al. (2001) should be used with phase equilibria modelling in THERMOCALC to constrain $P-T$ evolution of coronas (e.g. Ogilvie, 2010).

Through the application of equilibrium thermodynamics on an appropriate scale (i.e. that of local equilibrium - Korzhinksi, 1959; Thompson, 1959), corona evolution can be modelled either through quantitative physico-chemical diffusion modelling (Johnson and Carlson, 1990; Carlson and Johnson, 1991; Ashworth and Birdi, 1990; Ashworth et al., 1992, 1998; Ashworth, 1993; Ashworth and Sheplev, 1997) or calculated phase equilibria involving chemical potentials (White et al., 2008; Śtípská et al., 2010; White and Powell, 2011; Baldwin et al., 2015). While the former allows quantification of reaction affinity and chemical potential gradients across coronas bands, it is unable to practically accommodate variation in phase composition within a band. Moreover, it assumes that corona layer configuration formed during one continuous, single-stage diffusion-controlled process; i.e. component flux between local equilibria across all bands in the corona was controlled by chemical potential gradients on that scale. In contrast, forward modelling utilizing calculated chemical potential gradients to account for corona phase compositions and layer array assumes nothing about the sequence in which the layers form, and, since the chemical potential gradients prevailing are constrained by observed phase compositional variation within a layer, it allows a far more nuanced yet robust understanding of corona evolution and the implications for the path followed by a rock in $P-T-$ $X$ space. When combined with evolving physical diffusion models predicated on the experimental investigation of diffusion and nucleation in higher-variance systems (e.g. Jonas et al., 2015; Mueller et al., 2015), temporal resolution will be afforded to phase equilibria models, seamlessly integrating corona evolution in $P-T-X$ space with time.

\section{Data availability}

All data utilized in this study are included in Tables A1 and A2 in the Appendix. 


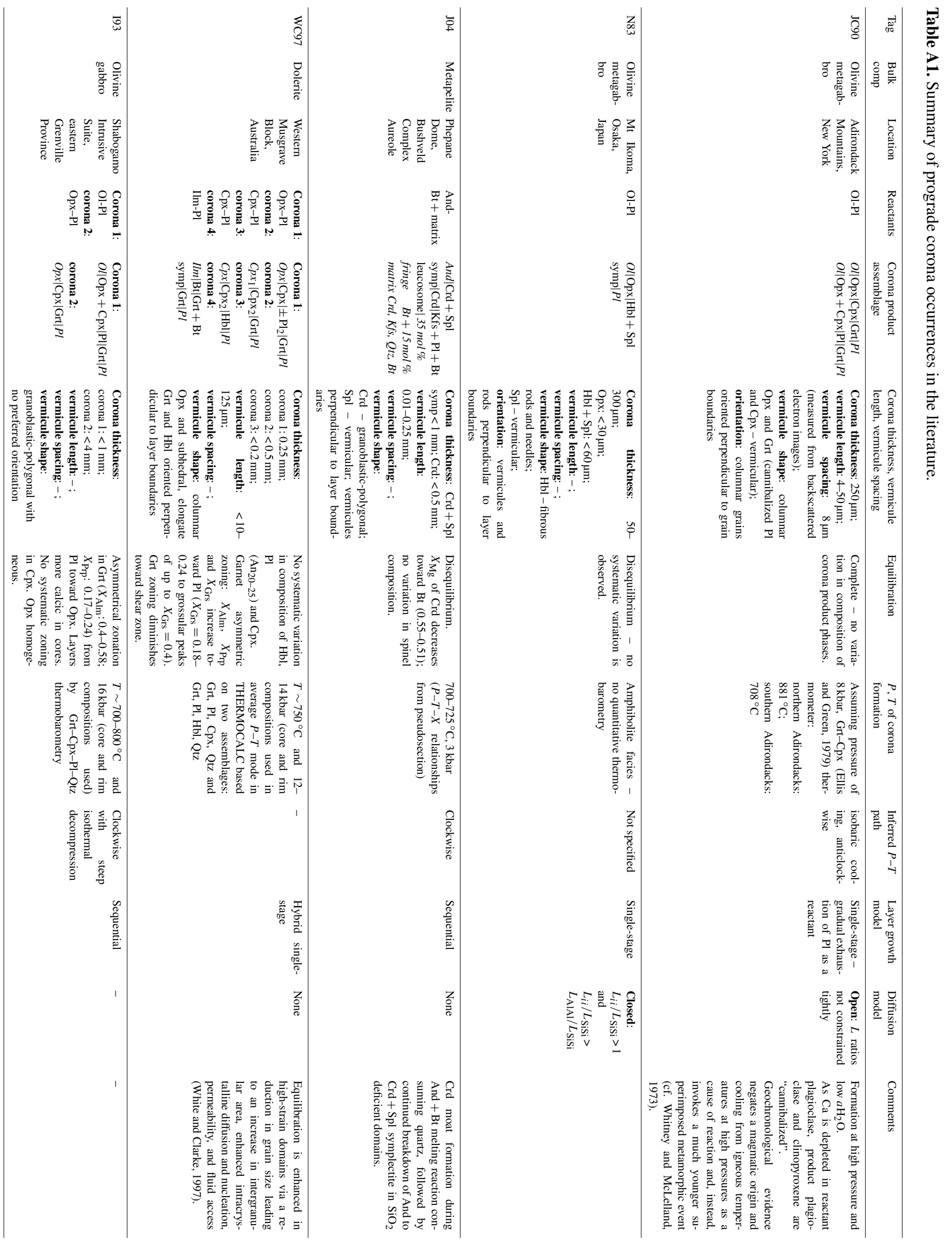




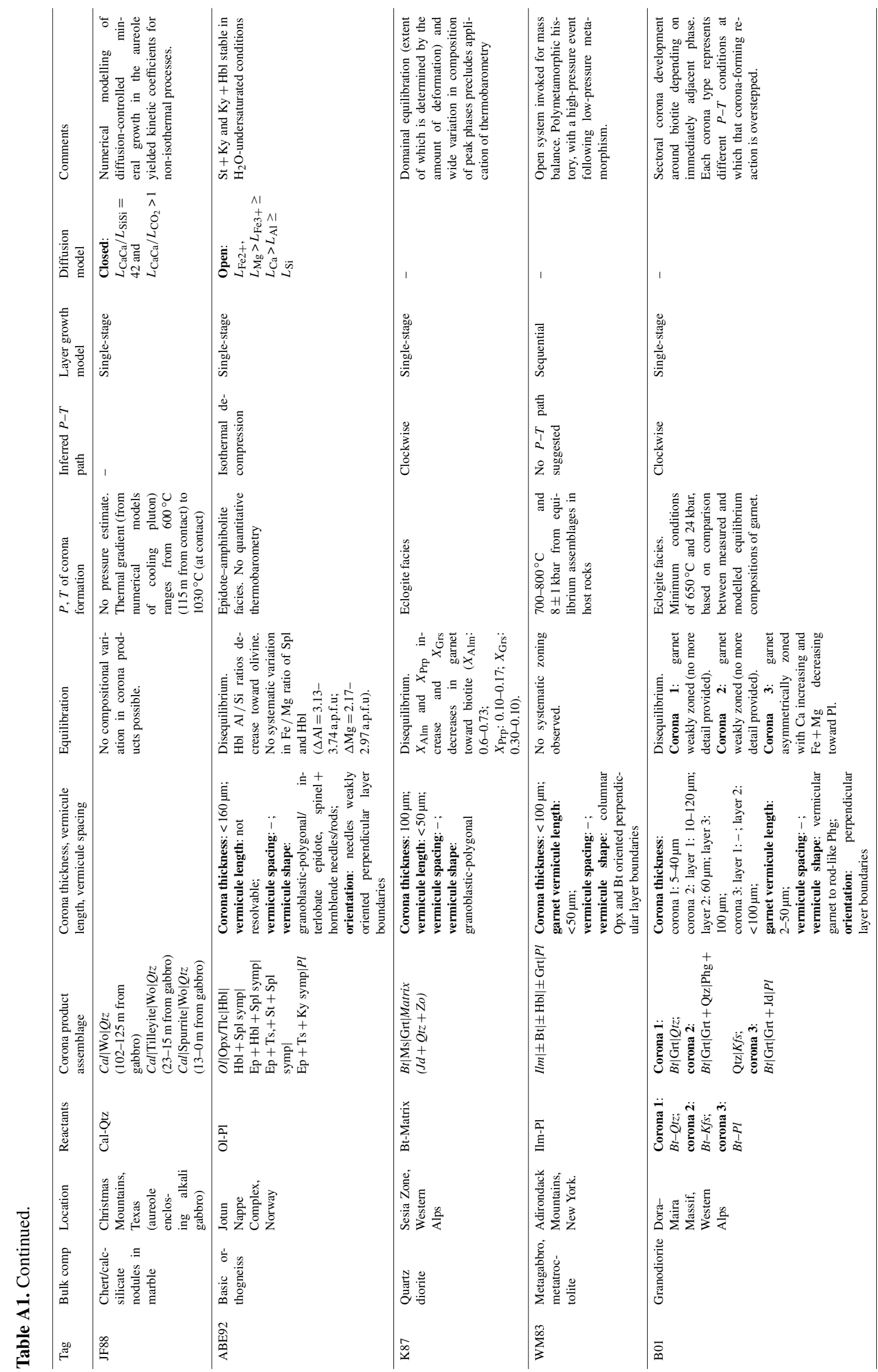



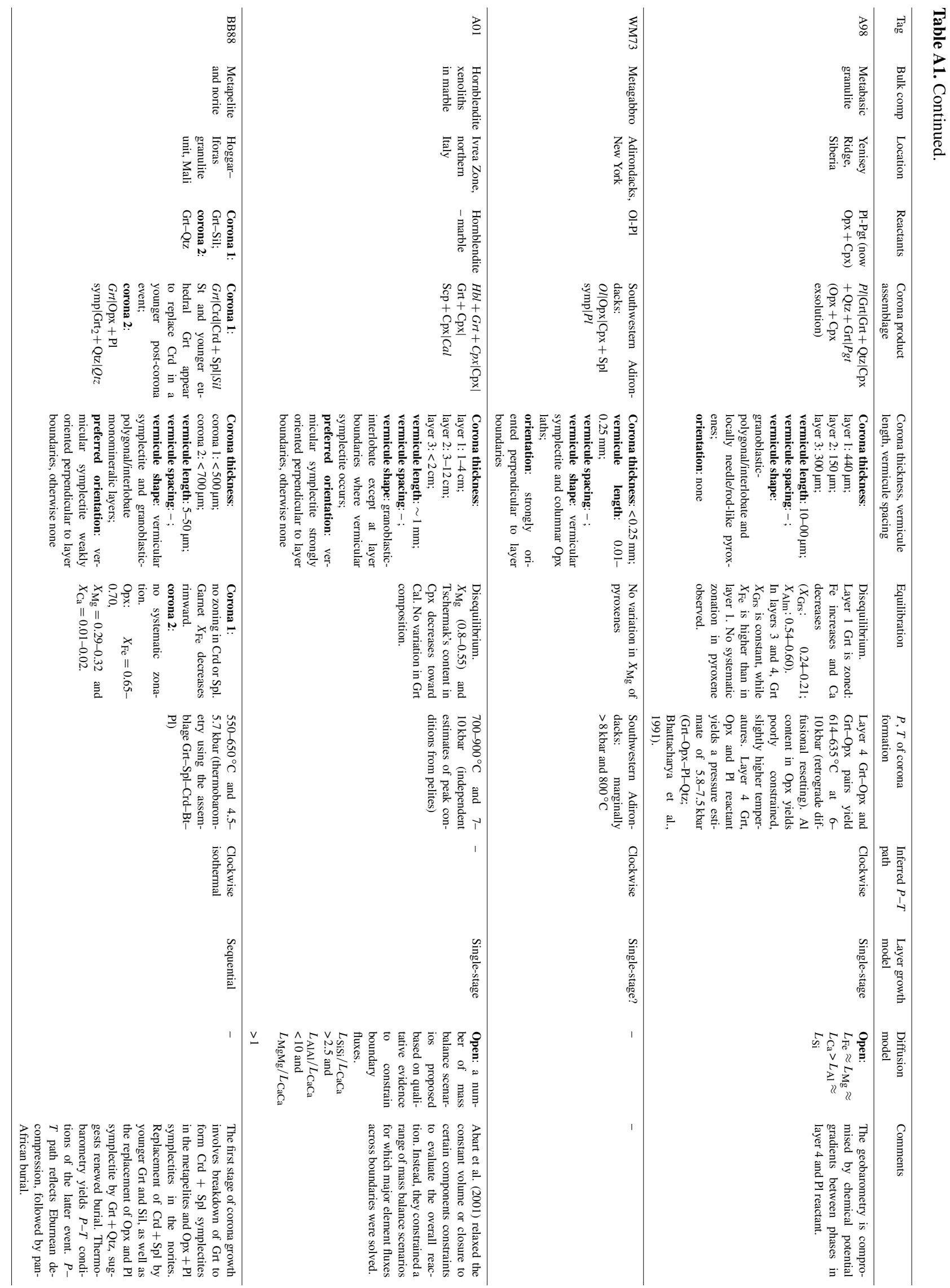


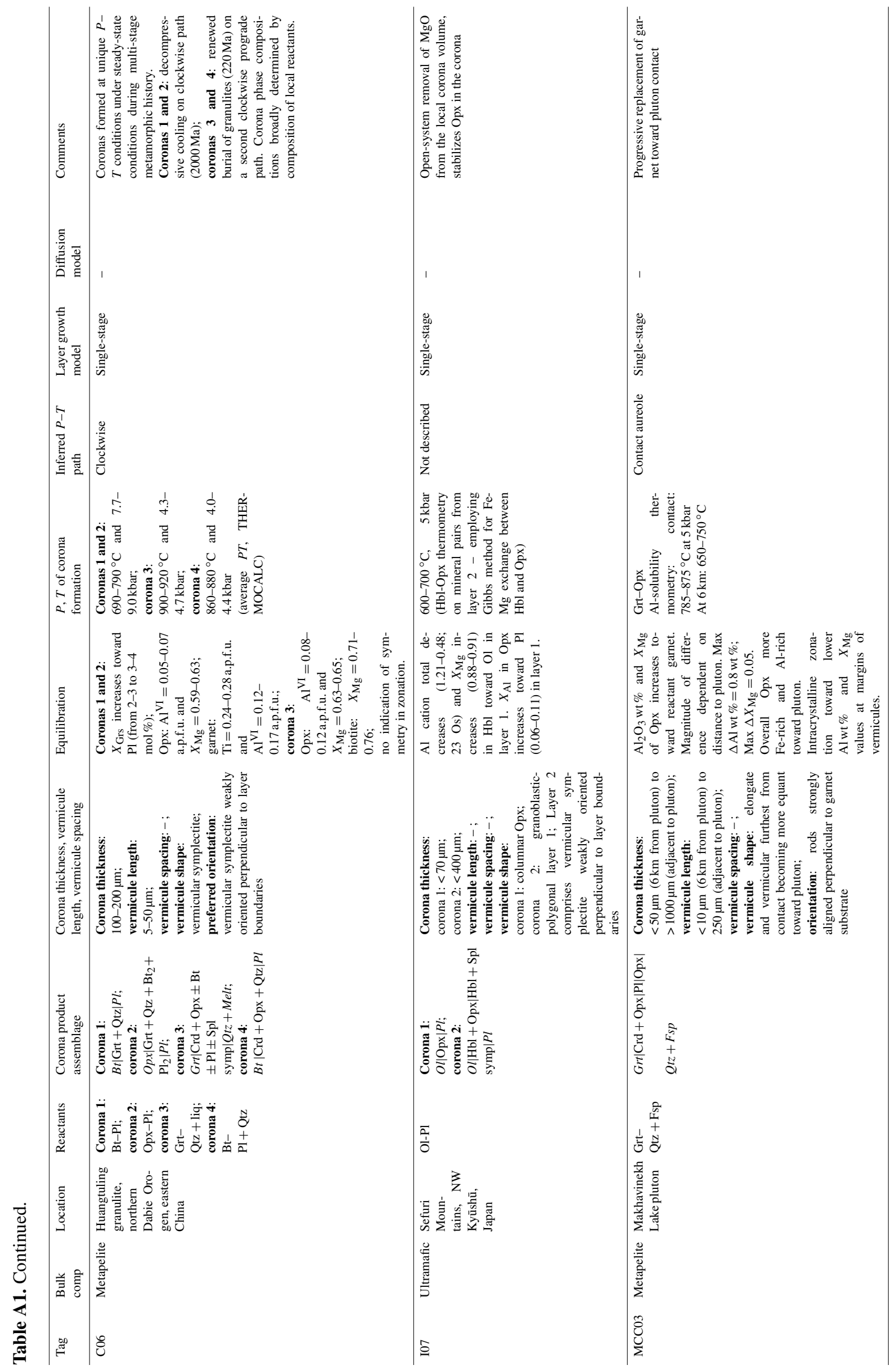




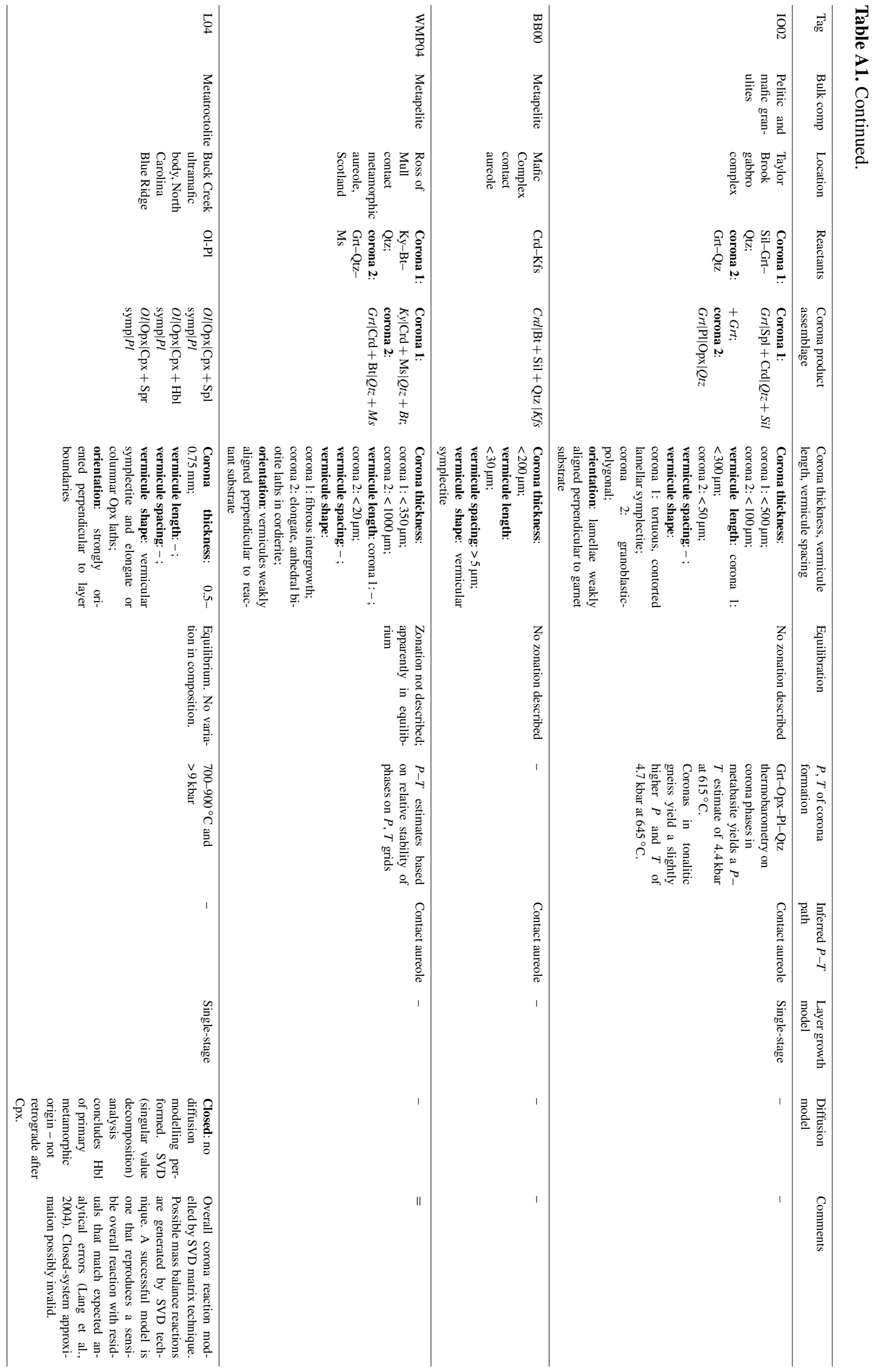




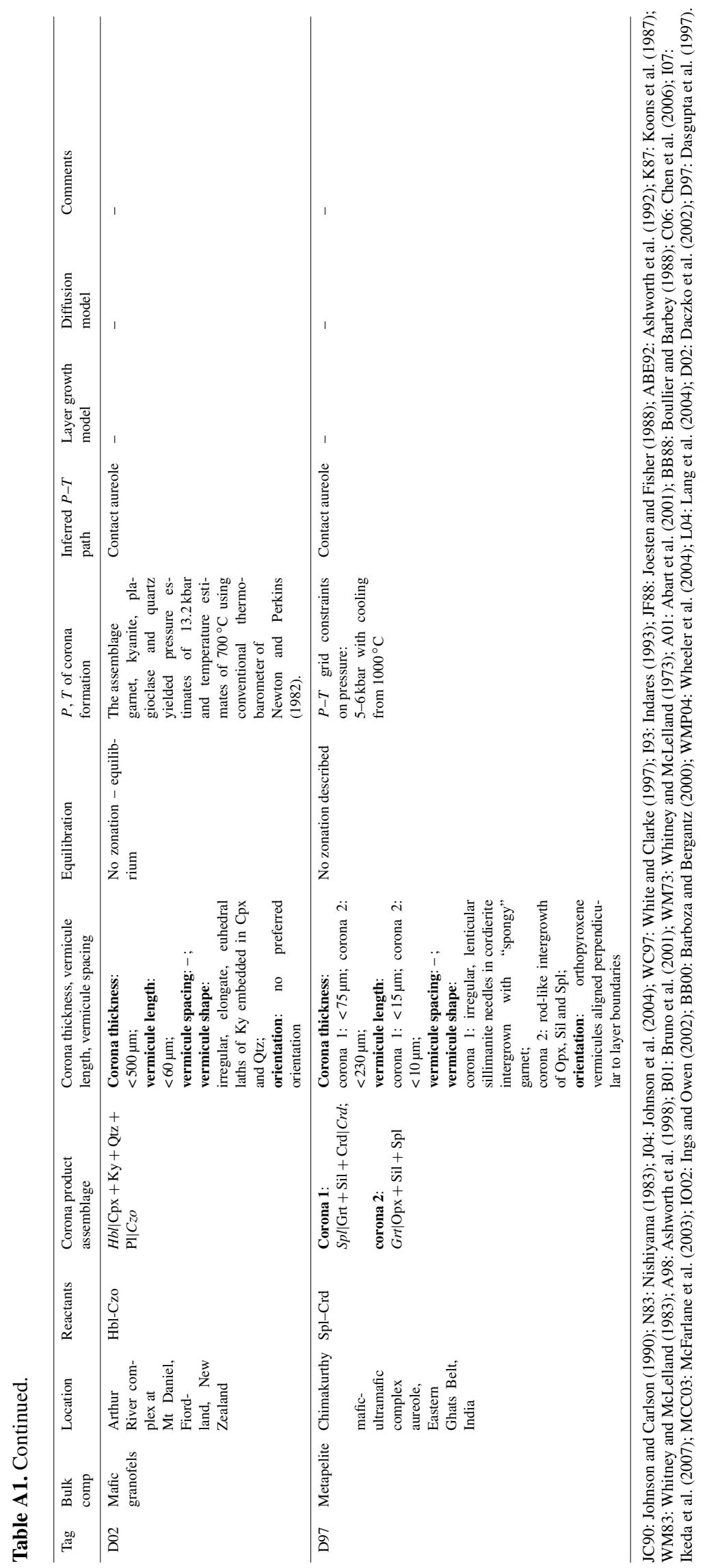




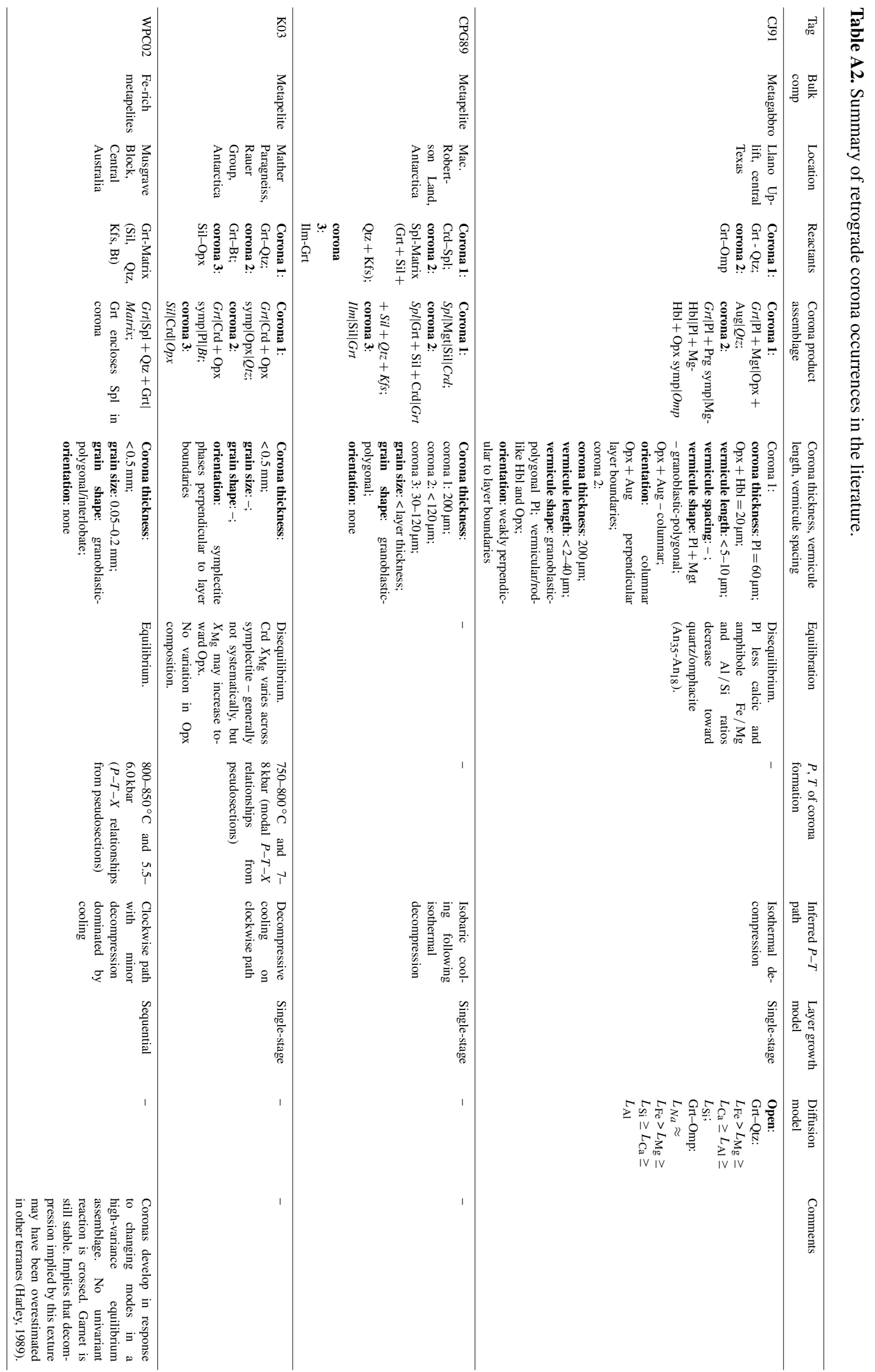




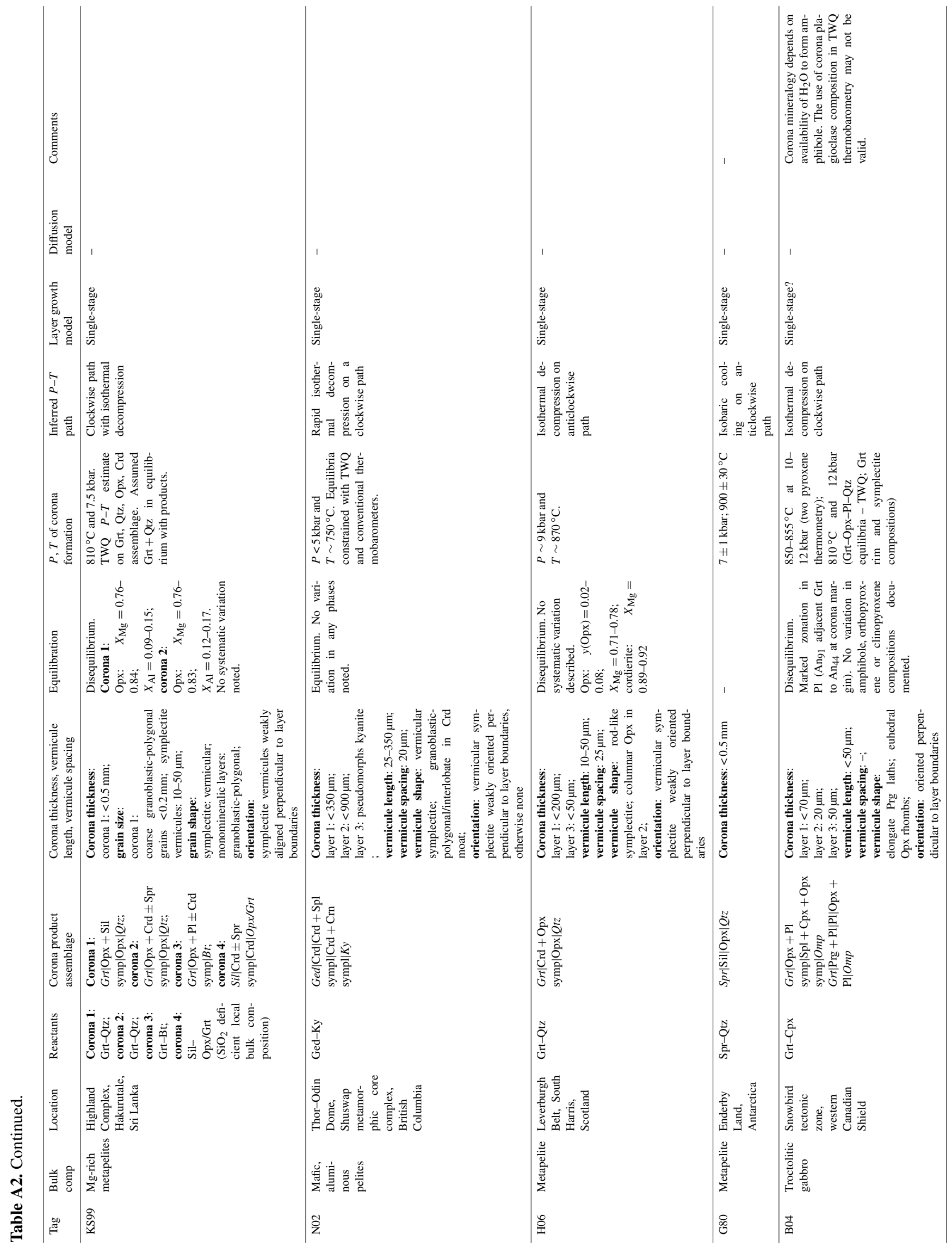



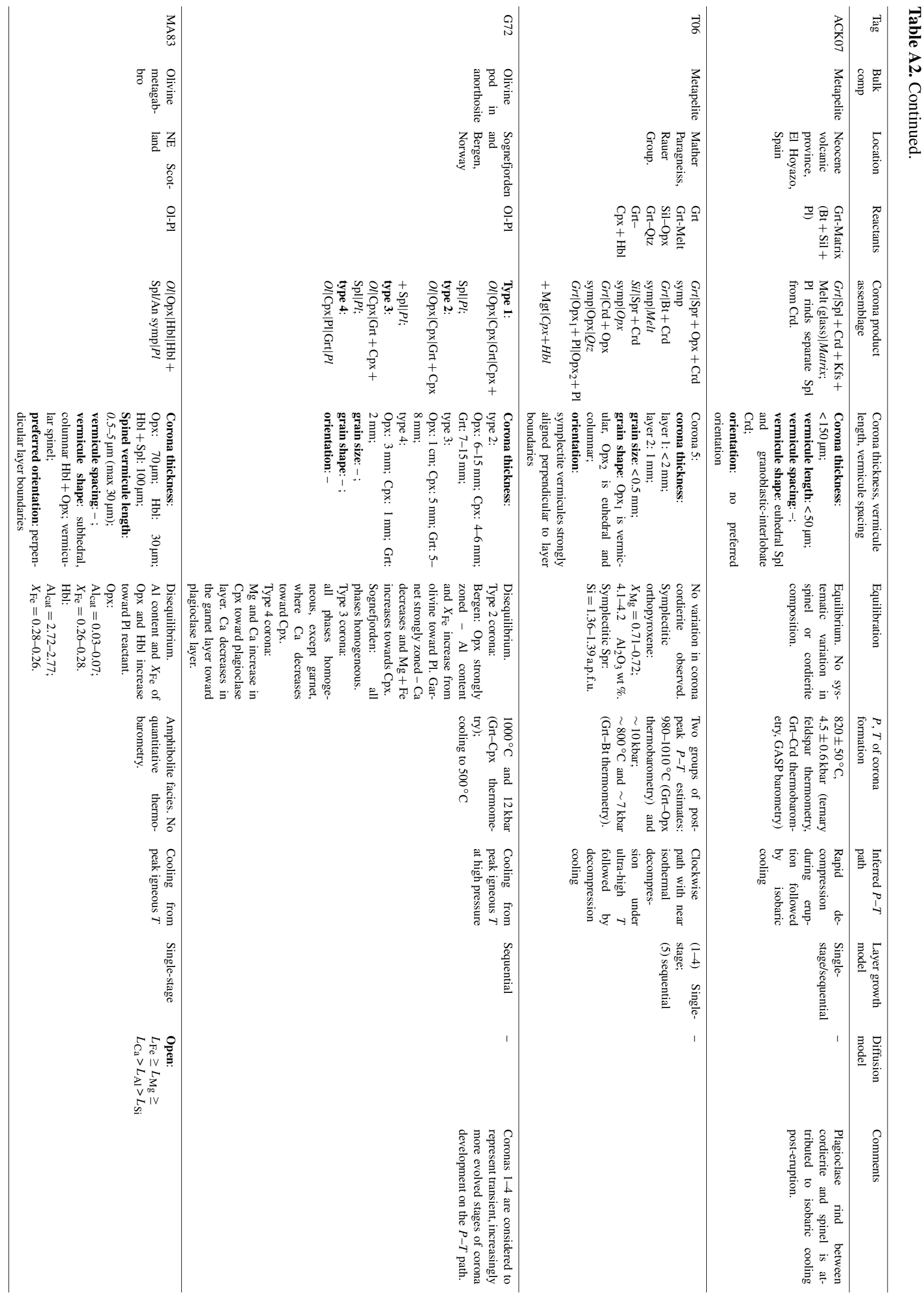

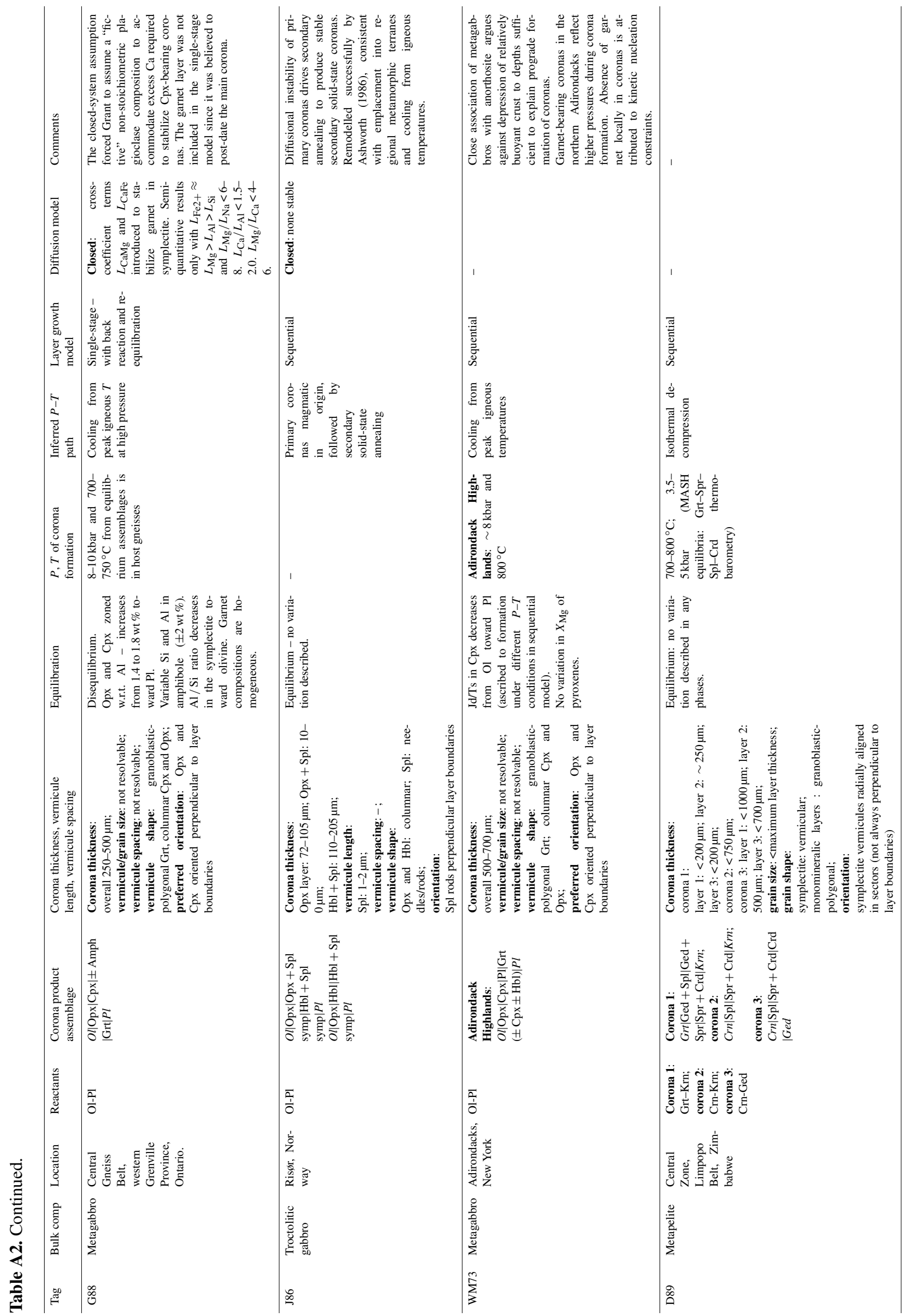


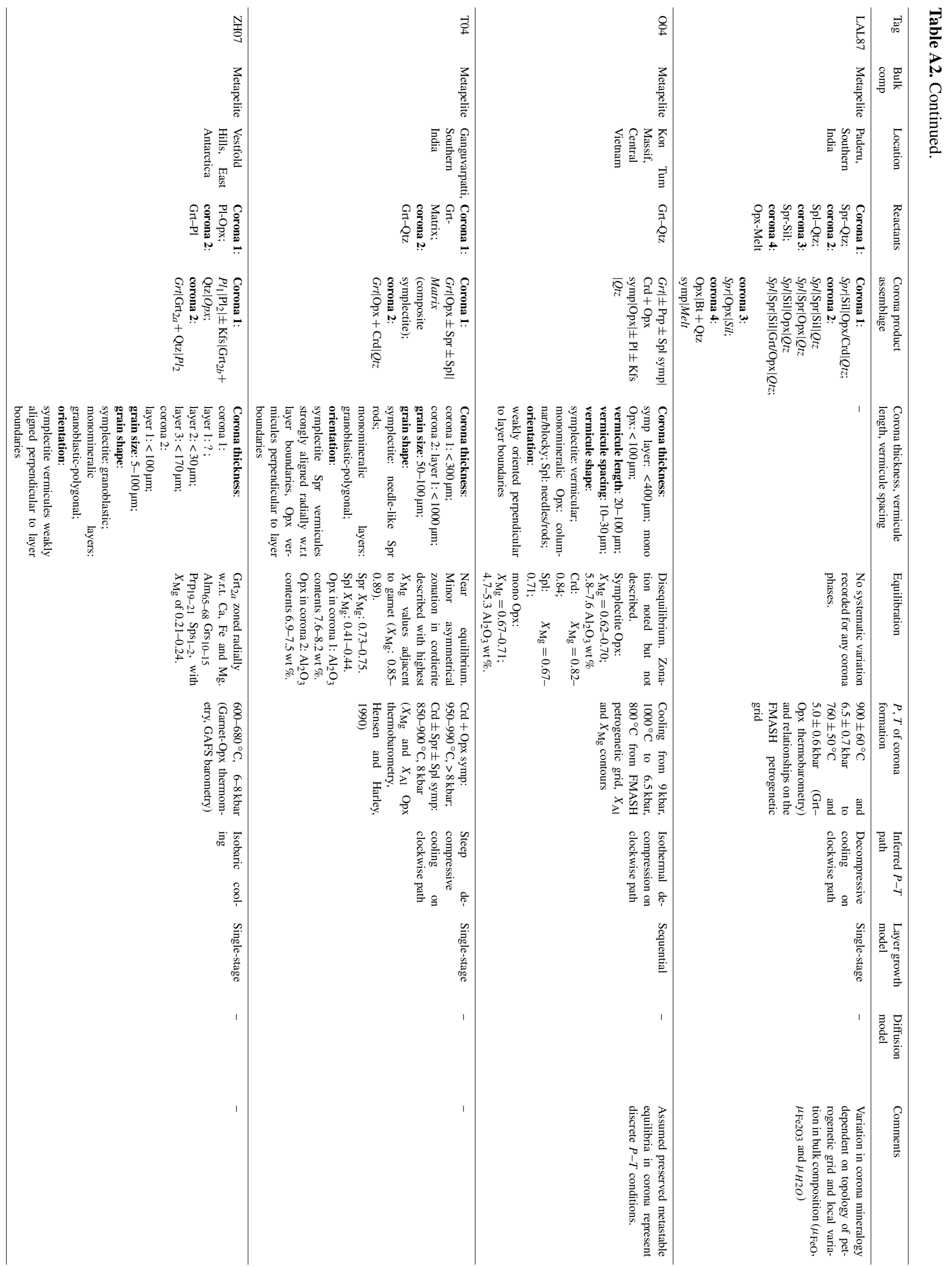



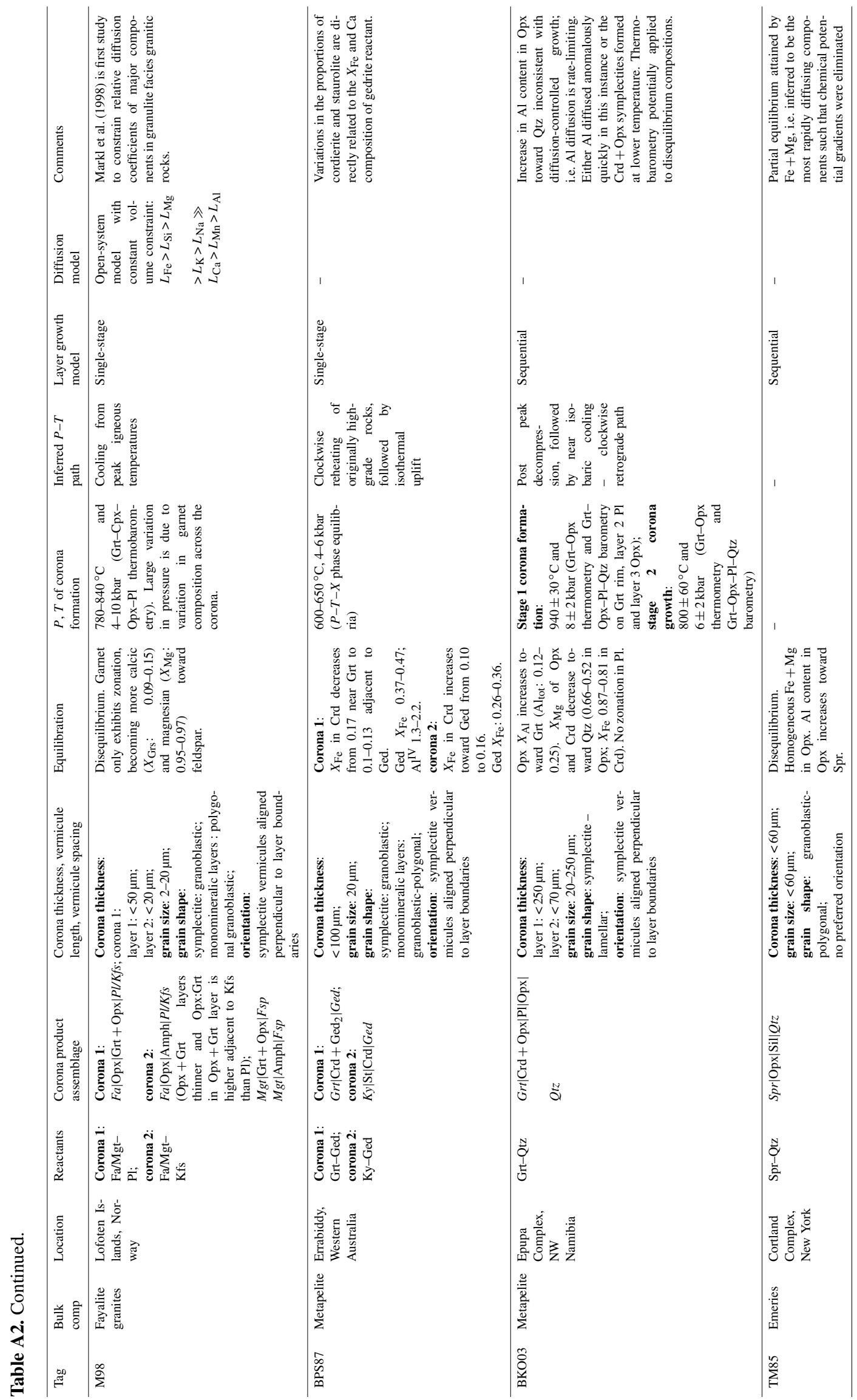


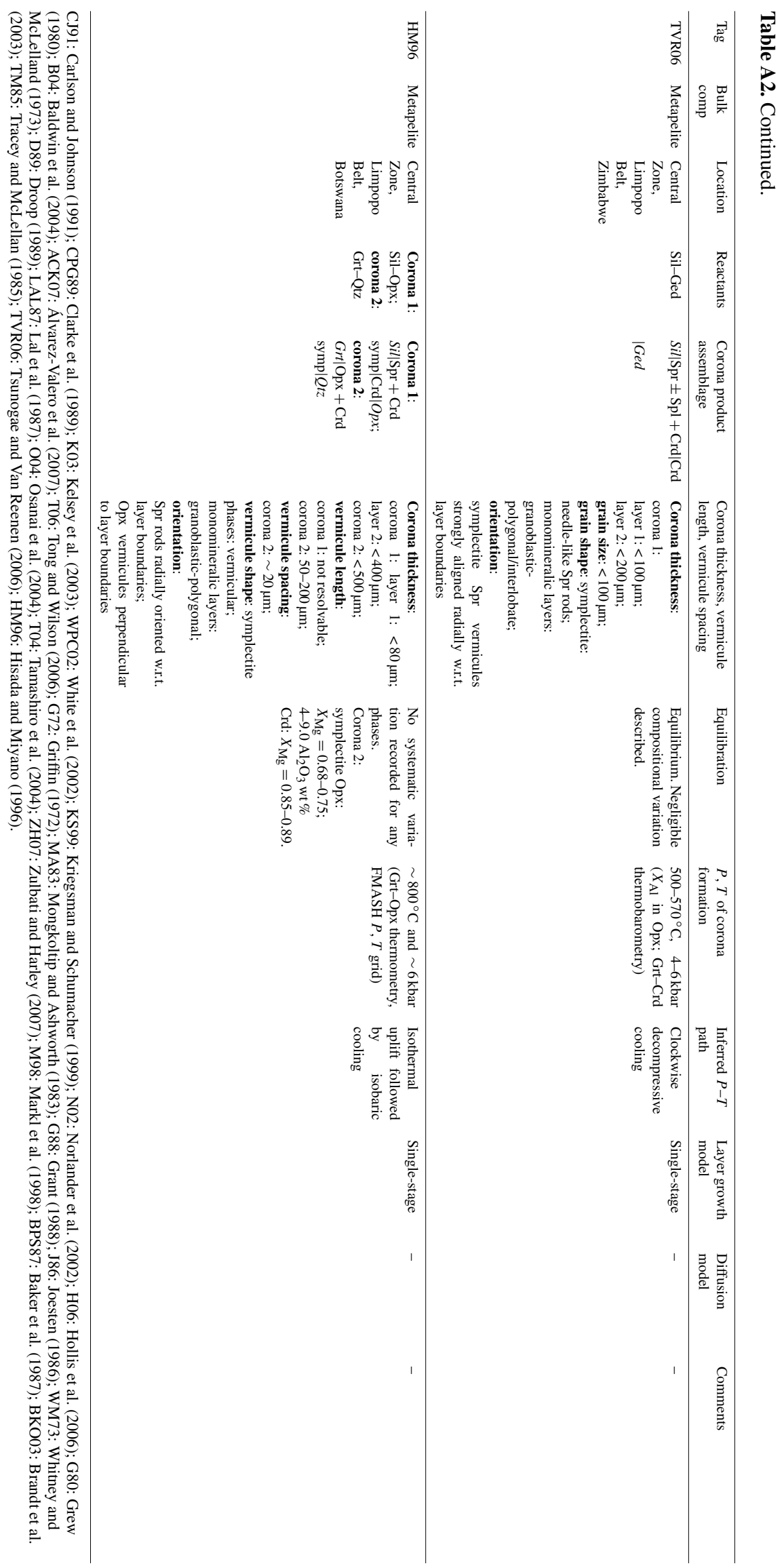


Competing interests. The authors declare that they have no conflict of interest.

Acknowledgements. Funding from the National Research Foundation Scarce Skills Scholarship and Rated Researcher Programmes is gratefully acknowledged. Tim Johnson and Thomas Mueller are thanked for insightful reviews.

Edited by: M. Heap

Reviewed by: T. Mueller and T. Johnson

\section{References}

Abart, R. and Petrishcheva, E.: Thermodynamic model for reaction rim growth: Interface reaction and diffusion control, Am. J. Sci., 311, 517-527, 2011.

Abart, R. and Schmid, R.: Silicon and oxygen self-diffusion in enstatite polycrystals: the Milke et al. (2001) rim growth experiment revisited, Contrib. Mineral. Petr., 147, 633-646, 2004.

Abart, R., Schmud, R., and Harlov, D. E.: Metasomatic coronas around hornblendite xenoliths in granulite facies marble, Ivrea zone, N Italy, I: Constraints on component mobility, Contrib. Mineral. Petr., 141, 473-493, 2001.

Abart, R., Petrishcheva, E., and Joachim, B.: Thermodynamic model for growth of reaction rims with lamellar microstructure, Am. Mineral., 97, 231-240, 2012.

Abart, R., Svoboda, J., Jerabek, P., Karadeniz, E. P., and Habler, G.: Interlayer growth kinetics of a binary solid-solution based on the thermodynamic extremal principle: application to the formation of spinel at periclase-corundum contacts, Am. J. Sci., 316, 309$328,2016$.

Ague, J. J. and Baxter, E. F.: Brief thermal pulses during mountain building recorded by $\mathrm{Sr}$ diffusion in apatite and multicomponent diffusion in garnet, Earth Planet. Sc. Lett., 261, 500-516, 2007.

Álvarez-Valero, A. M., Cesare, B., and Kriegsman, L. M.: Formation of spinel-cordierite-feldspar-glass coronas after garnet in metapelitic xenoliths: reaction modelling and geodynamic implications, J. Metamorph. Geol., 25, 305-320, 2007.

Ashworth, J. R.: The role of magmatic reaction, diffusion, and annealing in the evolution of coronitic microstructure in troctolitic gabbro from Risor, Norway: a discussion, Mineral. Mag., 50, 469-473, 1986.

Ashworth, J. R.: Fluid-absent diffusion kinetics of Al inferred from retrograde metamorphic coronas, Am. Mineral., 78, 331-337, 1993.

Ashworth, J. R. and Birdi, J. J.: Diffusion modelling of coronae around olivine in an open system, Geochim. Cosmochim. Ac., 54, 2389-2401, 1990.

Ashworth, J. R. and Chambers, A. D.: Symplectic reaction in olivine and the controls of intergrowth spacing in symplectites, J. Petrol., 41, 285-304, 2000.

Ashworth, J. R. and Sheplev, V. S.: Diffusion modelling of metamorphic layered coronas with stability criterion and consideration of affinity, Geochim. Cosmochim. Ac., 61, 3671-3689, 1997.

Ashworth, J. R., Birdi, J. J., and Emmett, T. F.: A complex corona between olivine and plagioclase from the Jotun Nappe, Norway, and the diffusion modelling of multimineralic layers, Mineral. Mag., 56, 511-525, 1992.

Ashworth, J. R., Sheplev, V. S., Bryxina, N. A., Kolobov, V. Y., and Reverdetto, V. V.: Diffusion-controlled corona reaction and overstepping of equilibrium in a garnet granulite, Yenisey Ridge, Siberia, J. Metamorph. Geol., 16, 231-246, 1998.

Ashworth, J. R., Sheplev, V. S., Khlestov, V. V., and Ananyev, A. A.: Geothermometry using minerals at non-equilibrium: a corona example European, J. Mineral., 13, 1153-1161, 2001.

Baker, J., Powell, R., Sandiford, M., and Muhling, J.: Corona textures between kyanite, garnet and gedrite in gneisses from Errabiddy, Western Australia, J. Metamorph. Geol., 5, 357-370, 1987.

Baldwin, J. A., Bowring, S. A., Williams, M. L., and Williams, I. S.: Eclogites of the Snowbird tectonic zone petrological and $\mathrm{U}-\mathrm{Pb}$ geochronological evidence for Paleoproterozoic high-pressure metamorphism in the western Canadian Shield, Contrib. Mineral Petr., 147, 528-548, 2004.

Baldwin, J. A., Powell, R., White, R. W., and Štípská, P.: Using calculated chemical potential relationships to account for replacement of kyanite by symplectite in high pressure granulites, J. Metamorph. Geol., 33, 311-330, 2015.

Barboza, S. A. and Bergantz, G. W.: Metamorphism and Anatexis in the Mafic Complex Contact Aureole, Ivrea Zone, Northern Italy, J. Petrol., 41, 1307-1327, 2000.

Boullier, A. M. and Barbey, P.: A polycyclic two-stage corona growth in the Iforas Granulitic Unit (Mali), J. Metamorph. Geol., 6, 235-254, 1988.

Brady, J. B.: Metasomatic zones in metamorphic rocks, Geochim. Cosmochim. Ac., 41, 113-125, 1977.

Brady, J. B.: Intergranular diffusion in metamorphic rocks, Am. J. Sci., 283A, 181-200, 1983.

Brandt, S., Klemd, R., and Okrusch, M.: Ultrahigh-Temperature Metamorphism and Multistage Evolution of GarnetOrthopyroxene Granulites from the Proterozoic Epupa Complex, NW Namibia, J. Petrol., 44, 1121-1144, 2003.

Bruno, M., Compagnoni, R., and Rubbo, M.: The ultra-high pressure coronitic and pseudomorphous reactions in a metagranodiorite from the Brossasco-Isasca Unit, Dora-Maira Massif, western Italian Alps: a petrographic study and equilibrium thermodynamic modelling, J. Metamorph. Geol., 19, 33-43, 2001.

Carlson, W. D.: Scales of disequilibrium and rates of equilibration during metamorphism, Am. Mineral., 87, 185-204, 2002.

Carlson, W. D. and Johnson, C. D.: Coronal reaction textures in garnet amphibolites of the Llano Uplift, Am. Mineral., 76, 756$772,1991$.

Carmichael, D. M.: Induced stress and secondary mass transfer: thermodynamic basis for the tendency toward constant-volume constraint in diffusion metasomatism, in: Chemical Transport in Metasomatic Processes, C 218, NATO Adv. Study Inst., Ser., Dordrecht, the Netherlands, 239-264, 1987.

Chen, Y., Ye, K., Liu, J. B., and Sun, M.: Multistage metamorphism of the Huangtuling granulite, Northern Dabie Orogen, eastern China: implications for the tectonometamorphic evolution of subducted lower continental crust, J. Metamorph. Geol., 24, 633-654, 2006.

Clarke, G. L., Powell, R., and Guiraud, M.: Low-pressure granulite facies metapelitic assemblages and corona textures from MacRobertson Land, east Antarctica: the importance of $\mathrm{Fe}_{2} \mathrm{O}_{3}$ 
and $\mathrm{TiO}_{2}$ in accounting for spinel-bearing assemblages, J. Metamorph. Geol., 7, 323-335,1989.

Daczko, N. R., Stevenson, J. A., Clarke, G. L., and Klepis, K. A.: Successive hydration and dehydration of high-P mafic granofels involving clinopyroxene-kyanite symplectites, Mt. Daniel, Fiordland, New Zealand, J. Metamorph. Geol., 20, 669-682, 2002.

Dasgupta, S., Ehl, J., Raith, M. M., Sengupta, P., and Sengupta, P.: Mid-crustal contact metamorphism around the Chimakurthy mafic-ultramafic complex, Eastern Ghats Belt, India, Contrib. Mineral. Petr., 129, 182-197, 1997.

Delle Piane, C., Burlini, L., and Grobety, B.: Reaction-induced strain localization: torsion experiments on dolomite, Earth Planet. Sc. Lett., 256, 36-46, 2007.

Dohmen, R. and Chakraborty, S.: Mechanism and kinetics of element and isotopic exchange mediated by a fluid phase, Am. Mineral., 88, 1251-1270, 2003.

Dohmen, R. and Milke, R.: Diffusion in polycrystalline materials: grain boundaries, mathematical models, and experimental data, Rev. Mineral. Geochem., 72, 921-970, 2010.

Droop, G. T. R.: Reaction history of garnet-sapphirine granulites and conditions of Archaean high-pressure granulite-facies metamorphism in the Central Limpopo Mobile Belt, Zimbabwe, J. Metamorph. Geol., 7, 383-403, 1989.

Ellis, D. J.: Osumilite-sapphirine-quartz granulites from Enderby Land, Antarctica: P-T conditions of metamorphism, implications for garnet-cordierite equilibria and the evolution of the deep crust, Contrib. Mineral. Petr., 74, 201-210, 1980.

Ellis, D. J. and Green, D. H.: An experimental study of the effect on $\mathrm{Ca}$ upon garnet-clinopyroxene $\mathrm{Fe}-\mathrm{Mg}$ exchange equilibria, Contrib. Mineral. Petrol., 71, 13-22, 1979.

Farver, J. and Yund, R.: Volume and grain boundary diffusion of calcium in natural and hot-pressed calcite aggregates, Contrib. Mineral. Petr., 123, 77-91, 1996.

Fisher, G. W.: The application of ionic equilibria to metamorphic differentiation: an example, Contrib. Mineral. Petr., 29, 91-103, 1970.

Fisher, G. W.: Non-equilibrium thermodynamics as a model for diffusion-controlled metamorphic processes, Am. J. Sci., 273, 897-924, 1973.

Fisher, G. W.: The thermodynamics of diffusion-controlled metamorphic processes, in: Mass Transport Phenomena in Ceramics, Plenum Press, New York, USA, 111-122, 1975.

Fisher, G. W.: Nonequilibrium thermodynamics in metamorphism, in: Thermodynamics in Geology, D. Reidel, Boston, USA, 381403, 1977.

Fisher, G. W. and Lasaga, A. C.: Kinetics of Geochemical Processes, Rev. Mineral., 8, 171-185, 1981.

Fisler, D. K., Mackwell, S. J., and Petsch, S.: Grain boundary diffusion in enstatite, Physics and Chemistry of Minerals, 24, 264 273, 1997.

Foster, C. T.: A thermodynamic model of mineral segregations vin the lower sillimanite zone near Rangeley, Maine, Am. Mineral., 66, 260-277, 1981.

Foster, C. T.: Thermodynamic models of reactions involving garnet in a sillimanite/staurolite schist, Mineral. Mag., 50, 427-439, 1986.
Gardés, E. and Heinrich, W.: Growth of multilayered polycristalline reaction rims in the $\mathrm{MgO}-\mathrm{SiO}_{2}$ system, part II: modelling, Contrib. Mineral. Petr., 162, 37-49, 2011.

Gardés, E., Wunder, B., Wirth, R., and Heinrich, W.: Growth of multilayered polycrystalline reaction rims in the $\mathrm{MgO}-\mathrm{SiO}_{2}$ system, part I: experiments, Contrib. Mineral. Petr., 161, 1-12, 2011.

Gibson, R. L.: Impact-induced melting in Archaean granulites in the Vredefort Dome, South Africa I.: Anatexis of metapelitic granulites, J. Metamorph. Geol., 20, 57-70, 2002.

Götze, L. C., Abart, R., Rybacki, E., Keller, L. M., Petrishcheva, E., and Dresen, G.: Reaction rim growth in the system MgO$\mathrm{Al}_{2} \mathrm{O}_{3}-\mathrm{SiO}_{2}$ under uniaxial stress, Contrib. Mineral. Petr., 99, 263-277, 2010.

Grant, S. M.: Diffusion models for corona formation in metagabbros from the western Grenville Province, Canada, Contrib. Mineral. Petr., 98, 49-63, 1988.

Grew, E. S.: Sapphirine+quartz association from Archaean rocks in Enderby Land, Antarctica, Am. Mineral., 65, 821-836, 1980.

Griffin, W. L.: Formation of eclogites and coronas in anorthosites, Bergen Arcs, Norway, Geol. Soc. Am. Mem., 135, 37-63, 1972.

Griffin, W. L. and Heier, K. S.: Petrological implications of some corona structures, Lithos, 6, 315-335, 1973.

Harley, S. L.: The origins of granulites: a metamorphic perspective, Geol. Mag., 126, 215-247, 1989.

Heidelbach, F., Terry, M. P., Bystricky, M., Holzapfel, C., and McCammon, C.: A simultaneous deformation and diffusion experiment: quantifying the role of deformation in enhancing metamorphic reactions, Earth Planet. Sc. Lett., 278, 386-393, 2009.

Helpa, V., Rybacki, E., Abart, R., Morales, L. F. G., Rhede, D., Jeřábek, P., and Dresen, G.: Reaction kinetics of dolomite rim growth, Contrib. Mineral. Petr., 167, 1-14, 2014.

Helpa, V., Rybacki, E., Morales, L. F. G., and Dresen, G.: Influence of stress and strain on dolomite rim growth: a comparative study, Contrib. Mineral. Petr., 170, 1-21, 2015.

Hensen, B. J. and Harley, S. L.: Graphical analysis of $P-T-X$ relations in granulite facies metapelites, in: High Temperature Metamorphism and Crustal Anatexis, chap. 3, edited by: Ashworth, J. R. and Brown, M., 19-56. Unwin Hyman, London, UK, 1990.

Hisada, K. and Miyano, T.: Petrology and microthermometry of aluminous rocks in the Botswanan Limpopo Central Zone: evidence for isothermal decompression and isobaric cooling, J. Metamorph. Geol., 14, 183-197, 1996.

Holland, T. and Powell, R.: An improved and extended internally consistent thermodynamic dataset for phases of petrological interest, involving a new equation of state for solids, J. Metamorph. Geol., 29, 333-383, 2011.

Holland, T. J. B. and Powell, R.: An internally consistent thermodynamic data set for phases of petrological interest, J. Metamorph. Geol., 16, 309-343, 1998.

Holland, T. J. B. and Powell, R.: Activity-composition relations for phases in petrological calculations: an asymmetric multicomponent formulation, Contrib. Mineral. Petr., 145, 492-501, 2003.

Hollis, J. A., Harley, S. L., White, R. W., and Clarke, G. L.: Preservation of evidence for prograde metamorphism in ultrahightemperature, high-pressure kyanite-bearing granulites, South Harris, Scotland, J. Metamorph. Geol., 24, 263-279, 2006.

Ikeda, T., Nishiyama, T., Yamada, S., and Yanagi, T.: Microstructures of olivine-plagioclase corona in meta-ultramafic rocks from 
Sefuri Mountains, NW Kyushu, Japan, Lithos, 97, 289-306, 2007.

Indares, A.: Eclogitized gabbros from the eastern Grenville Province: textures, metamorphic context, and implications, Can. J. Earth Sci., 30, 159-173, 1993.

Ings, S. J. and Owen, J. V.: "Decompressional" reaction textures formed by isobaric heating: an example from the thermal aureole of the Taylor Brook Gabbro Complex, western Newfoundland, Mineral. Mag., 66, 941-951, 2002.

Joachim, B., Gardés, E., Abart, R., and Heinrich, W.: Experimental growth of ackermanite reaction rims between wollastonite and monticellite: evidence for volume diffusion control, Contrib. Mineral. Petr., 161, 389-399, 2011a.

Joachim, B., Gardés, E., Velickov, B., Abart, R., and Heinrich, W.: Experimental growth of diopside + merwinite reaction rims: the effect of water on microstructure development, Am. Mineral., 97, 220-230, 2011b.

Joesten, R.: Evolution of mineral zoning in diffusion metasomatism, Geochim. Cosmochim. Ac., 41, 649-670, 1977.

Joesten, R.: The role of magmatic reaction, diffusion and annealing in the evolution of coronitic microstructure in troctolitic gabbro from Risor, Norway, Mineral. Mag., 50, 441-467, 1986.

Joesten, R. and Fisher, G. W.: Kinetics of diffusion-controlled mineral growth in the Christmas Mountains (Texas) contact aureole, Geol. Soc. Am. Bul., 100, 714-732, 1988.

Johnson, C. D. and Carlson, W. D.: The origin of olivine-plagioclase coronas in metagabbros from the Adirondack Mountains, New York, J. Metamorph. Geol., 8, 697-717, 1990.

Johnson, T. E., Brown, M., Gibson, R. L., and Wing, B.: Spinelcordierite symplectites replacing andalusite: evidence for meltassisted diapirism in the Bushveld Complex, South Africa, J. Metamorph. Geol., 22, 529-545, 2004.

Jonas, L., Mueller, T., Dohmen, R., Baumgartner, L., and Putlitz, B.: Transport-controlled hydrothermal replacement of calcite by Mg-carbonates, Geology, 43, 779-783, 2015.

Keller, L. M., Wirth, R., Rhede, D., Kunze, K., and Abart, R.: Asymmetrically zoned reaction rims: assessment of grain boundary diffusivities and growth rates related to natural diffusioncontrolled mineral reactions, J. Metamorph. Geol., 26, 99-120, 2008.

Keller, L. M., Götze, L. C., Rybacki, E., Dresen, G., and Abart, R.: Enhancement of solid-state reaction rates by non-hydrostatic stress effects on polycrystalline diffusion kinetics, Am. Mineral., 95, 1399-1407, 2010.

Kelsey, D. E., White, R. W., Powell, R., Wilson, C. J. L., and Quinn, C. D.: New constraints on metamorphism in the Rauer Group, Prydz Bay, east Antarctica, J. Metamorph. Geol., 21, 739-759, 2003.

Koons, P. O., Rubie, D. C., and Fruch-Green, G.: The Effects of Disequilibrium and Deformation on the Mineralogical Evolution of Quartz Diorite During Metamorphism in the Eclogite Facies, J. Petrol., 28, 679-700, 1987.

Korzhinskii, D. S.: Physicochemical Basis of the Analysis of the Paragenesis of Minerals, Consultants Bureau, New York, USA, 142 pp., 1959.

Korzhinskii, D. S.: The theory of systems with perfectly mobile components and processes of mineral formation, Am. J. Sci., 263, 193-205, 1965.
Kretz, R.: Symbols for rock-forming minerals, Am. Mineral., 68, 277-279, 1983.

Kriegsman, L. M. and Schumacher, J. C.: Petrology of sapphirinebearing and associated granulites from central Sri Lanka, J. Petrol., 40, 1211-1239, 1999.

Lal, R. K., Ackermand, D., and Upadhyay, H.: $P-T-X$ relationships deduced from corona textures in sapphirine-spinel-quartz assemblages from Paderu, southern India, J. Petrol., 28, 1139-1168, 1987.

Lang, H. M., Wachter, A. J., Peterson, V. L., and Ryan, J. G.: Coexisting clinopyroxene/spinel and amphibole/spinel symplectites in metatroctolites from the Buck Creek ultramafic body, North Carolina Blue Ridge, Am. Mineral., 89, 20-30, 2004.

Lasaga, A. C.: Geospeedometry: an extension of geothermometry, in: Kinetics and equilibrium in mineral reactions, edited by: Saxena, S. K., Springer, New York, USA, 81-114, 1983.

Markl, G., Foster, C. T., and Bucher, K.: Diffusion-controlled olivine corona textures in granitic rocks from Lofoten, Norway: calculation of Onsager diffusion coefficients, thermodynamic modelling and petrological implications, J. Metamorph. Geol., 16, 607-623, 1998.

McFarlane, C. R. M., Carlson, W. D., and Connelly, J. N.: Prograde, peak, and retrograde $P-T$ paths from aluminium in orthopyroxene: High-temperature contact metamorphism in the aureole of the Makhavinekh Lake Pluton, Nain Plutonic Suite, Labrador, J. Metamorph. Geol., 21, 405-423, 2003.

Milke, R. and Heinrich, W.: Diffusion-controlled growth of wollastonite rims between quartz and calcite: comparison between nature and experiment, J. Metamorph. Geol., 20, 467-480, 2002.

Milke, R. and Wirth, R.: The formation of columnar fiber texture in wollastonite rims by induced stress and implications for diffusion-controlled corona growth, Phys. Chem. Miner., 30, 230-242, 2003.

Milke, R., Wiedenbeck, M., and Heinrich, W.: Grain boundary diffusion of $\mathrm{Si}, \mathrm{Mg}$, and $\mathrm{O}$ in enstatite reaction rims: a SIMS study using isotopically doped reactants, Contrib. Mineral. Petr., 142, 15-26, 2001.

Mongkoltip, P. and Ashworth, J. R.: Quantitative estimation of an open-system symplectite-forming reaction: restricted diffusion of $\mathrm{Al}$ and $\mathrm{Si}$ in coronas around olivine, J. Petrol., 24, 635-661, 1983.

Mork, M. B. E.: Coronite and eclogite formation in olivine gabbro (Western Norway): reaction paths and garnet zoning, Mineral. Mag., 50, 417-426, 1986.

Mueller, T., Baumgartner, L. P., Foster Jr., C. T., and Roselle, G. T.: Forward modeling of the effects of mixed volatile reaction, volume diffusion, and formation of submicroscopic exsolution lamellae on calcite-dolomite thermometry, Am. Mineral., 93, 1245-1259, 2008.

Mueller, T., Watson, E. B., and Harrison, T. M.: Applications of diffusion data to high-temperature earth systems, Rev. Mineral. Geochem., 72, 997-1038, 2010.

Mueller, T., Cherniak, D., and Watson, B.: Interdiffusion of divalent cations in carbonates: experimental measurements and implications for timescales of equilibration and retention of compositional signatures, Geochim. Cosmochim. Ac., 84, 90-103, 2012.

Mueller, T., Massonne, H. J., and Willner, A. P.: Special Collection: Mechanisms, Rates, and Timescales of Geochemical Transport Processes in the Crust and Mantle. Timescales of exhuma- 
tion and cooling inferred by kinetic modeling: An example using a lamellar garnet pyroxenite from the Variscan Granulitge, Am. Mineral., 100, 747-759, 2015.

Niedermeier, D., Putnis, A., Geisler, T., Golla-Schindle, U., and Putnis, C.: The mechanism of cation and oxygen isotope exchange in alkali feldspars under hydrothermal conditions, Contrib. Mineral. Petr., 157, 65-75, 2009.

Nishiyama, T.: Steady diffusion model for olivine-plagioclase corona growth, Geochim. Cosmochim. Ac., 41, 649-670, 1983.

Norlander, B. H., Whitney, D. L., Teyssier, C., and Vanderhaeghe, O.: Partial melting and decompression of the ThorOdin dome, Shuswap metamorphic core complex, Canadian Cordillera, Lithos, 61, 103-125, 2002.

Ogilvie, P.: Metamorphic Studies in the Vredefort Dome, Unpublished PhD thesis, University of Witwatersrand, Johannesburg, South Africa, 772 pp., 2010.

Osanai, Y., Nakano, N., and Owada, M.: Permo-Triassic ultrahightemperature metamorphism in the Kontum Massif, central Vietnam, J. Miner. Petrol. Sci., 99, 225-241, 2004.

Perchuk, L. L., Tokarev, D. A., van Reenen, D. D., Varlamov, D. A., Gerya, T. V., Sazonova, L. V., Fel'dman, V. I., Smit, C. A., Brink, M. C., and Bisschoff, A. A.: Dynamic and Thermal History of the Vredefort Explosion Structure in the Kaapvaal Craton, South Africa, Petrology, 10, 395-432, 2002.

Powell, R. and Holland, T. J. B.: An internally consistent thermodynamic dataset with uncertainties and correlations: 3: application methods, worked examples and a computer program, J. Metamorph. Geol., 6, 173-204, 1988.

Powell, R. and Holland, T. J. B.: Calculated mineral equilibria in the pelite system KFMASH $\left(\mathrm{K}_{2} \mathrm{O}-\mathrm{FeO}-\mathrm{MgO}-\mathrm{Al}_{2} \mathrm{O}_{3}-\mathrm{SiO}_{2}\right.$ $\mathrm{H}_{2} \mathrm{O}$ ), Am. Mineral., 75, 367-380, 1990.

Powell, R., Holland, T. J. B., and Worley, B.: Calculating phase diagrams involving solid solutions via non-linear equations, with examples using THERMOCALC, J. Metamorph. Geol., 16, 577588, 1998.

Powell, R., Guiraud, M., and White, R. W.: Truth and beauty in metamorphic mineral equilibria: conjugate variables and phase diagrams, Can. Mineral., 43, 21-33, 2005.

Putnis, A.: Mineral replacement reactions, Rev. Mineral. Geochem., 70, 87-124, 2009.

Schmid, D. W., Abart, R., Podladtchikov, I., and Milke, R.: Matrix rheology effects on reaction rim growth II: coupled diffusion and creep model, J. Metamorph. Geol., 27, 83-91, 2009.

Sheplev, V. S., Kolobov, V. Yu., Kuznetsova, R. P., and Reverdatto, V. V.: Analysis of growth of zonated mineral segregation and characteristics of mass transfer during metamorphism. 1. Theoretical model in a quasi-stationary approximation, Soviet Geol. Geophys., 32, 1-12, 1991.

Sheplev, V. S., Kuznetsova, R. P., and Kolobov, V. Yu.: Analysis of growth of zonated mineral segregations and characteristics of mass transfer during metamorphism. 2. The system $\mathrm{SiO}_{2}-\mathrm{Al}_{2} \mathrm{O}_{3}-$ MgO-NaCaO, Russ. Geol. Geophys., 33, 73-80, 1992a.

Sheplev, V. S., Kuznetsova, R. P., and Kolobov, V. Yu.: Analysis of growth of zonated mineral segregations and characteristics of mass transfer during metamorphism. 3 . The model of steady diffusions, Russ. Geol. Geophys., 33, 46-52, 1992b.

Smit, C. A., Van Reenen, D. D., Gerya, T. V., and Perchuk, L. L.: $\mathrm{P}-\mathrm{T}$ conditions of decompression of the Limpopo high-grade ter- rain: record from shear zones, J. Metamorph. Geol., 19, 249-268, 2001.

Štípská, P., Powell, R., White, R., and Baldwin, J.: Using calculated chemical potential relationships to account for coronas around kyanite: an example from the Bohemian Massif, J. Metamorph. Geol., 28, 97-116, 2010.

Tajčmanová, L., Konopásek, J., and Connolly, J. A. D.: Diffusioncontrolled development of silica-undersaturated domains in felsic granulites of the Bohemian Massif (Variscan belt of Central Europe), Contrib. Mineral. Petr., 153, 237-250, 2007.

Tamashiro, I., Santosh, M., Sajeev, K., Morimoto, T., and Tsunogae, T.: Multistage orthopyroxene formation in ultra-high temperature granulites of Ganguvarpatti, southern India: implications for complex metamorphic evolution during Gondwana assembly, J. Miner. Petrol. Sci., 90, 279-297, 2004.

Thompson, J. B.: Local equilibrium in metasomatic processes, in: Researches in Geochemistry, Wiley, New York, USA, 427-457, 1959.

Tong, L. and Wilson, C. J. L.: Tectonothermal evolution of the ultrahigh metapelites in the Rauer Group, east Antarctica, Precambrian Res., 149, 1-20, 2006.

Tracy, R. J. and McLellan, E. L.: A natural example of the kinetic controls of compositional and textural equilibration, in: Advances in physical geochemistry 4, Springer-Verlag, New York, USA, 118-137, 1985.

Tsunogae, T. and Van Reenen, D. D.: Corundum + quartz and $\mathrm{Mg}$-staurolite bearing granulite from the Limpopo Belt, southern Africa: Implications for a $P-T$ path, Lithos, 92, 576-587, 2006.

Van Lamoen, H.: Coronas in olivine gabbros and iron ores from Susimäki and Riuttamaa, Finland, Contrib. Mineral. Petr., 68, 259-268, 1979.

Vidale, R.: Metasomatism in a chemical gradient and the formation of calc-silicate bands, Am. J. Sci., 267, 857-874, 1969.

Watson, E. B. and Mueller, T.: Non-equilibrium isotopic and elemental fractionation during diffusion-controlled crystal growth under static and dynamic conditions, Chem. Geol., 267, 111124, 2009.

Watson, E. B. and Price, J. D.: Kinetics of the reaction $\mathrm{MgO}$ $\mathrm{Al}_{2} \mathrm{O}_{3} \rightarrow \mathrm{MgAl}_{2} \mathrm{O}_{4}$ and $\mathrm{Al}-\mathrm{Mg}$ interdiffusion in spinel at 1200 to $2000{ }^{\circ} \mathrm{C}$ and 1.0 to $4.0 \mathrm{GPa}$, Geochim. Cosmochim. Ac., 66, 2123-2138, 2002.

Wheeler, J., Mangan, L. S., and Prior, D. J.: Disequilibrium in the Ross of Mull Contact Metamorphic Aureole, Scotland: a Consequence of Polymetamorphism, J. Petrol., 45, 835-853, 2004.

White, R. W. and Clarke, G. L.: The Role of Deformation in Aiding Recrystallization: an Example from a High-pressure Shear Zone, Central Australia, J. Petrol., 38, 1307-1329, 1997.

White, R. W. and Powell, R.: Melt loss and the preservation of granulite facies mineral assemblages, J. Metamorph. Geol., 20, 621632, 2002.

White, R. W. and Powell, R.: On the interpretation of retrograde reaction textures in granulite facies rocks, J. Metamorph. Geol., 29, 131-149, 2011.

White, R. W., Powell, R., and Clarke, G. L.: The Interpretation of reaction textures in Fe-rich metapelitic granulites of the Musgrave Block, central Australia: Constraints from mineral equilibria calculations in the system $\mathrm{K}_{2} \mathrm{O}-\mathrm{FeO}-\mathrm{MgO}-\mathrm{Al}_{2} \mathrm{O}_{3}-\mathrm{SiO}_{2}-$ $\mathrm{H}_{2} \mathrm{O}-\mathrm{TiO}_{2}-\mathrm{Fe}_{2} \mathrm{O}_{3}$, J. Metamorph. Geol., 20, 41-55, 2002. 
White, R. W., Powell, R., and Halpin, J. A.: Spatially-focussed melt formation in aluminous metapelites from Broken Hill, Australia, J. Metamorph. Geol., 22, 825-845, 2004.

White, R. W., Powell, R., and Baldwin, J. A.: Calculated phase equilibria involving chemical potentials to investigate the textural evolution of metamorphic rocks, J. Metamorph. Geol., 26, 181-198, 2008.

Whitney, P. R. and McLelland, J. M.: Origin of coronas in metagabbros of the Adirondack Mts., N.Y., Contrib. Mineral. Petr., 39, 81-98, 1973 .

Whitney, P. R. and McLelland, J. M.: Origin of biotite-hornblendegarnet coronas between oxides and plagioclase in olivine metagabbros, Adirondack region, NY, Contrib. Mineral. Petr., 82, 34-41, 1983.
Yund, R. A.: Rates of grain boundary diffusion through enstatite and forsterite reaction rims, Contrib. Mineral. Petr., 126, 224 236, 1997.

Zhang, Y.: Diffusion in minerals and melts: theoretical background, Rev. Mineral. Geochem., 72, 5-59, 2010.

Zulbati, F. and Harley, S. L.: Late Archaean granulite facies metamorphism in the Vestfold Hills, East Antarctica, Lithos, 93, 3967, 2007. 